
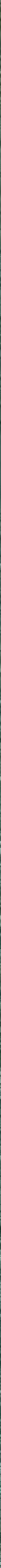

(1)

(7)

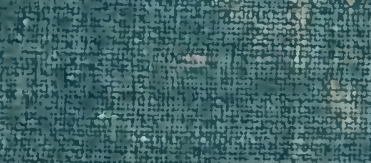







\section{THE \\ MATURATION OF THE EGG OF THE MOUSE}

BY

J. A. LONG AND E. L. MARK

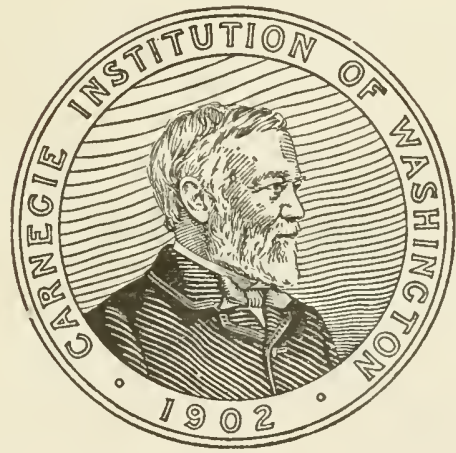

$$
\frac{120^{3}}{17111^{\circ}}
$$

WASHINGTON, D. C.

Published by the Carnegie Institution of Washington 


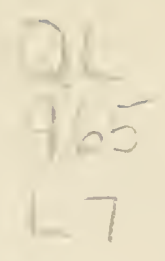

Carnegie Institution of Washington, Publication No. i42

Contributions from Zoölogical Laboratory of the Museum of Comparative Zoölogy at Harvard College. E. L. Mark, Director. No. 2i 6.

Copies of this Book

were first issued

APR 31911

PRESS OF J. B. LIPPINCOTT COMPANY

PHILADELPHIA 


\section{CONTENTS.}

Page

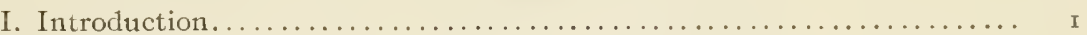

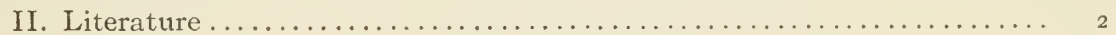

III. Material and methods . . . . . . . . . . . . . . . . . . . . . . . 6

IV. Time relations of parturition, maturation, ovulation, insemination, and

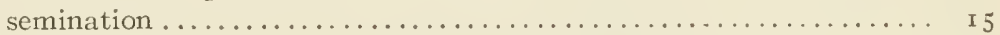

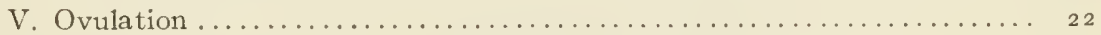

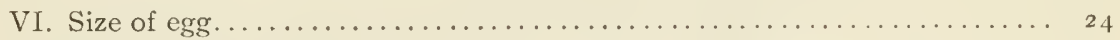

VII. Observations on the maturation processes................. 25

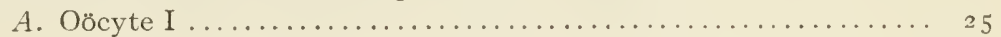

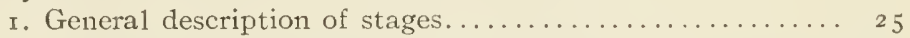

Stage I.-Germinative vesicle . . . . . . . . . . 25

Stage II.-Formation of first maturation spindle ..... 26

Stages III-V.-Development and division of first maturation spindle...................... 26

Stage VI.-Telophase of first spindle, and the first polar

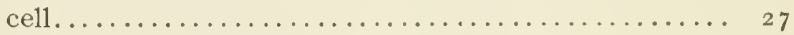

2. Chromatin parts of first maturation spindle......... 27

3. Achromatin parts of first maturation spindle......... 3 I

4. Centrosomes, circumpolar bodies, and clear region....... 32

5. Position and orientation of first maturation spindle..... 33

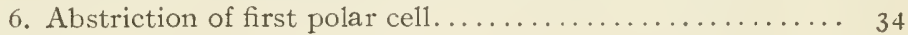

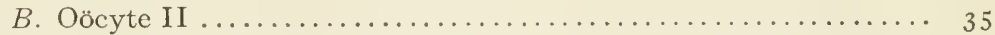

I. General description of stages.................. 35

Stage VII.-Formation of second maturation spindle... 35

Stage VIII._- "Equatorial platc" of second maturation spindle ............................. 35

Stage IX.-Division of second maturation spindle.... $3^{6}$

Stage X.-Telophase of second spindle and second polar

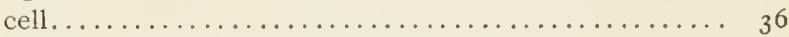

2. Chromatin parts of second maturation spindle........ ${ }_{3}^{6}$

3. Achromatin parts of second maturation spindle......... $3^{8}$

4. Centrosomes, circumpolar bodies, and clear region....... 39

5. Position and orientation of second maturation spindle... 40

6. Abstriction of second polar cell................. 40

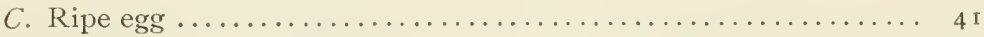

Stage XI.-The pronuclei.................... ${ }_{4}$ I

D. Polar cells............................... q I $^{\mathrm{I}}$

First polar cell. ........................... 4 I

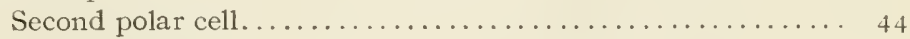

VIII. Criticisms and conclusions . . . . . . . . . . . . . . . . . . . 45

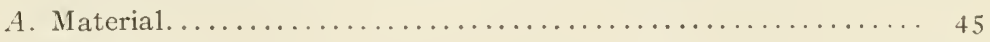

B. Methods. . . . . . . . . . . . . . . . . . . . . .

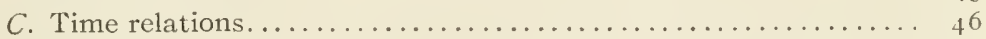

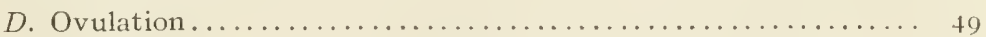

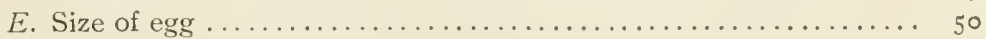


VIII. Criticisms and conclusions-Continued. Page

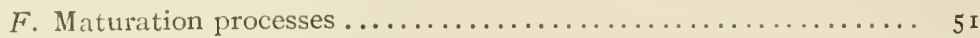

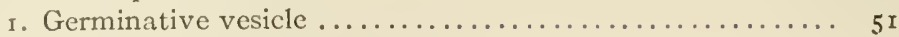

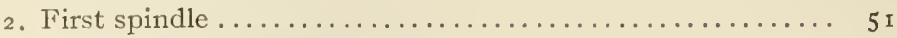

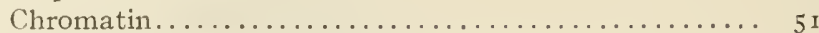

Achromatin ............................. 55

Centrosomes, circumpolar bodies, and clear region.... 56

Position and orientation ................. 57

Division of first spindle and abstriction of first polar cell 59

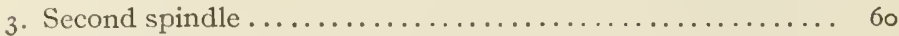

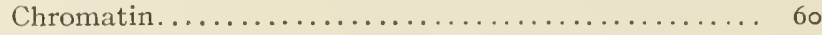

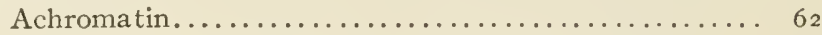

Centrosomes, circumpolar bodies, and clear region..... $6_{3}$

Position and orientation ...................... $6_{3}$

Division of second spindle and abstriction of second

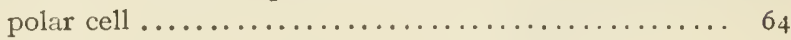

4. Polar cells .................................... $6_{4}$

5. Reduction ................................... 66

IX. Summary of the principal results in the study of the egg of the mouse... 67

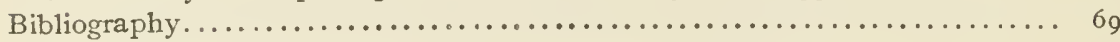

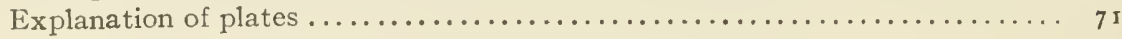




\title{
THE MATURATION OF THE EGG OF THE MOUSE.
}

\author{
By J. A. Long and E. L. Mark.
}

\section{INTRODUCTION.}

Researches into the maturation phenomena of both plants and animals have been extended greatly in recent years, and, although they have given rise to numerous different and sometimes conflicting theories, they point on the whole toward a striking uniformity of processes for all of the forms of life studied. Among the metazoa investigations have covered not only the maturation of eggs, but also the production of spermatozoa. These investigations have shown the general rule to be that by means of two mitoses, not separated from each other by a resting nuclear stage, there are formed in the one sex a ripe egg and two (or three) polar cells and in the other sex four spermatids. In many cases the origin, structure, and divisions of the chromosomes involved in these mitoses have received particular attention.

The greater number of works on the maturation divisions of eggs have been carried out on invertebrates, which furnish the most easily obtainable material. Work on vertebrates has been largely devoted to the study of amphibians and mammals. In the case of mammals, which perhaps present the most interesting field for the study of oögenesis, the investigation is especially difficult, since the kinds of mammals lending themselves to such researches are for several reasons relatively few; among these reasons are the large size of the more common domestic forms, the difficulty of breeding wild animals in captivity, and the infrequency of the breeding periods. Of the mammals most carefully studied (bat, rabbit, guinea-pig, and mouse) the last has been believed to be the only exception to the general rule that two polar cells are formed in the maturation of the egg.

According to the excellent works of Tafani and Sobotta, the egg of the mouse forms two polar cells in only a small proportion of cases; in the greater proportion of instances it produces only one polar cell. It was becanse of this apparent exception to the general law of maturation in metazoan eggs that the present piece of work was undertaken. It was begun in 1903 with the hope of finding some explanation for the supposed two classes of eggs.

It soon became clear that it would be necessary to go over the whole subject in a systematic way on the basis of the changes taking place in the chromosomes. To do this thoroughly has involved so much time that it has not been possible to give special attention to the cytoplasm. 
Since the summer of 1906 papers on this subject have been published by Gerlach, Coe and Kirkham, Kirkham, Lams et Doorme, and lastly by Sobotta. It is a satisfaction to confirm some of the results of these investigators. There are, however, a number of points in which we do not agree with any of our predecessors; some of these are due to differences of interpretation, some to differences of technique, and others to the insufficiency of material at the command of some of those who have preceded us.

A considerable part of the expense incurred in maintaining and caring for the mice has been covered by a grant from the Carnegie Institution of Washington, and a part of the same grant has been used in procuring the assistance of an aid to do part of the less important technical portion of the preparation of slides.

\section{LITERATURE.}

It is not our intention to give here a summary of the subject of the maturation of the egg of either invertebrates or vertebrates. The reader is referred to Boveri (1892), Rückert (1894), Häcker (1899), Korschelt und Heider (I903), and Grégoire (I905) for excellent general reviews of the literature of the whole field or special portions of it; to R. Hertwig (I903) for similar information relative to vertebrates; and to Sobotta (1895) and Kirkham $(1907 b)$ for surveys of the papers on mammals. The following brief account of the several works on the mouse will serve as an introduction to the results set forth in this paper. More detailed references will be made wherever necessary.

The first to study the egg of the mouse was Bellonci (1885). He described in ovarian eggs the spindle and the chromosomes arranged at its equator and considered them as being similar to those of some invertebrates. According to his account the first polar cell and the second spindle are formed while the egg is still in the ovary. The polar cell he considered a true cell with a membrane.

Tafani (I 889) studied both living and preserved eggs. He believed that the chromosomes of the first spindle, numbering twenty, were formed from the nucleolus while the egg was in the ovary, but that the division of the first spindle and the formation of the first polar cell took place after ovulation. He thought that in one-fifth of all cases the chromosomes left in the egg after the formation of the first polar cell produced a second spindle, while in the remaining four-fifths they were directly transformed into the female pronucleus. Thus, in his opinion, in about one-fifth of the eggs two polar cells were produced, while in four-fifths there was only one, the second polar cell being in the latter suppressed. No explanation of the cause of this difference was offered. He said that each of the polar cells contained either a nucleus or granules, 
and that the first polar cell, though it could change its shape and also vary in size, remained at the spot where it was formed.

Holl's paper ( 1893 ) dealt with the formation of chromosomes from the nucleolus. He made the number eighteen. Unfortunately, his material was so poorly preserved that his results are unreliable.

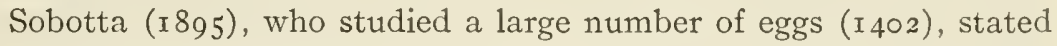
that only one polar cell was formed in about nine-tenths of the eggsa larger proportion than maintained by Tafani-while in the remaining one-tenth two were formed. Those eggs which abstrict only one polar cell are set free from the ovary in the stage of the germinative vesicle or of the early prophase of the first maturation spindle. This spindle is formed from the germinative vesicle after the egg reaches the oviduct. Just befor? the polar cell is cut off the spindle becomes radial in position.

In the other tenth of the eggs (those forming two polar cells) a first spindle is formed in the ovary 24 hours before ovulation. He does not say how it is formed, but emphasizes the fact that it lies deep in the egg and is twice as large as the spindle of eggs which produce but one polar cell. The chromosomes also are different from those of the single spindle. The division of the spindle which accompanies the abstriction of the polar cell in the ovary is only rarely seen. Then ovulation occurs, and, while the ovum is in the oviduct, the second spindle arises from the chromosomes remaining in the egg. This spindle is exactly like the single spindle of eggs forming but one polar cell. Consequently, in those eggs which produce a single polar cell, it is the first spindle and polar cell that are suppressed, the polar cell that is formed being the equivalent of the second polar cell of eggs that form two. In all spindles the chromosomes number twelve and divide transversely. There are no centrosomes nor polar radiations.

In a later paper Sobotta (I 899) describes and figures the division of the first spindle. He emphasizes its large size and deep position in the egg and the infrequency of this stage. He believes that the spindle axis turns from a tangential position, and, just before the cutting off of the polar cell, becomes radial, with one pole lying in the protuberance which will become the polar cell. He further says, in correction of his earlier statement, that the second spindle may be formed immediately before ovulation.

Gerlach (I906) agrees with Tafani and Sobotta that some eggs produce one polar cell, others two; but in his opinion the proportions are as three to one. He describes the origin of the first spindle, the chromosomes (twelve in number), and the formation of the first polar cell. This cell and the second spindle may be formed either in the orary or in the oviduct. Consequently ovulation may occur at any time from the stage of the first spindle to that of the second. According to his view, eggs in the oviduct with no polar cell must have the first spindle. 
Although, he says, only 25 per cent of all the eggs form two polar cells, all form two spindles, both of which divide; however, in those eggs which have only one polar cell, it is the second polar cell which is suppressed. This failure of the second polar cell to be formed is brought about by a rapid division of the spindle. As a result the chromosomes which would have been in the polar cell are retained in the egg cytoplasm, where they degenerate. The rapid division is, in turn, a consequence of late semination.

Gerlach finds that the two polar cells are separated by a varying distance. This he explains as the result of the migration of the second spindle from the point at which the first polar cell was formed. Semination interrupts the migration and causes the spindle to divide in the position it may have reached when it was stopped, whatever that position may be. He believes that in both divisions the chromosomes are divided crosswise, but he thinks that, for theoretical reasons, one of the divisions should be considered longitudinal (i.e., an equation division). The chromosomes of the first spindle are tetrads, those of the second, dyads. In one case he found what he considered a centrosome. The first polar cell is larger than the second.

Lams et Doorme (I907) deal chiefly with the cytoplasm. They, however, describe both spindles. The second spindle is slightly smaller than the first, but it can be identified only by the presence of the first polar cell. They believe that both spindles divide and that two polar cells are cut off in all cases. The abstriction of the first polar cell and the formation of the second spindle from the chromosomes left in the egg take place in the ovary. Ovulation occurs, then, during the stage of the second spindle. The second polar cell is formed in the oviduct after semination. They maintain that the second polar cell is larger than the first, also that the first degenerates. Each spindle has twelve chromosomes; centrosomes may exist, though they are not regularly present.

Kirkham (I907) believes that in all eggs two polar cells are formed, the first always being produced while the ovum is in the ovary. In his opinion the first and second spindles differ in the nature of their chromosomes, those of the first being tetrads, the second, dyads. The number of chromosomes is twelve. Centrosomes occur at the poles of both spindles. The first polar cell is larger than the second and different in chromatin content. He assumes that in most eggs the first polar cell is forced through the zona pellucida and is lost.

Melissinos (1907), in his paper on the development of the mouse makes, in passing, a few remarks on maturation. He thinks that 25 per cent of the eggs form two polar cells, and he places the number of chromosomes at eight. But his figures are so diagrammatic and indicate such poor fixation of his material that not much weight can be given to them.

Since I 895 Sobotta ( 1907 ) has considerably changed his former views. He now maintains that one-fifth (instead of one-tenth) of the eggs form 
two polar cells, and that not only this one-fifth, but all of the eggs, produce two spindles. However, he still thinks that in 4 out of every 5 eggs the first spindle does not divide, but is metamorphosed directly into the monaster of the second spindle, and that half of its chromosomes must degenerate in the egg. Thus, in his opinion, the first polar cell in four-fifths of the eggs is suppressed by the failure of the first spindle to divide. He thinks that this conclusion is supported by the fact that the metakinesis of the first spindle is only rarely seen. When the first polar cell is formed it is cut off while the egg is in the ovary, and the second spindle, too, arises before ovulation. He adds somewhat to his previous description of the chromosomes, the spindles and their divisions. His view has changed also in regard to the number of chromosomes in both spindles. He now counts sixteen instead of twelve. Sobotta reviews and criticizes the work of Gerlach, and touches on the papers of Kirkham and Lams et Doorme.

Sobotta (I908), in his latest paper, gives a clear summary of the present state of investigation on the maturation processes, and points out that he believes the mouse to be an exception to the general rule. He then briefly outlines his own results and reviews and criticizes the recent papers of Gerlach, Melissinos, Kirkham, and Lams et Doorme. 


\section{MATERIAL AND METHODS.}

The mice used at the beginning of this work were received from the lot reared by Professor Castle and Dr. G. M. Allen in connection with Dr. Allen's work on the Heredity of Coat Color in Mice. Some were white and some were hybrids obtained by crossing wild gray mice (Mus musculus) with the white variety bought of dealers. There were a few white and hybrid individuals of less simple ancestry; also black, chocolate, and golden agouti (Allen, I904). These served as a beginning for the subsequent stock of 400 to 500 kept on hand for material during the greater part of the past five years.

As the vigor and fertility of the stock became lessened by inbreeding, new white mice procured from several dealers in different parts of the country and a few gray mice caught wild were introduced with beneficial results. Thus the animals furnishing eggs for study were of cosmopolitan ancestry. Besides the introduction of new blood, pains were taken to mate as distantly related animals as possible in order to keep up the standard of the stock. With the idea at first of finding out whether there was any possible relation between the number of polar cells and the coat-color inheritance, whites and hybrids were mated (giving whites and hybrids in equal proportions); but on finding no such relation, hybrids and whites were paired only for convenience in distinguishing sex.

As a supplement to the account of the care of mice by Dr. Allen (I 904), whose methods the writer has in general used, the following may be of value to those working with mice and rats. Fig. A (plate A) shows a modification of the cage originally used in the Harvard Zoological Laboratory. The improvement consists in making the lids a fer inches shorter and putting the hinges, not at the highest part of the cage, but further down on the inclined surface. This arrangement greatly decreases the danger of pinching under the lid frightened mice which have run up the sides to the top, and, finding an opening, are trying to get out; it also facilitates catching the mice in the upper corners.

Since water left in open dishes soon becomes fouled, use was made of the supply bottle shown near the corner of the left-hand cover in fig. $A$ and in section at 5 , fig. $D$ (p. 9). One of these was put on each cage. It consists of a 3 -ounce, wide-mouth bottle fitted with a rubber stopper pierced by a bent glass tube of about $6 \mathrm{~mm}$. inside diameter. The tube has its lower end bent just enough to prevent the escape of water when undisturbed and is at the same time large enough and open enough to allow air bubbles to ascend as the water is lapped out of the free end by the mouse. This device, arranged as shown in fig. $A$, with the tube projecting through the wire mesh into the cage, insures an easily accessible supply of clean, fresh water.

Mice thrive well on rich bread-and-milk, oats, and sunflower seed. They find an occasional bit of lettuce a relcome addition. 


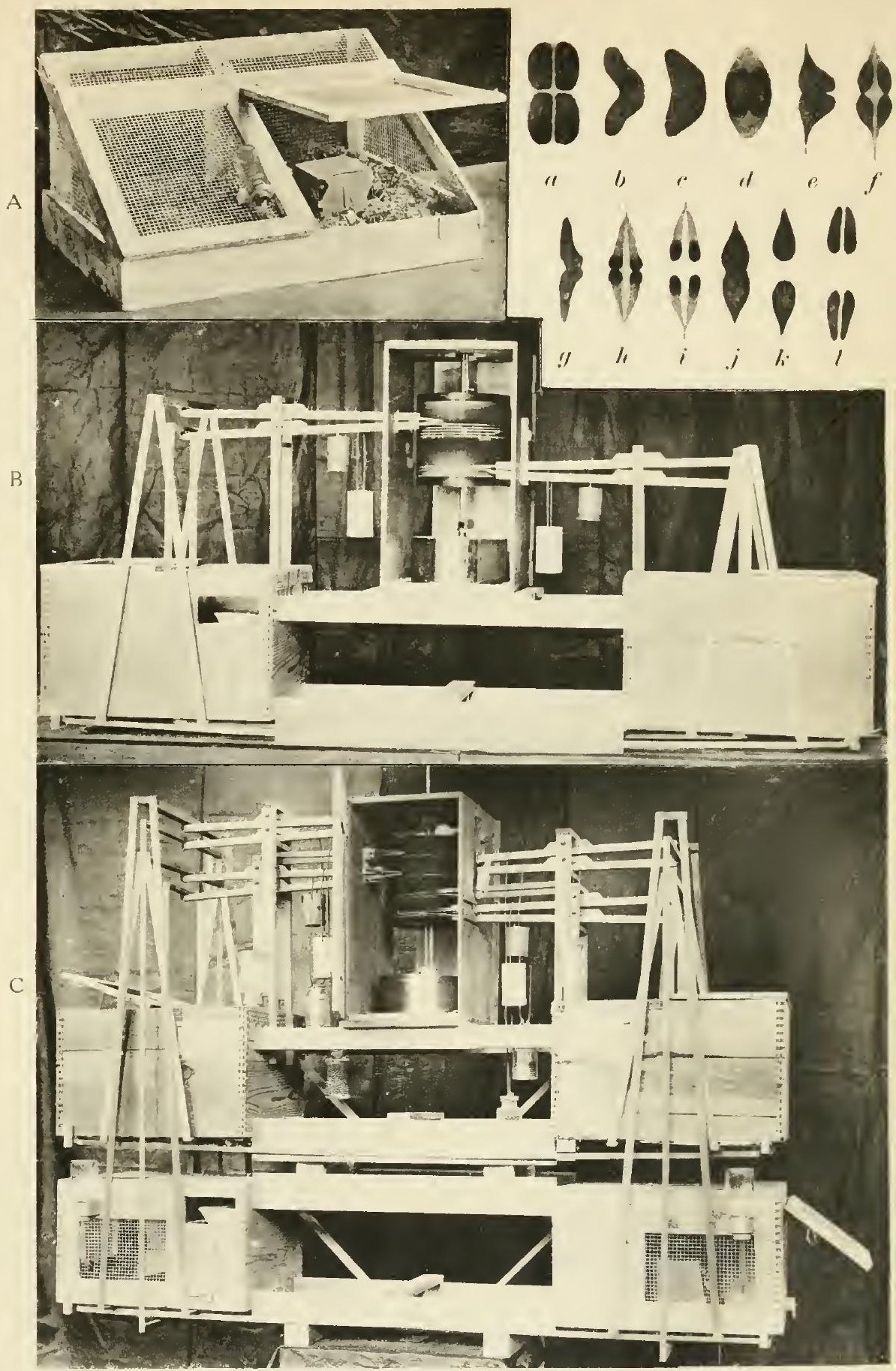

A. Mouse Cage. (For description see p. 6.)

$\mathrm{B}, \mathrm{C}$. Suspended mouse cages, with self-recording apparatus to indicate approximately the time of parturition of a gravid female. (See pp. 7-10.)

G. Chromosomes of first maturation spindle. (See pp. 28-30.) 

For distinguishing individuals the system of holes and notches punched in the ears, used by Professor Castle and Dr. Allen, was employed (Allen, r 904). In addition to a book for serial numbers, sex, parentage, color, and date of birth arranged according to the serial numbers, it was found convenient to have another book in which there was devoted to each cage a separate sheet, whereon were set down the serial number, sex, and color of each of the mice in the corresponding cage. When mice were transferred from one cage to another, corresponding records were made on each sheet, making it possible, when necessary, to trace a mouse from one cage to another, and to determine its matings.

Individual records were kept of the breeding females only. These records, the record of litters, etc., were made on paper of uniform size perforated for file-binding. To lessen the possibility of error, the same sheets also served for all subsequent records of insemination, killing, fixing, etc. Finally, a new serial number, corresponding with the number on the slides prepared from the killed individuals, was also recorded on these sheets.

Sobotta (I 895) states that under natural conditions mice breed most actively during two periods in the year, one in the spring (April and May), the other in late summer and early autumn (from the middle of August to the end of September); but that if kept warm they breed all winter. Since the mice used in this work have been kept warm and well fed at all times of the year, the conditions have not been favorable for determining the natural breeding seasons.

As previous investigators have shown, female mice are in heat and ovulate soon after parturition.) The eggs for the present work have been obtained, with one exception, from the ovaries and oviducts during the first 40 hours after parturition.

It has been the custom of the junior writer to look over the stock of breeding mice every 5 days ( 5 days being the average time before parturition when pregnancy is first easily recognizable) to note pregnant females and to remove from males such as were to be observed and killed. Apparently it has been the habit of former investigators to leave the two sexes together and not to determine with exactness either the time of parturition or of fertilization. It was felt from the first that a fair degree of accuracy in the determination of the times of parturition and insemination would be of great advantage; and, since it was found that parturition may occur at any time during the 24 hours of a day, it was necessary to make frequent observations.

In order to increase accuracy in observation and to save much time during both day and night, the apparatus illustrated in figs. $B, C$ (plate $\mathbf{A}$ ), and $D$ was planned and made by the junior writer. Its purpose was to serve in recording automatically the approximate time of the birth of litters. In this apparatus advantage has been taken of the 
fairly constant habit of mice to take food or water at frequent intervals. The food is placed on a stationary shelf in the cage, whereas the nest and the floor of the cage are made independent of the rest of the cage and of each other. By making the movements of the delicately poised nest and floor self-recording, the activities of the mouse can be determined. The change in the record after parturition is due to the increase in the weight of the nest depending on the presence of the young mice in the nest even when the mother is away. The apparatus is constructed on the principle of a simple balance, the movements of which are recorded on a chronograph drum revolving once in 12 hours. The parts shown in fig. $D$ at $\mathrm{I}$ and 2 constitute a unit and accommodate one mouse. The apparatus as finally perfected, fig. $C$, has a capacity of four mice, all the records being made simultaneously on the same chronographic drum.

The essentials of each unit are shown in fig. $D$; I is a diagrammatic side view, and 2 is an end view. Each unit consists of a box, fixed in position, but having a movable floor composed of two parts, each of which is suspended independently of the other and may move in a vertical direction. The box $(B)$, about $\mathrm{I}_{5} \times \mathrm{I}_{2} \times \mathrm{I}_{\mathrm{O}}$ inches, rests upon supports as seen in figs. $B$ and $C$. Each box has either the top or side made of wire netting having quarter-inch meshes and is provided with a door (D) at one end or on the top (see lower box on right side and upper box on left side, fig. C). The floor is of thin, light wood made in two separate parts - a central part, the nest-floor (fig. $D, \mathrm{I}$ and $2, \mathrm{NF}$ ), supporting the nest $(\mathrm{N})$, and a marginal part, the main floor (MF). The two parts of the floor are suspended from the ends of two levers or balance arms (NL, FL), the opposite ends of which terminate in pointers (NP, FP) in contact with the revolving drum of a chronograph (CR). The levers are supported on pivot fulcrums at $\mathrm{O} O$, and the pointers are made of very thin spring-brass so pointed and bent as to scratch the smoked paper enveloping the drum. The suspension of the floors is effected by means of thin strips of wood the upper ends of which are attached to the ends of cross-beams. Each cross-beam in turn rests on the end of its lever by means of a glass-and-steel bearing. To the under side of the middle of each cross-beam is attached a piece of glass ( $G$, fig. $D, I, 2,3,4)$, which rests on a steel knife-edge (E) secured to the end of the lever (NL or FL). Slipping of the glass on the steel edge is prevented by making a slot (fig. $D, 3$ and $4, \mathrm{SL}$ ) in each of the two pieces of sheet zinc $(Z)$ with which the glass $(G)$ is held in place on the under side of the cross-beam, the knife-edge (E) occupying the slot. To all the edges of each floor are fastened strips of light tin $(\mathrm{T})$. These prevent the mouse from easily gnawing out and also keep in place the nest $(\mathrm{N}$, which is an inverted strawberry basket) and the sawdust with which the main floor is sprinkled. To the floors are further attached light wood strips (S S, provided with metal ends for reducing friction), which keep the floors from touching each other or the box. The floors and attached 
parts are counterbalanced by the weights (W W), which may be so adjusted that the floors move up and down at a very light touch. The extent and place of the excursion of the levers are controlled by check blocks, shown in plate $A$, figs. $B$ and $C$, attached to the outside of the chronograph box. The feed dish (FD) is on a little shelf attached to the inside of the box, and thus independent of the movable parts, as is also the water bottle.

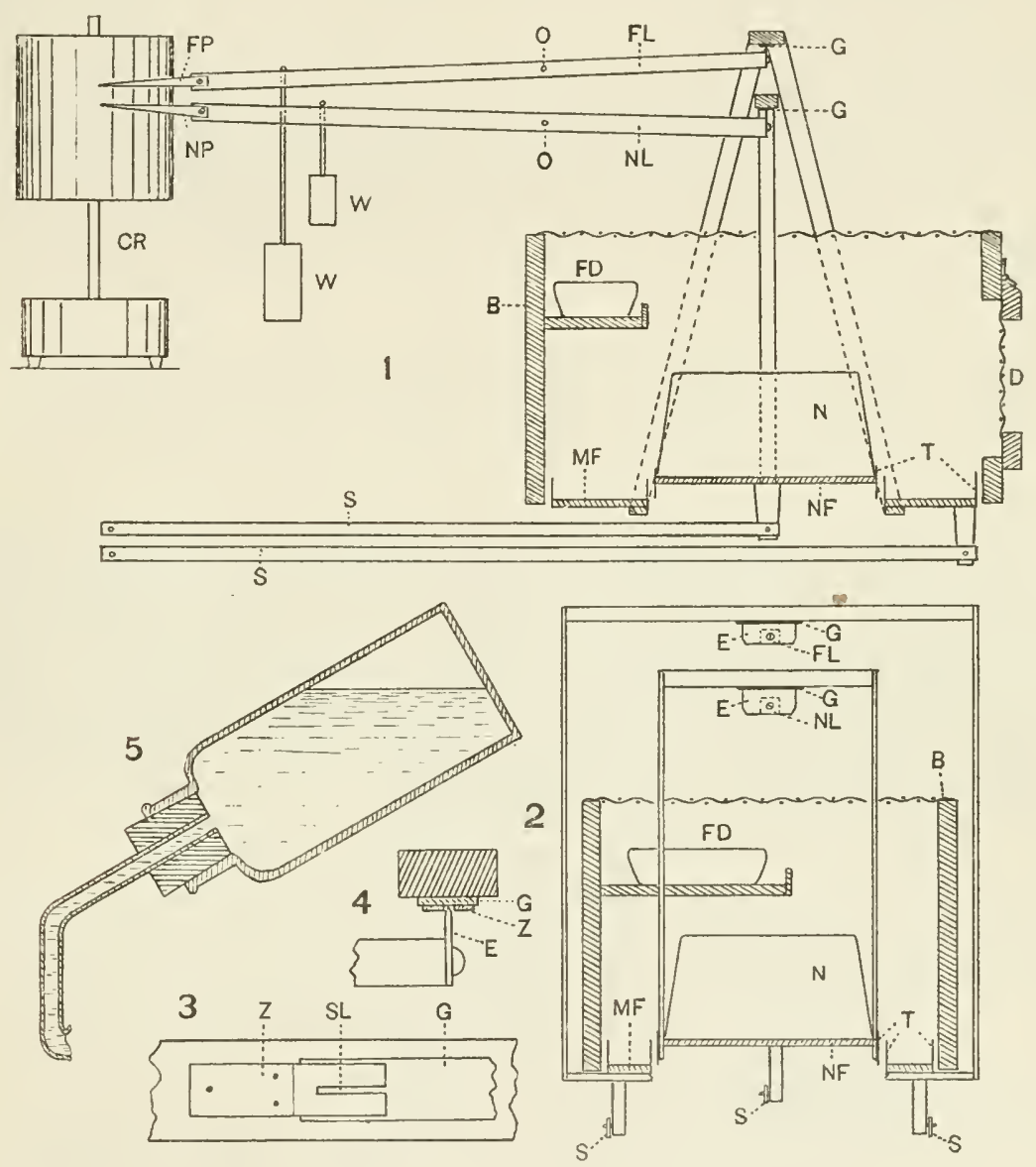

Fig. $D$.

In use, the weights are so adjusted that the empty nest $(\mathrm{N})$ with its floor (NF) is raised to its upper limit, but may be depressed by a weight of only 2 to 3 grams; the main floor (MF), on the other hand, requires about ro grams to depress it.

When, therefore, there is no mouse present, both parts of the floor (NF and MF) are up, and the pointers (NP FP, fig. E) are down. If, under these conditions, the chronograph drum is set in motion, the two 
pointers will inscribe lines in the position of the lines between $a$ and $b$, fig. E. A pregnant female placed on the floor (MF) causes its pointer (FP) to go up, as at $b$. As long as she remains on the floor the record is like that between $b$ and $c$. When she enters the nest, the nest pointer (NP) goes up and the floor pointer (FP) down, the record being that between $c$ and $d$. When she leaves the nest and goes directly to the food, the record becomes that between $d$ and $e$, as at first. The record at $e$ shows that she again enters the nest, but on her way jumps to the main floor (vertical mark on line FP). If, before again making an exit (as she must for water and food), she gives birth to a litter of little ones, on the one hand her weight will still be sufficient to depress the floor (MF), as at $f$, and on the other, the young will be heavy enough to keep the nest down, so, that no matter how often she goes in and out, the nest pointer (NP) will make an unbroken line, the floor pointer alone making vertical marks.

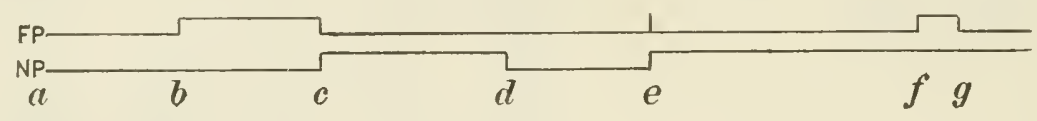

FIG. E.

Knowing the time when the record began or ended, it is an easy matter to ascertain the limits of a period of time, of day or night, within which parturition occurred. The length of the period-depending on the frequency of the excursions which the mouse makes-may vary from about I 5 minutes to 6 hours, but is usually from $\frac{1}{2}$ hour to 2 hours. Table I, based on the observation of 147 mice, is interesting as showing the degree of precision of these observations.

TABLE I.-Observations.

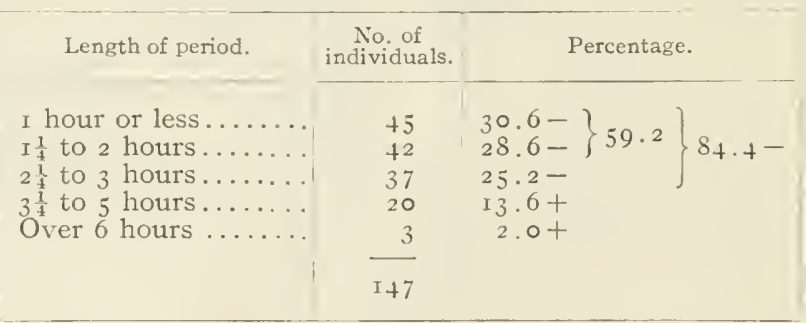

From this it is seen that in nearly one-third of the cases the period is not over I hour; in nearly two-thirds (about 60 per cent) it is not over 2 hours, and in nearly $\delta_{5}$ per cent it does not exceed 3 hours. In all subsequent calculations the middle point of the period is adopted in each case, so that the greatest inaccuracy as to time can not exceed half the length of the period, and assumably will be on the average much less. 
At this point it is convenient to define two terms which will be frequently used in the following pages, viz, "insemination" and "semination." The first refers only to the introduction of the male sexual elements into the genital tracts of the female by the act of coitus or otherwise. The second, which means the same in this connection as the German "Besamung," applies to the access of the spermatozoa to the eggs in the oviduct, the coming into contact of the male and female reproductive cells. Both terms are distinct from "penetration" and "fertilization."

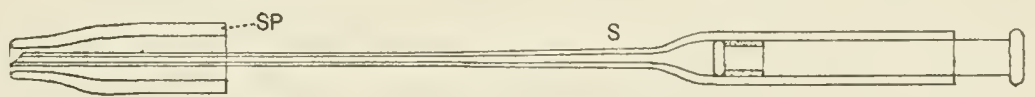

Fig. F.-Glass syringe and speculum, about three-fourths actual size.

In order to control the time of semination, artificial insemination has been used in nearly all the cases where fertilized eggs have been desired. The method is a simple one, and with a little experience the operation becomes easy. It may be performed quickly and without the use of ether, and apparently produces neither pain nor injury to the mouse. The spermatozoa are obtained from the vasa deferentia of a male killed for the purpose and are put into a small amount of tepid physiological salt solution ( 0.75 per cent ordinary table salt), in which they will live for several hours. The spermatozoa from one male are sufficient for several females. The mass of spermatozoa thus diluted is drawn into the long, narrow part of a glass syringe (S, fig. $F$ ), made for this purpose. If the spermatozoa become disseminated in the salt solution - a fact easily recognized in the syringe because of the increasingly milky appearance of its contents and a diminution of the solid mass of spermatozoa--they are active and capable of fertilizing. In practicing artificial insemination, the mouse is held under the left hand, being confined between two pieces of cotton-batting, one above and one below. The base of the tail is grasped between the first joint of the left thumb and the metacarpal of the left forefinger.

By means of a glass speculum (SP, fig. F) introduced into the vagina and held between the left thumb and the tip of the left forefinger, it is easy to see the somewhat constricted orifice of the neck of the uterus, and to introduce into the uterus by means of the syringe operated by the right hand a very few drops of the fluid containing spermatozoa. The speculum and syringe are best kept at body temperature by immersing them in hot water, taking care not to injure the spermatozoa. Only spermatozoa from freshly killed males were used.

There can be no doubt that the eggs fertilized by means of artificial insemination are perfectly normal. Artificial insemination is a common practice in the breeding of horses and dogs, the offspring produced by such methods being quite sound and perfect (Heape, I897; Iwanoff, 
I903). Moreover, in coöperation with Professor Castle, the junior writer obtained in 1904 by the above-described method a litter of three rats, which have been used for breeding purposes in Dr. Castle's experiments. Similar breeding experiments with mice are too few to be of any value; but eggs of mice artificially inseminated when compared with those of mice naturally impregnated appear normal in every respect. ${ }^{1}$

In all, I 49 mice have been artificially inseminated, but as only 85 have been studied in detail the rest unfortunately can not be included here. 3 I of the 85 have furnished eggs which contained spermatozoa or pronuclei. A further discussion will be found on page 20 .

Only sound mice, white, hybrid, and black, have been used for study. They have been killed at all hours of the day and night during the first 40 hours after parturition. While at first chloroform was used, it was found to be quite as humane and quicker to stun them and then break their necks by pinching them quickly with the thumb and forefinger just behind the head.

The ovaries with the oviducts attached were immediately removed and fixed for from 20 to 60 minutes in the following modification of Zenker's fluid: 2 per cent corrosive sublimate, 2 per cent potassium bichromate, to per cent glacial acetic acid. The fluid was made up in two separate solutions: (A) 4 per cent bichromate, (B) 4 per cent (aqueous sol.) sublimate and 20 per cent acetic acid. When desired for use, equal portions of $\mathrm{A}$ and $\mathrm{B}$ were mixed. After fixation the ovaries and oviducts were washed in several changes of warm water until fairly white, i.e., from $\mathrm{I} 2$ to 24 hours; then left in 70 per cent alcohol containing iodine for from I 2 to 24 hours; quickly dehydrated, cleared in xylol, and embedded in paraffin. This process gives clear fixation of ovarian eggs without shrinkage of eggs or nuclei and without destroying the finer st.ucture. Various other mixtures, with and without osmic acid, have not given satisfactory results.

The whole ovary and oviduct were cut into sections 8 micra thick, as thinner sections divide the nuclei and spindles into too many parts. The sections were affixed to slides with albumen, being spread by the water method, and were stained by one or the other of these three methods: (I) with iron hæmatoxylin followed by either Congo red or orange $G$, (2) with Böhmer's hæmatoxylin and Congo red, or (3) with Mallory's (I905) phosphotungstic-acid hæmatoxylin. The first gives clear outlines, but does not show the structure of chromosomes well. Böhmer's dye when used for 24 hours or more gives excellent results. Mallory's, when used in just the right way, is the best of any of the stains tried. The method employed for Mallory's stain was as follows: From water the sections were put into a constantly agitated solution of 0.25 per cent

${ }^{1}$ Since the above was written the junior writer has obtained two litters of perfectly healthy mice by artificial insemination performed about 24 and 30 hours, respectively, after parturition. 
potassium permanganate for 10 minutes; rinsed in water; transferred to a 5 per cent solution of oxalic acid for 20 minutes; washed thoroughly in water; and left in the stain for from 18 to 36 hours. The process was completed by a final rinsing, rapid dehydration, and mounting in balsam.

The results given in the following pages are based on $I, 000$ eggs obtained from 147 mice. Only clearly normal eggs have been used, those in the ovaries being in all cases in large ripe or nearly ripe follicles, never in small or manifestly degenerating ones. Each egg was carefully studied with a Zeiss $2 \mathrm{~mm}$., homogeneous immersion, apochromatic objective and a No. I 2 compensating ocular. Sketches and measurements were made for each egg on separate sheets of paper of uniform size (see page 7), which could be subsequently arranged as desired. Tables 2 and 3 , which will be referred to again, show in a comparative way the number of eggs in various stages, and also other data to be discussed later. 
I 4 THE MATURATION OF THE EGG OF THE MOUSE.

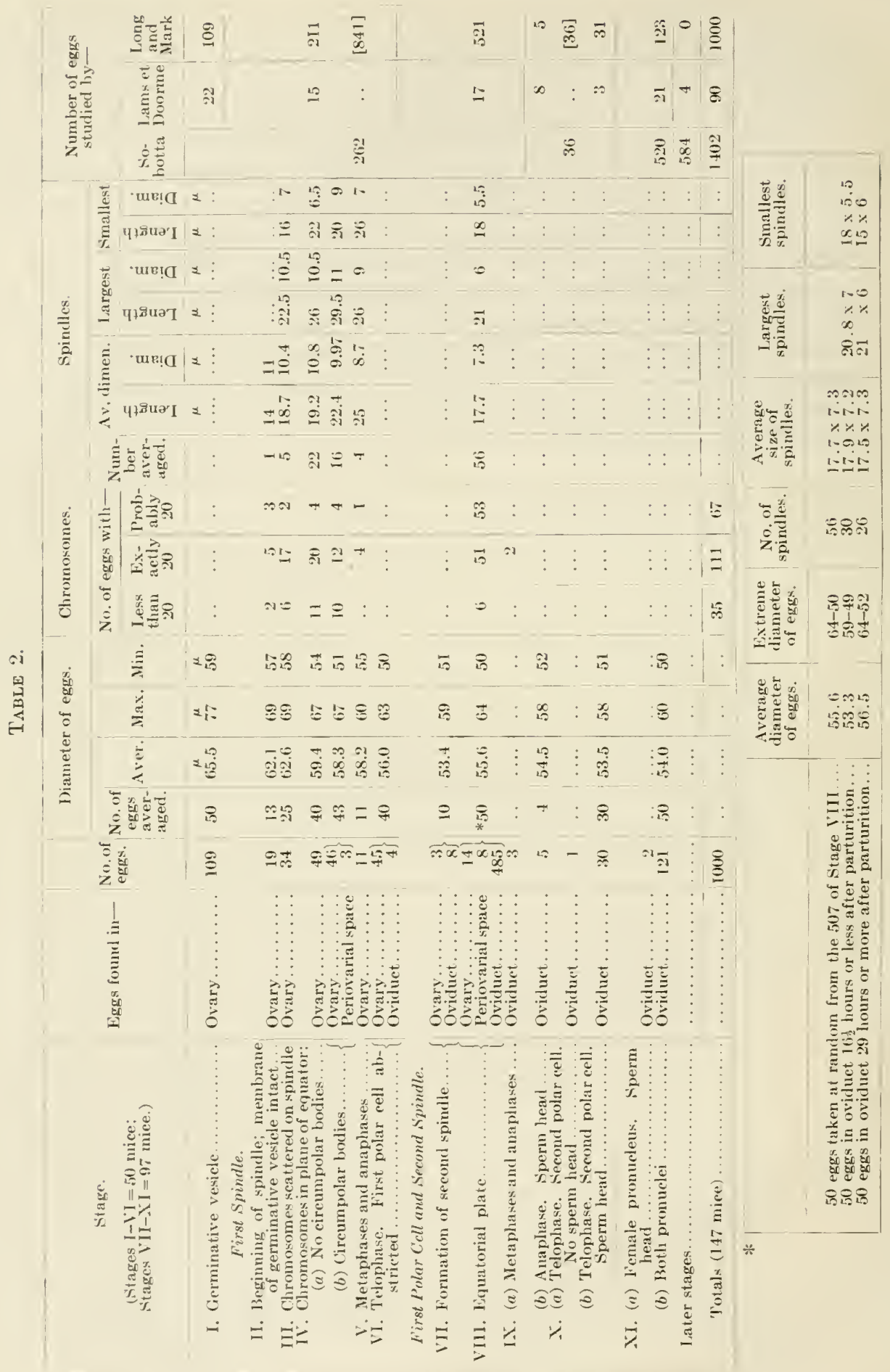




\section{TIME RELATIONS OF PARTURITION, MATURATION, OVULA- TION, INSEMINATION, AND SEMINATION.}

Parturition may occur at any hour of the day or night; although, as table 3 shows, it takes place more frequently in the early morning. TABLE 3.-Number of cases of parturition during each of 6 four-hour periods of a day.

\begin{tabular}{|c|c|c|c|}
\hline Period. & & ses. & Period. \\
\hline $\begin{array}{l}6 \text { a.m. to Io } \mathrm{a} . \mathrm{m} \text {. } \\
\text { Io } \mathrm{a} . \mathrm{m} \text {. to } 2 \mathrm{p.m} \text {. } \\
2 \text { p.m. to } 6 \mathrm{p.m} \text {. } \\
6 \text { p.m. to Io } \mathrm{p.m} \text {. } \\
\text { Io } \mathrm{p} . \mathrm{m} \text {. to } 2 \text { a.m. } \\
2 \text { a.m. to } 6 \text { a.m. }\end{array}$ & $\begin{array}{r}24 \\
21 \\
18 \\
23 \\
21 \\
40 \\
147\end{array}$ & $\begin{array}{r}30 \\
24 \\
22 \\
21 \\
18 \\
32 \\
147\end{array}$ & $\begin{array}{l}4 \text { a.m. to } 8 \mathrm{a} . \mathrm{m} \text {. } \\
8 \text { a.m. to i } 2 \mathrm{~m} \text {. } \\
\text { r } 2 \mathrm{~m} \text {. to } 4 \text { p.m. } \\
+ \text { p.m. to } 8 \text { p.m. } \\
8 \text { p.m. to r } 2 \text { night. } \\
\text { I } 2 \text { night to } 4 \text { a.m. }\end{array}$ \\
\hline
\end{tabular}

The distribution is nearly the same whether the periods begin at 4 a.m. or at 6 a.m.

The eggs which mature at each ovulation average nearly seven, and are in general fairly evenly divided between the two ovaries. In the maturation processes of the eggs of each individual there is a synchronism which appears tolerably exact when the adopted stages cover fairly long periods; more specifically, in most cases all the eggs of a given mouse are in one or the other of the following stages: with ( $\mathrm{I}$ ) the germinative vesicle, or (2) the first maturation spindle, or (3) the first polar cell and second spindle. It rarely occurs that the eggs from one ovary are very much in advance of those produced by the other; in fact, a marked difference was observed in only two mice, and in these the most widely separated stages exhibited, on the one hand, the germinative vesicle, and on the other, the first polar cell and second spindle. Between eggs from the same ovary there is still less difference.

If, however, the processes of maturation are divided into shorter periods, as in table 2 (p. I 4), the synchronism appears less perfect. Neglecting, for the time, mice with eggs in the stage of the second spindle (VIII, table 2) - a stage which may persist for 24 hours or more-and considering only those ( 50 in number) which show eggs in stages between the beginning of the formation of the first spindle and the abstriction of the first polar cell, inclusive (Stages II to VI inclusive), it was found that in a few less than half the mice (22) each individual had all its eggs in only one stage (either Stage I, III, IV, or VI), while the other 28 mice had eggs which fell within some two or three consecutive stages from Stage I to Stage VII. In no individual were the eggs confined to either of the single Stages II, V, VII. In other words, one or the other of two conditions prevails; either, first, all the eggs from a given mouse may be in one or the other of the four following stages: (I) the germinative vesicle, (III) the first spindle with the chromosomes not yet 
drawn into the equatorial plate, (IV) the first spindle in the equatorialplate stage with or without circumpolar bodies (see p. 33), (VI) the telophase of the first spindle and the first polar ccll just cut off; or, secondly, some of the eggs may be in one stage, some in another. If, under the latter condition, some eggs show either (II) the beginning of the first spindle within the germinative vesicle, or (V) the separation of the daughter chromosomes of the first spindle, or (VII) the formation of the second spindle, others are sure to be in one or more of the adjoining stages.

The conclusions to be drawn from these observations are, first, that some stages occupy less time than others, since, owing to the somewhat imperfect synchronism, in some cases all the eggs fall into one stage, whereas in other cases some fall into one stage, others into another stage; and, secondly, that the stages passed comparatively quickly are those of the formation of the first spindle (II), of the dividing of the first spindle and the cutting off of the first polar cell (V), and of the formation of the second spindle (VII). Furthermore, the small numbers of eggs in these three stages bear out these conclusions. In a similar way it can be shown that the division of the second spindle takes place in a relatively very short time.

In the foregoing considerations Stages IVa and IVb can not with fairness be separated, since there is much less difference between them than between any other two stages. Also, neither of them is rare. Of the two, IVb is more often associated with other stages.

There is considerable variation among mice in regard to the time relation between the stage of the egg and the interval between parturition and killing. This variation may be so great that mice killed for eggs in the oviduct are found to have them still in the ovary, and vice versu. Nevertheless, a detailed study of this relation shows a uniformity sufficient to enable one to say about when certain stages occur, and to determine approximately the time of ovulation. Moreover, in connection with a knowledge of the relative length of the stages, it is possible to form something of an idea of the rapidity of the whole process and of its parts.

How long before ovulation the germinative vesicle presents the conditions shown at parturition is not known. It may be weeks or even months. But it is quite certain that for several days, perhaps weeks, before ovulation it has the structure which is found during the first I 2 hours after parturition. Usually within I 5 or I 6 hours after parturition the vesicle has given place to the first maturation spindle. More seldom it persists longer, even up to $20 \frac{1}{2}$ hours after parturition.

The earliest first maturation spindle that we have observed was formed $13^{\frac{3}{4}}$ hours p.p. ${ }^{1}$; and the latest was in existence at $28 \frac{1}{2}$ hours p.p. Since the formation of the spindle is very rapid, it is probable that the

${ }^{1}$ For sake of brevity we have employed for post partum the abbreviation p.p. 
first spindle may arise as late as about 28 hours p.p. According to these observations, then, the first spindle divides and gives rise to the first polar cell not earlier than $\mathrm{I} 3 \frac{3}{4}$ hours p.p., nor later than $28 \frac{1}{2}$ hours p.p. This conclusion is rendered the more probable by the observations that

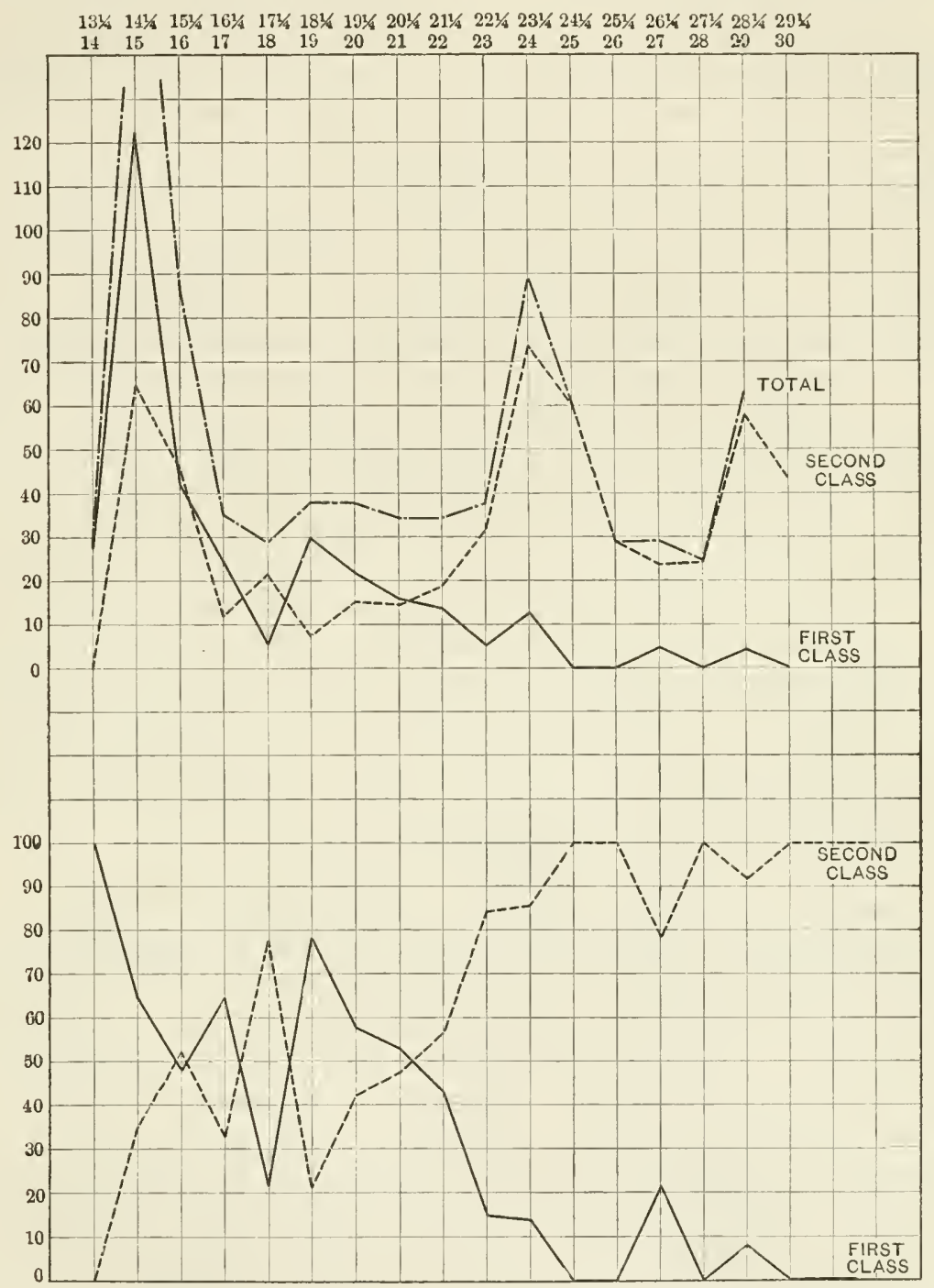

the youngest egg in which the first polar cell was completely cut off was taken from a female killed i 4 hours p.p., and that the oldest egg in which the formation of the first polar cell was barely completed was from an individual killed 27 hours p.p.

Very frequently the second spindle has been found completely formed as early as 16 hours, and occasionally as early as $14 \frac{1}{2}$, p.p. The 
latest epoch at which it may originate depends on the time when the first polar cell is formed, which, as above stated, may be as late as $28 \frac{1}{2}$ hours p.p. It can be found in unfertilized eggs in a normal condition up to at least 40 hours p.p.

The accompanying "curves" (page I 7 ) are given to illustrate the ratio between two classes of eggs: the "first class" embraces eggs containing the germinative vesicle, or the first spindle in any of its stages up to the recently formed first polar cell (Stages I to VI, table 2); the "second class," eggs of all succeeding stages (Stages VII to XI). A consideration of these curves reveals some facts, or at least probabilities, concerning the amount of time required for certain parts of the maturation process. In the upper diagram the unbroken line represents the number of eggs in the first class, obtained at various indicated epochs (hours) after parturition, and the dotted line the number of eggs in the second class at corresponding epochs. The sum of the two curves, shown by the dot-and-dash line, includes all the eggs obtained up to 30 hours p.p. In the lower diagram the unbroken and dotted lines give, respectively, in percentages the ratios of the number of eggs in the first and second classes to the total number of eggs; they are, of course, reciprocals of each other.

The general trend of the percentage curve shows from the I 4 -hour to the 16 -hour epoclis p.p. a rapid decrease in the proportion of eggs of the first class during the early periods. The great fluctuations in the periods between 16 and 23 hours and between 26 and 28 hours are probably due to the small numbers of eggs obtained in those periods (compare upper diagram), and very likely would disappear to a large extent with more abundant material.

The whole process of maturation can be conveniently divided into two parts, the first embracing those stages which are included in the first class of eggs and the second part those in the second class. It should be borne in mind that eggs of the first class are constantly in a state of activity and are steadily advancing toward the formation of the first polar cell; whereas eggs of the second class, if not seminated, remain for 24 hours or more in a quiescent condition in the stage of the second spindle (Stage VIII). Consequently, the length of the period in which the eggs of the first class fall would be an approximate measure of the time required for that part of the process; but a similar period for the second class would not be a measure of the amount of time necessary for the completion of the second part of the process. The time required for the latter is calculated by other means. Since in eggs above the twenty-third hour p.p. the proportion of the first class is very small, it can be said that usually the first part of maturation is completed within the period between I4 and 23 hours p.p. When it is noted, further, that the curve representing the percentage of eggs in the first class drops very rapidly from the $\mathrm{I} 4$ th to the $\mathrm{I} 8 \mathrm{th}$ hour, it is fair to 
assume that the first part of maturation in a large majority of cases occurs between the I 4-hour and the I8-hour epochs p.p. While it is quite possible that the first part of maturation requires fully 4 hours (as for example from i 4 to i 8 hours p.p.), it seems highly probable that it may be accomplished within 2 hours, for the reason that at the I6-hour epoch as many eggs have reached the second part of maturation as are still in the first part. If that assumption is true, the process beginning at I 4 hours p.p. would be finished at I 6 hours, that starting at i 6 hours would end at i 8 hours, and so on.

The second part of the maturation process - the formation of the second spindle, the division of the spindle, and the formation of the second polar cell-probably requires only a very short time (perhaps only a few minutes). But the period when this takes place depends, as Tafani and Sobotta have pointed out, on the time of semination, this part of the maturation process being apparently dependent on the stimulation due to the presence of the spermatozoon in the egg.

Now, the earliest stage of an egg containing a spermatozoön that we have observed came from a mouse killed $20 \frac{1}{4}$ hours p.p., but most of the fertilized eggs were obtained from animals killed between 23 and 3 I hours p.p. Thus generally the second part of the process occurs at a period which begins somewhere between $2 \frac{1}{4}\left(20 \frac{1}{4}\right.$ minus $\left.I 8\right)$ and $I_{7}$ ( 3 I minus I 4) hours after the completion of the first. Consequently the whole process of maturation probably requires not less than 4 hours. However, as we have seen (p. I 7), the first part of maturation may occur quite lateas late as $28 \frac{1}{2}$ hours p.p. In such case it is entirely conceivable that spermatozoa might reach the oviduct simultaneously with the eggs, and, as a result, the second part of maturation might not be delayed but begin immediately on the completion of the first.

It must be concluded, then, that the process of maturation (i.e., from the disappearance of the germinative vesicle to the completion of the second polar cell) may be accomplished within about 2 hours, but probably requires more, from 4 to i 5 hours, the longer period (above 4 hours) being due to delay in the time of semination.

The time of ovulation is not rigidly fixed with regard either to parturition or to the maturation of the egg. Table 2 shows the location (ovary, oviduct, etc.) of eggs in the several stages, and table 4 the intervals p.p. when eggs in Stages III, IVb, VI, VII, and VIII were obtained. Also, table 4 does not include all the mice whose eggs fall in the above stages, but only those bearing on ovulation. Two mice (Stage IVb, table 2 and table 4 ), one killed $14 \frac{3}{4}$ and the other $18 \frac{1}{4}$ hours p.p., showed in the periovarial space two eggs and one egg respectively. Each of the three eggs had the first spindle in the "equatorial-plate" stage with circumpolar bodies. The ovaries contained other eggs of the same stage in ripe follicles. Referring again to tables 2 and 4, the eggs in Stage VI were all found in the ovary except four (from two mice killed I $6 \frac{1}{2}$ and 
24 hours p.p., respectively), which were in the oviduct along with other eggs in Stages VII and VIII. The eight eggs of Stage VII which were from the oviduct came from six mice killed at from i 5 to $I_{7}$ hours p.p., all being associated with eggs in Stage VIII. Of the three eggs of Stage VII which were still in the ovary, one was from a mouse killed $22 \frac{3}{4}$ hours p.p., and two were from two mice killed $15^{\frac{1}{2}}$ and $I 6$ hours p.p., respectively. Of the eggs in Stage VIII, many were in the oviduct even as early as $14 \frac{3}{4}$ hours p.p. Among a few (7) mice, however, having all their eggs in Stage VIII, in three (killed $14 \frac{3}{4}, 19 \frac{1}{4}$, and $22 \frac{1}{2}$ hours p.p., respectively) eggs occurred in the ovary, in the periovarial space, and in the oviduct; in two (killed $\mathrm{x} 4 \frac{3}{4}$ and 28 hours p.p., respectively) eggs were found in both ovary and oviduct; in one (killed $\mathrm{I}_{4} \frac{\mathrm{I}}{2}$ hours p.p.) eggs were discovered in both ovary and periovarial space; and in another (killed r 6 hours p.p.) the periovarial space and oviduct contained eggs. In Stage III some eggs were observed in the ovary $28 \frac{1}{2}$ hours p.p. It follows, therefore, that ovulation occurs from $I 4 \frac{1}{2}$ to $2 \delta \frac{1}{2}$ hours p.p., and that eggs when discharged may be in any stage from the end of the "equatorial-plate" stage of the first spindle (Stage IVb) to that of the second spindle (Stage VIII).

TABLE 4.-Mice killed during ovulation, showing location of eggs and hours p.p. when they were obtained.

\begin{tabular}{|c|c|c|c|c|c|}
\hline \multirow{2}{*}{ Stage. } & \multirow{2}{*}{$\begin{array}{l}\text { Individual No. } \\
\text { of mouse. }\end{array}$} & \multirow{2}{*}{$\begin{array}{l}\text { Hours p.p. } \\
\text { when killed. }\end{array}$} & \multicolumn{3}{|c|}{ Location. } \\
\hline & & & Ovary. & $\begin{array}{l}\text { Periovarial } \\
\text { space. }\end{array}$ & Oviduct. \\
\hline III & I $8_{3}$ & $28 \frac{1}{2}$ & $\mathbf{x}$ & & \\
\hline IVb & 220 & I $4 \frac{3}{4}$ & $\mathrm{x}$ & $\mathbf{x}$ & \\
\hline & 140 & $18 \frac{1}{4}$ & $x$ & $x$ & \\
\hline$V I$ & I IO & I $6 \frac{1}{2}$ & 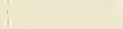 & & $\mathrm{x}$ \\
\hline & 126 & 24 & i & & $\mathbf{x}$ \\
\hline VII & 75 & I 6 & 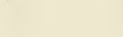 & $\mathbf{x}$ & $\mathrm{x}$ \\
\hline & ${ }^{1} \mathrm{IOI}$ & ${ }^{1} 5$ & 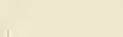 & & $\mathbf{x}$ \\
\hline & IO3 & I $5 \frac{1}{2}$ & 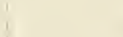 & & $\mathrm{x}$ \\
\hline & 107 & I $5 \frac{1}{4}$ & f & & $\mathbf{x}$ \\
\hline & I IO & I $6 \frac{1}{2}$ & ' & & $\mathbf{x}$ \\
\hline & I 44 & I 7 & 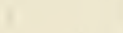 & & $\mathbf{x}$ \\
\hline & 86 & 16 & $\mathbf{x}$ & & \\
\hline & 100 & I $5 \frac{1}{2}$ & $\mathrm{x}$ & & \\
\hline & I42 & $22 \frac{3}{4}$ & $\mathrm{x}$ & & \\
\hline VIII & $\begin{array}{c}\text { Several } \\
70\end{array}$ & I $4 \frac{3}{4}$ & 1 & $\mathbf{x}$ & $\mathbf{x}$ \\
\hline & 75 & 162 & 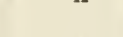 & $\mathrm{x}$ & $\mathrm{x}$ \\
\hline & 80 & $14 \frac{3}{4}$ & $\mathrm{x}$ & $\mathbf{x}$ & $\mathrm{x}$ \\
\hline & 95 & $14 \frac{3}{4}$ & $\mathbf{x}$ & & $\mathbf{x}$ \\
\hline & I I 3 & I $9 \frac{1}{4}$ & $\mathrm{x}$ & $\mathrm{x}$ & $\mathbf{x}$ \\
\hline & I I 8 & $22 \frac{1}{2}$ & $\mathrm{x}$ & $\mathbf{x}$ & $\mathbf{x}$ \\
\hline & I 87 & 28 & $x$ & & $\mathbf{x}$ \\
\hline
\end{tabular}

${ }^{1}$ Eggs in Stage VII in only one oviduct. Eggs in Stage I were also found, but in the ovary of the opposite side of the body.

As already mentioned (p. I 2), out of 85 mice artificially inseminated $3^{I}$ produced fertilized eggs. No attempt is made here to analyze ex- 
haustively the reasons for failure in so many (54) cases, but some of the apparent causes will be given for the benefit of those who may wish to use the method for breeding purposes, or for a continuation of the study of the phenomena of fertilization in mammals.

The number of hours after parturition when mice were inseminated varied from $9 \frac{1}{2}$ to $28 \frac{1}{2}$; and the time between insemination and killing varied from $3 \frac{1}{2}$ to $17 \frac{1}{2}$ hours, as many time combinations as possible being made. Before considering the two classes of eggs from the inseminated individuals - the fertilized and the unfertilized-I 4 cases can at once be deducted from the latter, because the eggs in those 14 mice were found in the ovaries, where semination is of course not to be expected.

In the first class (cases resulting in fertilized eggs) the times of insemination were pretty evenly distributed between $16 \frac{1}{2}$ and $28 \frac{1}{2}$ hours p.p. ; two, however, lay outside these limits, being at $9 \frac{1}{2}$ and $14 \frac{1}{2}$ hours p.p., respectively. All these mice were killed at from 4 to $\mathrm{I}^{\frac{1}{2}}$ hours after insemination, the one inseminated at $9^{\frac{1}{2}}$ being killed $13 \frac{1}{2}$ hours later (23 hours p.p.), and the one at I $4 \frac{1}{2}, 6$ hours later ( $2 \circ \frac{1}{2}$ hours p.p.). In the second class (resulting in unfertilized eggs) most of the inseminations were made between I I and I $8 \frac{1}{2}$ hours p.p.; a few, however, were evenly distributed between $20 \frac{1}{2}$ and $28 \frac{1}{2}$ hours p.p. The animals were killed at from $3 \frac{1}{2}$ to $\mathrm{I} 7 \frac{1}{2}$ hours after insemination.

A comparison of the two classes brings out the fact that the inseminations in both extend over almost exactly the same period of time, but with a somewhat different distribution; and a more detailed examination of the data (not recorded here) shows that as the inseminations were delayed more and more after parturition the proportion of successful ones increased. Accordingly, the optimum time for insemination lies between 18 and 30 hours p.p.

The most obvious causes of failure are (I) too early insemination, in which case possibly the conditions of the uterus are sometimes unfavorable for the continued existence of the spermatozoa, (2) killing too soon after insemination to allow the spermatozoa time to reach the eggs, (3) late ovulation, and (4) combinations of two or all of these factors.

The time required for the spermatozoa, after introduction into the uterus, to reach the eggs in the first part of the oviduct nearest the ovary varies from 4 to 7 hours in mice inseminated about the same number of hours p.p. Of these eggs some contained the heads of spermatozoa, some both pronuclei. Assuming, as is reasonable, that all the eggs, because they lie very near one another, are seminated at nearly the same time, one must conclude that the time required for a spermatozoön to develop into a pronucleus is very short indeed. According to the same reasoning pronuclei must grow very rapidly. Since the first spindle never persists until the egg reaches the oviduct, semination occurs only during the stage of the second maturation spindle. An account of the effect of semination on maturation is given on p. 35 . 


\section{OVULATION.}

The time when ovulation occurs in relation to parturition and the maturation of the egg has already been given (p. I 9). No attempt has been made to determine how often ovulation occurs, nor the regularity of such occurrence. It is perhaps worthy of record, however, that a female kept isolated and killed 6 weeks after parturition gave eggs in the oviduct in the stage of the second spindle, a fact which does not conflict with Sobotta's statement that ovulation occurs at intervals of 3 weeks. On the other hand, careful records of the births of litters show that the 3 -weeks periods are not constant, in fact, that they vary by several days. As far as known to us, no careful examination into the causes of these variations in mice has been made. ${ }^{1}$

Although the irregularity in the occurrence of ovulations--which may be as great as days or even weeks-may possibly be caused by coitus, it is certain that the first ovulation after parturition is entirely independent of such external condition, because females removed from males before they give birth to young always furnish eggs in the oviduct if killed at the proper time.

Just as there is a lack of perfect synchronism in the maturation processes, so here some eggs pass from the ovary early enough to have already reached the oviduct, while in the same individual others are in the periovarial space, and still others are in the ovary. Since in each of seven cases eggs were found in two, or sometimes three, of these places, it is highly probable that in few or no mice do the eggs leave the follicles at exactly the same time.

In the ovaries of a mouse killed $22 \frac{1}{2}$ hours p.p., there occurred three follicles (plate 6 , figs. $38,39,40$ ) showing in a rare way three stages in the process of ovulation. First, the completely ripe follicle about to rupture (fig. 38 ); secondly, the ruptured follicle before the escape of the egg (fig. 39); and, thirdly, the flowing out of the contents of the follicle carrying the egg with them (fig. 40). They are all later conditions than those figured by Sobotta (1907), and are an interesting supplement to his observations. In fig. 38 the granulosa cells which form the sides and fundus of the follicle are so numerous that they form a thick wall several (four or more) cells deep, as Sobotta has pointed out; but the side of the follicle next the surface of the ovary has already become attenuated to such an extent that at its middle the nuclei of granulosa cells are entirely wanting. The theca folliculi having also disappeared in that region, the fluid contents of the follicle come into direct contact with the germinal epithelium, which is stretched out into a thin mem-

${ }^{1}$ Postscript.-During the year 1910 Dr. J. Frank Daniel has independently found the variation in the gestation of mice to be even greater than we have stated. He has worked this out in considerable detail, as may be seen in his forthcoming paper in the Journal of Experimental Zoölogy, Vol. 9, No. 4. 
brane with widely scattered nuclei. The discus proligerus is already separated from the rest of the granulosa, and its cells, except those constituting the corona radiata, which still show the radial arrangement about the egg, are becoming detached from one another. As in the other two follicles, the first polar cell has been produced, and the second spindle (not shown in the drawing) is fully formed. There is a small space between the zona pellucida and the vitellus.

In fig. 39 (plate 6) the contents of the follicle have begun to flow out into the periovarial space through an opening at the surface of the ovary. The opening does not have the appearance one would expect to result from a rupture due to pressure from within, but rather from a condition produced by the migration of cells away from the rupturing region. The viscidity of the fluid is indicated by the sinuous, more or less parallel, line-like markings of the escaping contents (see also Sobotta, I 895), and the plasticity of the discus cells is shown by the partial obliteration of the radial arrangement of the corona cells around the egg. The distance between zona and vitellus is so much increased on the deep side of the egg that the polar cell lies in the space thus formed quite free from contact with either.

In the last stage (fig. 40) the egg lies in the periovarial space, the follicle having collapsed. Here, too, there is the same lack of evidence of a violent tearing of the follicle wall. The contents of the follicle still have the appearance of a viscous substance. The flattening of the egg, probably caused by unequal pressure-perhaps due to the narrowness of the space between the ovarian capsule and the wall of the ovarysuggests considerable plasticity. This condition can also be seen subsequently in eggs which lie between ridges of the oviduct. The zona is separated from the vitellus, as in the preceding stage, and the polar cell is detached from the egg, though not shown in fig. 40.

The corona cells surround the egg in its passage to the oviduct and persist for a varying number of hours. 


\section{SIZE OF EGG.}

All measurements made to determine the size of eggs at different stages of maturation have been made on eggs fixed in the same way and measured with the same objective and the same eyepiece and micrometer. The diameter does not include the zona pellucida. Since the egg is seldom quite spherical the longest and the shortest diameter of the middle section of the series into which each egg was cut was measured. Half the sum of these two measurements was taken as the diameter of the egg.

Table 2 (p. I 4) shows clearly the changes in size of the ovum as it advances in maturation. Under the heading "Diameter of eggs" the first column gives the number of eggs measured; the second column, the average diameter of all these eggs; the third and fourth columns, the diameters of the largest and the smallest eggs of each lot measured.

It will be seen that, with one exception, there is a steady decrease in size from Stage I to Stage VII. The exception, Stage II, shows only a slight deviation and is probably due to the fact that the average is based on so small a number (I 3 ) of eggs. Stages IV $a$ and IVb, hitherto treated by us as Stage IV, show the same progressive decrease. There is a small reduction in size at the time the first polar cell is formed (Stage VI), and another in Stages VII and VIII, when the eggs have left the ovary and have been in the oviduct for only a short time. Possibly the fact that Stage VII is not intermediate in value between Stages VI and VIII may be due, as presumably in Stage II, to the small number (Io) of eggs on which the average is based. Eggs that were observed in the oviduct about 29 hours or more p.p. show a slight increase in size (see foot-note to table 2). The sizes in the remaining stages can have no special meaning because the eggs had been in the oviduct varying lengths of time.

Aside from the change in volume, there is, as the column of maximum and minimum diameters shows, considerable individual variation. 


\section{OBSERVATIONS ON THE MATURATION PROCESSES.}

In considering the various topics of maturation the processes are dealt with by stages, the chief characteristics of which have been briefly suggested in table 2 (p. I 4). It seems desirable, however, to give a more precise definition of these stages before proceeding to a detailed account of maturation.

It should be borne in mind that these stages, though fairly distinct, are, nevertheless, only periods in a continuous process of development and therefore connected with each other by intermediate conditions.

\section{A. OÖCYTE I.}

\section{General Description of Stages.}

Stage I.-Germinative Vesicle.

The germinative vesicle, nearly up to the time when it is transformed into the first maturation spindle, presents the following conditions (compare plate I, fig. I):

It is somewhat eccentric in position, nearly spherical, and from I9 to 26 (on the average 23) micra in diameter. It has a uniformly thin, lightly staining, smooth membrane, and is filled with a clear, homogeneous substance, the karyoplasm. At one side lies the vesicular nucleolus, usually in contact with the nuclear membrane. Immediately inside the membrane, and particularly around the nucleolus (plasmosome), are masses of chromatic substance attached to these structures by achromatic material of irregular, though often threadlike, form. There are a few strands, remnants of the linin network of an earlier stage, running through the karyoplasm. Figure I, plate I, illustrates these conditions, except for the condition of the nuclear membrane.

The spheroidal, or sometimes lenticular, nucleolus is about 8.5 micra in its longest diameter, and has a fairly thick, deeply staining wall of uniform thickness. It contains only a clear, homogeneous substance, never any chromatic bodies such as are attached to its outer surface, either as distinct bodies or as apparent thickenings of its membrane (fig. I).

The chromatic masses of the nucleus are usually globular, though sometimes of an irregular form, and have no correspondence with chromosomes of later stages either in number or in shape. In phosphotungstic-acid hæmatoxylin some of them are stained deep blue, like chromatin; a few pink, like cytoplasm. There are in addition deeply stained granules scattered through the nucleus. These are usually associated with the achromatic substance.

Preparatory to the advent of the first spindle, the germinative vesicle moves a little nearer the surface of the egg, but the depth at which it comes to lie is not the same in all cases. It then decreases in size, and its membrane becomes a little fainter and presents a very irregular, wrinkled appearance (fig. I). 
Stage II.-Formation of First Maturation Spindle.

The passage from the preceding stage to this one is rapid. The germinative vesicle has shrunk still more and is surrounded by a narrow, clearer region, in which, however, there are cytoplasmic granules (figs. 2 and 3 ). Its contents are no longer clear and homogeneous, but show a granular condition, much like that of the immediately surrounding cytoplasm. A few achromatic threads are still visible. The nucleolus and chromatic spherules have disappeared (compare fig. I with figs. 2 and 3 ), and instead there is a group of chromosome bodies, which is usually located at one side, rather than in the middle, of the nucleus.

Figs. 2, 3, 4, and 5 show the first steps in the formation of the first maturation spindle. The fundaments of the chromosomes differ greatly in form. Some are masses of irregular shape, which it is hard to distinguish from the large granules; some are ring-like; a few are elongated and show a simple or a compound curve; still others show divisions into two or four parts (figs. 2 and 3). Later (figs. 4 and 5), these all become completely differentiated and assume more definite and characteristic forms, some in advance of others. As they assume more precise forms they become more separated from one another. Their number is at first uncertain, but by the time they have reached the condition seen in figs. 4 and 5 it is clearly 20 (see table 2 , Stage II, p. I 4 ).

At an early stage in their development the fundaments of the chromosomes lie in a group at one side of a homogeneous portion of the karyoplasm which is denser than the surrounding nuclear contents (figs. 3 and 4). This denser portion, at first indefinite in form (fig. 4), increases in size and develops into the first maturation spindle. As it grows the chromosomes move apart and all come to lie at its surface. At length it becomes elliptical in outline (fig. 5), and then shows delicate fibrillations extending from pole to pole. At the same time the substance of the spindle becomes less homogeneous, showing granules distributed through it, so that, except for the fibrillations, it becomes in appearance more like the rest of the karyoplasm. Meanwhile, the clear zone around the nuclear membrane disappears (figs. 2 to 5 ), and at the same time the general contents of the germinative vesicle assume more nearly the appearance of the surrounding cytoplasm; the nuclear membrane, which meanwhile has shrunk little, if any, more, is gradually dissolved (fig. 5), vanishing more quickly in some regions than in others. Its disappearance may begin in some parts very early (fig. $3 b$ ).

Stages III to V.-Development and Division of First Maturation Spindle.

Stage III (plate I, figs. 6, 7 , and 7 a).-With the complete disappearance of the membrane of the germinative resicle the spindle is left free in the midst of the cytoplasm. It is broadly elliptical (fig. 6) and shows, not only on its surface but in the interior as well, very fine fibrillations, which conform in direction to its shape. As in Stage II, 
there are granules scattered throughout its substance and the chromosomes are still distributed over its surface. Sometimes the surrounding cytoplasm shows a faint radial structure, which has the axis of the spindle at its center (fig. 7).

Stage IVa (plate 2, figs. 8, $8 a, 8 b$, and 9).-In this stage the chromosomes are drawn into the region of the equatorial plane, some lying at the surface and some nearer the axis of the spindle, where all make up a cluster having the form of an uneven disk, the so-cal'ed equatorial plate. The spindle fibers are still very delicate. Occasionally the radial structure of the surrounding cytoplasm seen in the preceding stage can still be observed (fig. 8).

Stage IVb (plates 2 and 3 , figs. I 2 to I 4 ).--The chromosomes, still near the plane of the equator of the spindle, are sometimes visibly attached to the spindle fibers, which are now much more easily seen. However, the chief characteristics of this stage are the tormation of several circumpolar bodies at each end of the spindle and the appearance of a clearer cytoplasmic region surrounding the spindle on all sides. The spindle in this stage begins to elongate and to become correspondingly narrower.

Stage V (plates 3 and 4 , figs. I 4 to $\mathrm{I}_{7}$ ).-This stage is characterized by the division and separation of the chromosomes (metaphase and anaphase of nuclear division). Fig. I 4 shows several chromosomes already divided into halves, while others are in process of separation. Figs. I 5, I6, and $\mathrm{I}$ show more advanced stages in the migration of the daughter chromosomes toward the poles of the spindle and also an increasing diminution in the number and size of the circumpolar bodies and in the extent of the clear region in the neighboring cytoplasm. The more advanced representatives of this stage (figs. I 6 and I 7 ) show thickenings of the interzonal filaments midway between their ends, and also the beginning of the constriction which cuts off the first polar cell.

Stage Vi.-Telophase of First Spindle and the First Polar Cell.

(Plate 4, Fig. I8.)

In this stage the daughter chromosomes, both in the egg and in the polar cell, have fused into compact masses, which are still joined to each other by the interzonal filaments. The middle thickenings of the filaments have united to form the "cell plate," which is continuous at its edge with the vitelline membrane where the latter has been constricted to form the neck of the polar cell. The circumpolar bodies have disappearec and the clear cytoplasmic region is very pale.

\section{Chromatin Parts of First Maturation Spindle.}

The origin of the fundaments of the chromosomes has already been described (p. 26). Although we are unable to state how these fundaments are formed from the chromatin of the germinative vesicle, the changes by which they are converted into the characteristic mature chromosomes can be traced with a fair degree of certainty. 
Fully formed chromosomes are shown in plate A, fig. $G$ (e to $j$ ) and in figs. 6 to $\mathrm{I} 4$ (plates I to 3 ). In fig. $G$ a typical chromosome is shown at $f$ in face view (i.e., looking toward the axis of the spindle along that radius of its equator which passes through the middle of the chromosome), and at $e$ in side view (i.e., looking in the direction of the tangent to the equator of the spindle which cuts the chromosome at its middle point). To the pointed ends of the chromosome are attached the spindle fibers; the side of $e$ (fig. $G$ ) which is directed to the right is that which is turned away from the axis of the spindle. The chromosome is composed of four deeply stained parts, which are more or less completely separated from one another by two deep constrictions, one longitudinal, the other, less complete, transverse. In a sense the separation is incomplete in both directions, because the four deeply stained parts are connected to one another by a less deeply stained substance, in which they are, as it were, embedded. This substance may possibly be in part nonchromatic, but probably it contains a certain amount of chromatin. This diminution in the proportion of chromatin is also evident at the pointed ends of the chromosomes, where, as already stated, the spindle fibers are attached (see $e$ and $f$ ). The chromosome illustrated by the two views $g$ and $h$ differs from that seen in $e$ and $f$ chiefly in being more elongated, the four median, deeply stained regions of $h$ being the upturned adjacent ends of the four parts resulting from the elongation of the corresponding thicker four parts shown in $f$. In both these cases the transverse division is less conspicuous than the longitudinal. In $j$ both divisions are obscured by the temporary fusion or adhesion of the four parts. The cross-division is, however, represented by a constriction. To one or other of these three conditions can be referred all the other forms of the fully developed chromosomes, the differences being due merely to various degrees of fusion or separation of the parts. All of these chromosomes ultimately lie with their long axes approximately parallel to that of the spindle.

We return now to the fundaments of the chromosomes and their development into the forms last described. It is to be noted that in the early stages (figs. 2 and 3 ) some fundaments show only a single (longitudinal) division. The transverse division, seen clearly in the left-hand chromosome of fig. $4 a$, arises a little later, as may be inferred from the condition shown in the lower right chromosome of fig. $4 a$ and in the lower (pale) chromosome of fig. 5 ; this division may perhaps arise much later. The 4-part condition appears to be a typical one. When it persists as late as the time of the formation of the spindle, the chromosome generally lies with its long axis parallel to that of the spindle (fig. 5). Were there no forms intermediate between this and the one shown in $f$ (fig. $G$ ), the four parts of the one might be referred in all cases directly to the corresponding parts of the other. But the forms $b$ and $c$ ( $d$ answering for the face view of both $b$ and $c$ ) are apparently intermedi- 
ate between $a$ and $e$, for the stages of nuclear metamorphosis illustrated in figs. $5,6,7$, and $7 a$, which exhibit these forms of chromosomes ( $b$ and c) are in other respects intermediate between the conditions shown in fig. 4 and those of figs. 8 and 9 , which present respectively the forms of chromosomes shown diagrammatically in $a$ and $f$ (plate A, fig. $G$ ).

Owing to the lack of exact synchronism in the formation of the chromosomes, it is impossible to say with certainty which of the forms $b$ and $c$ precedes the other, or even to assert that they are not independent of each other. If they do represent successive conditions of one and the same chromosome, it might be imagined that the condition $b$ had been brought about by a secondary union of the four parts of such a chromosome as is shown in $a$, followed by a bending in the equatorial region, and that the condition $c$ was afterwards reached simply by a thickening of the chromosome in the region of the bending; but, on the other hand, the reverse sequence might have occurred, and it may be urged in support of this view that $c$ and $b$ represent respectively the stages $e$ and $g$, differing from the latter chiefly in the obliteration of the cross-division, the one corresponding with the equator of the spindle. As the sequence $e \mathrm{~g}$ seems the more natural one for those two forms, so in the former the sequence $c b$ would be a natural inference. The basis for the conclusion that the forms $b$ and $c$ pass through a stage corresponding to $a$ is the apparent absence of those forms ( $b$ and $c$ ) in the earlier stages of nuclear metamorphosis and the prevalence of the $a$ condition. It must, however, be borne in mind that this does not amount to a demonstration, and that individual variations in eggs or slight differences in preservation may afford the real explanation of the conditions.

In $b$ and $c$ the transverse division of the earlier stage, $a$, has, then, either vanished by fusion, or has not yet appeared, whereas the longitudinal one is quite evicient (plate A, fig. $G, d$, and plate I, figs. 7 and $7 a$ ). At the ends of the chromosome, where the spindle fibers are attached $(d)$, the chromatin is less deeply stained, as also in $f$. The change from the condition seen in $d$ to that of $f$ is accomplished either by the reappearance of the transverse division, or, in case it had not existed in the fundament, by the first appearance of a cross-division. There is no reason, however, to suppose that the form $f$ might not in some cases arise directly from $a$, the transverse division never being obscured. As figs. 4, 5, and 6 (plate I) show, some chromosomes develop more rapidly than others.

The individual chromosomes differ somewhat in size and all seem to become a little smaller as they approach completion. They are at first distributed over the surface of the spindle only. After they have become concentrated in the region of the equatorial plane, some are still found at the surface, but others are in the interior of the spindle. Even at the beginning of metakinesis all do not lie exactly in the equatorial plane (fig. $3_{3} b$ ). For this reason in cross-sections of spindles many of the chromosomes are cut in two; polar views of the "equatorial 
plate" are therefore unsatisfactory for counting chromosomes. It is an interesting fact that in the spindles drawn in figs. Io and II (plate 2) the chromosomes lie nearer that end of the spindle which is more pointed and about which the evidences of cytoplasmic radiations are more pronounced.

The chromosomes are oriented with their long axes parallel to the long axis of the spindle. The few exceptions may in some instances be natural, but in others they certainly are due to displacement by the knife in cutting (figs. $12, \mathrm{I} 3 b, x$ and $x^{\prime}$ ).

The separation to form the daughter chromosomes always takes place at the middle of the chromosome and at right angles to its long axis (plate A, fig. $G, f$ to $l$ ). While, in general, all the daughter chromosomes migrate toward the spindle poles at the same time (fig. ${ }_{5}$ ), it sometimes happens that one or more of the chromosomes divides and the halves move apart at an early stage before their sister chromosomes show any signs of migration (two pairs in fig. 9). In the latter case the precocious daughter chromosomes show no longitudinal division, while in the former they are clearly split lengthwise (plate A, fig. $G, i, l$; plate 3 , fig. ${ }_{5}$ ). Fig. I 5 shows a spindle which is nearly parallel to the surface of the egg; in this case each daughter chromosome consists of halves, each of which is elongated and somewhat tapering, the narrower end being directed toward the pole of the spindle; the halves are parallel to each other or slightly converging toward the ends which point to the pole. In another spindle, of like age but occupying a radial position in the egg, the halves of each daughter chromosome are in contact at their polar ends, but widely separated at the equatorial end, thus together forming a distinct V. In fig. 17 the daughter chromosomes are more compact, and fewer show the longitudinal division. Some of them are much more elongated than others. The spindle in plate 3 , fig. 16 , being cut obliquely, shows the daughter chromosomes more clearly. The two limbs of each daughter chromosome are easily distinguishable, each being somewhat dumb-bell shaped. The two lie side by side, and in some cases by bending assume the form of flattened rings (fig. I6b). Later the chromosomes at each end of the spindle fuse into a compact, deeply staining, disk-shaped, or sometimes cup-like, mass (plate 4 , fig. 18 ).

In spite of the differences of opinion which have been expressed concerning the number of chromosomes, we think there can be no doubt that typically in the animals we have studied it is 20. A knowledge of the structure of the chromosomes makes it possible in many cases to be absolutely sure that this is the number. Table 2 gives the results of our observations on this subject. The accuracy of the counting depends on the stage of the spindle and the position which it occupies with respect to the plane of cutting. When the chromosomes are scattered along the spindle (figs. 6,7 , and $7 a$ ), they obscure one another least and frequently can be counted with perfect accuracy. Upon the formation of the 
"equatorial plate," however, they become crowded, and the crowding increases as division approaches. Figs. I 5 and I 6 illustrate exceptionally favorable cases, in which the number can be determined satisfactorily, at least at one end of the spindle. It rarely happens that a spindle lies wholly in one section; it is usually cut into two or three parts. This is frequently of advantage. (See figs. 7 and $7 a, 8 a$ and $8 b$, ro $a$ and $10 b$, etc.) When the axis of the spindle is parallel to the plane of cutting, the chromosomes, which are hardened by the process of preservation, are seldom cut by the knife, but are pushed to one side. Sometimes they are dragged out of place (figs. I $2, x$, г $3 b, x$ and $x^{\prime}$ ), or even completely out of the spindle into the cytoplasm (fig. 12), where they lie at the surface of the section on the side of the spindle toward which the knife moved. In the spindle shown in fig. I 2 the chromosomes (not all of which are drawn) number 20 , including the one lying to the left of the spindle. This fact, the displacement of chromosomes, doubtless accounts for some of the cases where there seem to be fewer than 20 . In the spindle shown in figs. $z_{3} a$ and $3_{3} b$, for example, where there are only 18 , displacement is clearly shown in two chromosomes ( $x$ and $x^{\prime}$ ) lying at the upper surface of the lower section (13b); and it is quite possible that others have been completely removed.

\section{AChromatin Parts of First Maturation Spindle.}

The origin of the spindle has been described under Stage II. At first broadly elliptical, it changes its form, becoming slightly sharper at the poles and, on the average, longer and narrower, especially in the later stages, as division approaches. The fibers are not limited to the surface of the spindle, nor to any part of it, but are uniformly distributed, as can be seen in cross-sections of the spindle. They do not converge as straight lines to a point, but curve inward toward the poles, without, however, meeting (figs. 8, 9, I I left end, I 2, г $3 a$, I $3 b$, г $4 a$ ). Consequently they are never parallel, and the spindle poles are more or less open. However, in two otherwise apparently normal spindles (figs. IO, I I) the fibers at one pole do meet at a point, from which there are a few radiations extending into the surrounding cytoplasm.

Besides the change in proportions, there is also, on the average, a small increase in volume. At Stages III, IVa, and IVb the average dimensions are, respectively, in micra, $18.7 \times 10.4,19.2 \times 10.8$, and $22.4 \times 9.9$. The variations in size in each stage are considerable (see table 2, p. I 4). With metakinesis the spindles elongate considerably and become narrower. Three such spindles, parallel or nearly parallel to the surface of the egg (fig. I 5), give as an average a length of 26 micra and a diameter of 8 micra; another, almost exactly radial in position, gives the corresponding measurements of $23 \times$ I I micra.

As the spindle develops, the fibers, at first in the young spindle evident only as feeble fibrillations, become more distinct. They are 
usually smooth in appearance and of uniform size from end to end (figs. $8 a, 8 b, 9,10$, I I). A little later they often exhibit minute, granular thickenings at irregular intervals along their lengths (figs. I I, I $3 a,{ }_{3} b$, I $4 a$ ). The polar ends of the fibers become thickened and more or less confluent in the later stages (IVb and V; figs. I $2, \mathrm{I} 3 a, \mathrm{I} 3 b, \mathrm{I} 4, \mathrm{I} 5$ ), frequently to such an extent that the end of the spindle looks homogeneous, and the fibers are distinguishable only as faint striations (fig. I 5). In some cases the attachment of some of the fibers to chromosomes is evident (figs. IO, I I, I $3 a, \mathrm{I}_{3} b, \mathrm{I}_{4}, \mathrm{I}_{4} a$ ). In addition to these fibers there are, however, others, very delicate ones, running from pole to pole without being attached to any chromosome (figs. I $3 a, 3_{3} b$ ). These probably constitute a part of the interzonal filaments. The latter, when the daughter chromosomes have separated, are very fine (fig. I 5). Later (figs. 16 and 17 ) they become thicker, and in the telophase (fig. I 8 ) they apparently become fused into a pale, nearly homogeneous, faintly striated bundle, lying between the two deeply stained masses resulting from the confluence of the chromosomes. The chromosomes, drawn nearly to the end of the spindle, lie in a somewhat deeply staining matrix (fig. I 7), which is perhaps derived from the spindle fibers.

At the middle of each interzonal filament is a thickening, a " $\mathrm{Zwi}_{w}$ schenkörperchen." The number of these was not determined. The thickenings, at first elongated, become more globular (fig. I 7), and at length by fusion give rise to the "cell plate" (fig. I 8), a disk-shaped mass staining moderately deeply. The further fate of the interzonal filaments and the "Zwischenkörperchen" will be discussed later (pp. 34 and 43).

\section{Centrosomes, Circumpolar Bodies, ANd Clear Region.}

Although recently the existence of centrosomes in connection with the first maturation spindle in the ovum of the mouse has been asserted, the evidence, so far as our preparations show, points clearly to the entire absence of centrosomes. Not even in the two cases illustrated in plate 2 , figs. IO, II, is there any hint of a centrosome at the ends where the fibers converge to a point, although there are clearly a few fiber-like radiations in the surrounding cytoplasm. If there were any centrosomes present, one would expect them to stain as sharply as those in the surrounding follicle cells during division. In the eggs from which figs. Io and i i were drawn there are no polar radiations except those figured and mentioned above, nor have any other instances been observed in which there were polar radiations as marked as these. Occasionally a few fibers may be observed outside the limits of the spindle (figs. 9, I1, I2, I $3 b$ ) and extending from the poles obliquely toward the plane of the equator.

The two conditions mentioned as characteristic of Stage IVb are the circumpolar bodies and the clear region around the whole spindle. The two arise at about the same time and likewise disappear together; they both reach their greatest prominence at the stage when the chromoscmes divide-at metakinesis. 
The circumpolar bodies have been so named because they are grouped around the poles of the spindle (figs. I3, I4). Their origin is not known beyond the fact that they come into existence gradually at the spindle poles. They are variously shaped (figs. I $3 a, 13 b, 14,14 a$, I5), no one form having predominance over others. Some have irregular forms or are roughly spherical, others are pear-shaped, still others disk-like. In ordinary plasma stains they are very inconspicuous, apparently being composed of a homogeneous substance somewhat denser than the surrounding cytoplasm. In phosphotungstic-acid hæmatoxylin, on the contrary, they become deep blue, like the chromosomes, from which they are distinguishable only by their forms. They apparently have no connection with the spindle fibers (figs. I $3 a$, I $3 b$, I $4 a$ ), and after the chronosomes have reached the ends of the spindle they fade away (plate 3, fig. I6) and disappear altogether (plate 4, fig. I8).

The clear region around the spindle is often visible in sections as a faint, broad zone before the circumpolar bodies appear (figs. I I and I 2), and it often persists for a short time after they have vanished (figs. I6 and 18 ). When most conspicuous it is comparatively narrow. It appears more homogeneous than the surrounding cytoplasm by reason of its being less granular; but at no time is it quite free from granules.

\section{POSITION AND ORIENTATION OF FIRST MatuRation SPINDle.}

The depth at which the spindles lie is variable. Whether the fully formed spindle remains at first in the position which was occupied by the germinative vesicle when its membrane vanished is undecided. At all events, before the time when the chromosomes divide, the spindles may be found at different depths. When the polar cell is about to be cut off the spindle comes to lie near the surface of the egg, assumably in the region of the animal pole. The axis of the spindle may be parallel, oblique, or perpendicular to a tangent to the surface of the egg at the point nearest the spindle. These positions are not characteristic of particular stages, but may be found at any epoch in the maturation. The perpendicular position is least often met with, the oblique at various angles, and the parallel positions are the most frequent. It seems quite possible that the spindle maintains its original orientation when it approaches the surface to divide. At least, it is certainly true that the perpendicular position is not requisite for the formation of the polar cell (see p. 34), for of ten spindles in the stages shown in figs. I5, I6, and I 7 , only one was perpendicular, the others being either parallel or somewhat oblique. The perpendicular one was in a stage corresponding to that illustrated by fig. I 5. In nearly all examples of the stage shown in fig. I 8 the bundle of interzonal filaments is oblique to the radius of the egg, though sometimes it varies only a little from that position. In other cases it is very much bent, apparently as a result of a more rapid ingrowth of the cell wall on one side during abstriction of the polar cell. 


\section{Abstriction of First Polar Cell.}

The process of abstriction begins as soon as the daughter chromosomes have come close to the poles of the spindle and the "Zwischenkörperchen" have attained the condition shown in fig. I 7. While the spindle may sometimes be perpendicular to the surface of the egg, as already stated, one pole lying in an elevation or protrusion, the condi-

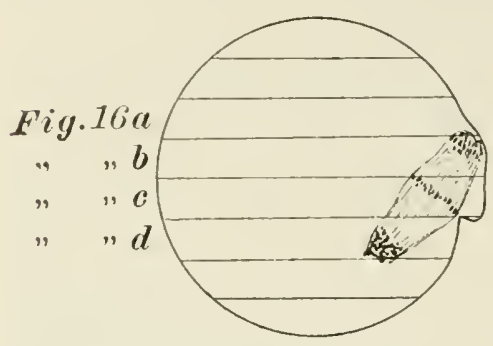

Fig. $H$.

(Compare figs. I 6 a to I $6 d$, plate 3.$)$ tions indicate that, in most cases at least, the spindle is either parallel or oblique to the surface (figs. I 5, I6, I 7). The pole nearer the surface does not at first lie in the middle of the protrusion, but at one edge of it (fig. 17). The constricting process begins on the side nearest the "Zwischenkörperchen," where in the surface of the egg a deep, sharp groove brings the vitelline membrane into contact with the "Zwischenkörperchen" of the side of the spindle nearest the surface. The same condition exists also in fig. $\mathrm{x} 6$, in which the plane of sectioning is very oblique to the axis of the spindle, as may be seen by comparison with fig. $H$, which is a diagrammatic reconstruction of an imaginary section of the egg in a plane perpendicular to that of the actual sections, but parallel to the axis of the spindle. (Compare plate 3, figs. I6a to $16 d$.)

No other stage between this and that shown in fig. I 8 having been found, the further steps in the process can only be inferred. However, it is highly probable that the contact between the vitelline membrane and the "Zwischenkörperchen," shown in fig. I 7 , advances until it has quite encircled the spindle. The result is that the entire periphery of a disk-like body formed by the fusion of the "Zwischenkörperchen" is finally in contact with the vitelline membrane (fig. I8), and the original protrusion, now become more voluminous and containing the superficial group of chromosomes, is thus separated from the egg. The interzonal filaments, brought into a more nearly radial position during the constriction, form the bulk of the neck of the polar cell. A little later the constriction is completed by the ingrowth of the cell membranes of both egg and polar cell in such a way as to cut off the interzonal filaments and leave the "Zwischenkörperchen" on the outside of the cell membranes of both polar cell and egg. Thus is formed the first polar cell and the oöcyte of the second order. 


\section{B. OÖCYTE II.}

\section{General Description of Stages.}

The chief criterion according to which an egg may be judged to be an oöcyte of the first order or of the second order is the character of the chromatin contents. As the sequel will show, this is the only reliable standard. It will naturally occur to the reader that the oöcyte of the second order must be accompanied by the first polar cell, and that this fact would be a satisfactory criterion. But the following facts complicate the situation: first, some fertilized eggs exhibit two polar cells, some but a single one; secondly, there is dispute as to whether this single polar cell is homologous with the first or second one of eggs having two. In the description of the following stages it will be assumed that the egg naturally has two polar cells, and the question as to how many polar cells are actually formed will be treated of in a later chapter.

\section{Stage Vil.-Formation of Second Maturation Spindle.}

(Plate 4, Fig. I9.)

It is fair to infer from the comparatively long duration of the preceding Stage (VI) that the disk-shaped mass of chromatin which results from the more or less complete fusion of the chromosomes left in the egg after the formation of the first polar cell probably remains for some time without perceptible change of morphological conditions, and that the persisting half of the interzonal filaments likewise undergoes little change during this period. With the close of this period of apparent inactivity Stage VII begins. It embraces only the metamorphosis of the chromatin mass and what are probably the achromatic remnants of the first spindle into the fully formed second maturation spindle. This process, unlike the one involved in the completion of the first spindle, is so rapid that it can not be subdivided into stages and traced step by step.

Stage ViII.- "Equatorial Plate" of Second Maturation Spindle. (Plates 4, 5, Figs. 20 TO 27.)

As this stage is unique, in that it depends on the occurrence of semination for its normal termination, it may have a greater length than any other part of the whole maturation process, and is therefore the one most easily obtained. If semination is early, the spindle divides without undergoing any previous alterations; on the other hand, if the access of spermatozoa be hindered, the spindle, though remaining comparatively inactive, undergoes certain changes as a result.

When newly formed, the second maturation spindle (plates 4 and 5, figs. 22 to 24 ) is very similar to the first spindle immediately before its metakinesis, differing from it only in being a little smaller, in the structure of its chromosomes, and in their more exact arrangement in the plane of the equator. If semination is prevented, the resulting prolonged quiescence of the spindle is characterized by a diminution in 
the number of the circumpolar bodies, and often by their complete disappearance, and by the disappearance of the clear region previously described as surrounding the first spindle.

Stage IX.-Division of Second Maturation Spindle.

(Plate 5, Figs. 28 to 30.)

The separation of the daughter chromosomes takes place, as a rule, only after a spermatozoön has touched or penetrated the egg. However, in the case of one animal - a mouse which had not been inseminated-one of the eggs contained the divided chromosomes arranged in two parallel daughter plates, which were still near the equator of the spindle; another egg from the same mouse presented a stage still further advanced (plate 5 , fig. 28), the two groups of daughter chromosomes in this case having migrated nearer to the poles of the spindle.

Stage X.-Telophase of Second Spindle and Second Polar Cell.

(Plate 5, Fig. 30.)

The beginning of the abstriction of the second polar cell resembles that of the first. This stage, indeed, agrees so closely with the corresponding stage in the formation of the first polar cell (Stage VI, p. 27), from which it seems to differ only in the presence in the oöcyte of the head of a spermatozoön, that it need not be described here. It may be said that, of 30 eggs in this stage, only I failed to show the head of a spermatozoön.

\section{Chromatin PaRts of Second Maturation SPINDLE.}

The chromosomes of the second maturation spindle arise directly from the chromatin mass which remains in the egg after the abstriction of the first polar cell, i.e., without an intervening vesicular stage of the nucleus. This mass breaks up into fragments, but whether or not each of these fragments is the equivalent of a chromosome, either single or multiple, it is difficult to determine. Whatever their mode of origin, the fragments are fairly (or even very) irregular in form, incompletely separated from one another, and of uncertain number (plate 4 , fig. Ig). Some of them bear a slight resemblance to the daughter chromosomes of the previous dirision which had nearly reached the poles of the first spindle (fig. 16 ). Sometimes (fig. $19 b$ ) they are embedded in a matrix of homogeneous substance denser than the surrounding cytoplasm. They are never scattered, and soon become arranged in the plane of the equator of the future spindle, where they may constitute a group having the form of an imperfect ring. No stages between this and that of the completely formed chromosomes have been observed.

The chromosomes of the completed second spindle (figs. 23 and 24) often closely resemble the daughter chromosomes of the first spindle as they appear when they have nearly finished their poleward migration (fig. I6), for each mother chromosome of the second spindle is composed of a pair of elements, and these elements vary in form, independ- 
ence, and relative position (figs. 23 to 27 , plates 4,5 ; fig. $I$ ). Fig. $I$ ( $m$ to $r$ ) illustrates several of these variations. In the simplest form of chromosomes, shown at $m$, each element is a straight rod, either of uniform size (see also fig. 25), or slightly constricted in the middle. The constriction is likewise evident in chromosomes seen when looking nearly in the direction of the axis of the spindle (figs. 20, 2I). Viewed under these conditions usually one element of the pair is partially covered by the other. Even after the separation of the daughter chromosomes from each other, this constriction or dumb-bell condition of the daughter chromosome is evident, whether seen endwise (fig. 28) or in side view. In $p$ (fig. $I$ ) the constriction is carried still further, sometimes to such an extent that the mother chromosome appears to be composed of four nearly independent parts ( $x$, fig. 24a). Sometimes the daughter chromosomes are curved rods (fig. $I, r$; plate 5 , figs. 24b, 26), or are of an irregular crescent shape (o). Fusion or adhesion of the two elements at one or more points gives rise to figures like $n$ (see also figs. $20,23 a, x)$. When the elements are more elongated and curved, rings ( $q$, also figs. $24 a, 25,26$ ) are formed by the fusion of the corresponding ends of the two daughter chromosomes. Occasionally, when the fusion of the ends (as in $n$ ) is well advanced and the constriction in the middle of each is complete, the original separation between the two elements is obscured and the mother chromosome then appears to be composed of two parts, the long axes of which are perpendicular to

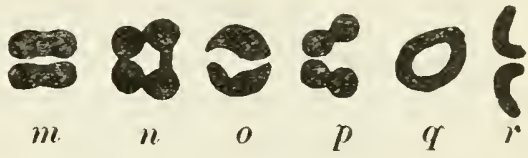

FIG. I. the plane of the equator. Forms like those shown in figs. 25 and 27 , which occur in eggs that have remained long in the oviduct, are explained by the fact that with age the elements tend to elongate. In any of these forms of chromosome the parts may be parallel to each other, or, according to the point at which the spindle fibers are attached, separated at one end $(n, p, r)$ or at the middle $(o, q)$.

The chromosomes are never arranged at the surface of the spindle, but from the beginning are uniformly distributed in the plane of its equator (figs. 20 to 24 ), and are so oriented that that plane passes between the two elements of each mother chromosome. This arrangement of the daughter chromosomes in one plane is preserved even after metakinesis (figs. $28 a$ and $28 b$ ).

The number of chromosomes is 20 ; but the proportion of cases in which the number can be determined with accuracy is smaller than in the case of the first spindle, because in the second spindle the chromosomes are more crowded and their forms are less regular than in the first spindle. When, in cutting, the chromosomes fall in two sections the difficulty of counting is usually increased. However, knowing the structure of the chromosomes, it has been possible in many cases to be 
quite certain that the number is 20 (see table 2, p. 14). In figs. $23 a$ and $23 b$ there are only i 9 chromosomes, one probably having been lost in cutting. Figs. $24 a$ and $24 b$ exhibit together 20 , one having been so cut that a half of it lies in each section. The two sections (24a and $24 b)$ contain, respectively, 8.5 and II.5 chromosomes. Polar views of the "equatorial plate" are usually the most satisfactory ones for counting. In fig. 20 , a polar view, there are clearly 20 chromosomes; one of these $(x)$, seen in face view, corresponds to fig. $I, n$. In figs. $28 a$ and $28 b$ (an anaphase) the number can not be determined with perfect accuracy, because the long axes of the daughter chromosomes are perpendicular to the plane of the section. Two of the larger chromosomes ( $x$ and $x^{\prime}$ ) may well be double; if so, the number in this case also is 20 .

In the division of the chromosomes, the two elements of each mother chromosome separate and then migrate to the opposite poles of the spindle. Figs. $28 a$ and $28 b$ (plate 5) are polar views of the two daughter plates at a stage of migration corresponding to that of fig. I6, and are drawn from a non-seminated egg. In fig. 29, which represents a slightly later stage than fig. 28 , the individual chromosomes are no longer distinguishable. They seem quickly to lose their identity and merge into a single disk-shaped mass (fig. 30 ), as in the case of the first spindle.

\section{Achromatin Parts of Second Maturation Spindle.}

The interzonal filaments left in the egg after the first polar cell is cut off persist for a while along with the chromatin mass. About the time when the chromatin breaks up into fragments, they lose their connection with the cell plate (plate 4 , fig. $19 b$ ). It is probable, but not certain, that they contribute to the formation of the matrix in which the chromatin fragments are embedded, and also to the formation of the fibers of the completed second maturation spindle.

The second spindle begins as a somewhat pear-shaped, apparentiy homogeneous body at the time when the chromatin mass divides into fragments. When completed it is more or less elliptical (fig. 22), like the first spindle, but it varies more in form than does the first spindle, being occasionally more slender and having more sharply pointed ends. However, as observed from the surface of the egg, it often appears very broad (figs. 23, 24), owing to its being flattened in the direction of the radius of the egg (fig. 20). Such spindles when seen edgewise appear very narrow (fig. 22); they always lie nearer the surface of the egg than those which are circular in cross-section.

The fibers of recently formed spindles resemble quite closely those of the later stages of the first spindle in being smooth, of uniform diameter-except at their polar ends, where they are thickened-and curved inward toward the poles (figs. 22 and 24 ). The thickenings at the polar ends are not to be seen in fig. 23 , because the spindle was stained in Böhmer's hæmatoxylin and Congo red, which are not favorable for 
demonstrating the fibers and circumpolar bodies clearly. As a rule, the individual fibers and their attachment to the chromosomes are not easily distinguishable. Although one can not be absolutely certain that there are fibers which are continuous from pole to pole without being connected to any of the chromosomes, it is perhaps reasonable to assume that such is the case, because of the general similarity of the second spindle to the first one, where such a condition is fairly evident. The daughter chromosomes, after their migration toward the poles of the spindle, are connected by interzonal filaments (figs. 29, 30). "Zwischenkörperchen" form midway between the ends of the filaments, as described for the first spindle (p. 32), and later fuse into a cell plate.

The second spindles do not differ from one another much in size, nor do their dimensions, on the average. change appreciably with prolonged existence due to the absence of semination. This constancy in size is shown by a comparison of spindles from two groups of eggs: one group composed of eggs which have been but a short time in the oviduct (taken not later than $\mathrm{I} 6 \frac{1}{2}$ hours after parturition), the other of eggs taken from the oviduct 29 or more hours after parturition. Because of the unfavorable position of many spindles, measurements of only 30 young and 26 old ones could be used. The average dimensions for the young spindles are: length 17.9 micra, diameter 7.2 micra; for the old spindles: length I 7.5, diameter 7.3 micra. A comparison of these averages with those of the mature, or nearly mature, first spindles in Stages IV $a$ and IVb (viz., I $9.2 \times 10.8$ micra, and $22.4 \times 9.9$ micra, respectively) proves that the second maturation spindle is somewhat smaller than the first.

\section{Centrosomes, Circumpolar Bodies, and Clear Region.}

For the second spindle, as for the first, the existence of typical centrosomes is highly improbable. However, there are at certain times structures which to some extent resemble centrosomes.

The circumpolar bodies (figs. 22, 24) correspond exactly in position, abundance, and general appearance to those of the first spindle. When the spindle is first fully formed they are already present, and persist for some time. But with spindles which, in the absence of semination, persist for a long time they have a tendency to dwindle away, sometimes, however, leaving a few granules at the poles where centrosumes might be expected (figs. 25, 26, 27). These statements are based upon a comparison of the eggs used in calculating the size of the spindle. The eggs in the oviduct (and a few in the periovarial space and in the ovary) taken from mice killed $16 \frac{1}{2}$ hours or less p.p. show in most instances well-developed circumpolar bodies, whereas most of the eggs from animals killed 29 or more hours p.p. show very few or none of them. These bodies also disappear following normal metakinesis induced by semination after the chromosomes have migrated and become confluent (figs. 29a, 30), as in the case of the first spindle. 
In some of the eggs from a mouse killed about 33 hours p.p. and not inseminated, there appear a few cytoplasmic radiations at the spindle poles, from which the circumpolar bodies have vanished. Also in the egg illustrated in fig. $29 a$, the cytoplasmic granules around the inner end of the spindle are oriented with their long axes in a radial direction; but otherwise the evidence of cytoplasmic radiations about the poles of the second maturation spindle has been lacking.

As already stated regarding the first spindle, the clear region around the spindle exists at the same time with the circumpolar bodies, except that it may appear a little before them (fig. I9), and sometimes persists longer (fig. 30). It can usually be found surrounding the spindles of eggs which have been only a short time in the oviduct (figs. 20, 2 I, 22 , $23,24)$, but in most eggs in which the circumpolar bodies have vanished, it has likewise disappeared (figs. 25, 26, 27). It bccomes quite faint (figs. 29, 30), or is altogether gone, after the chromosomes have divided.

\section{Position and ORIENTATION OF SECONd Maturation SPINDLE.}

The second maturation spindle always lies near the surface of the egg-in fact, sometimes so near that its flatness (fig. 20) is apparently due to pressure. There is no satisfactory evidence that it moves through the cytoplasm, although it is found at different distances from the first polar cell when that is present. This topic will be taken up later (pp. 44 and 63 ).

There is less variation in the orientation of the second spindle than in that of the first. Very rarely, indeed, can it be found perpendicular to the surface; occasionally it is oblique, but in the majority of cases it is parallel to the surface. It is parallel in all instances in which the daughter chromosomes have separated and have reached, or nearly reached, the poles before the abstriction of the second polar cell begins; but in those in which the abstriction has begun (figs. $29 a, 29 b$ ) it is

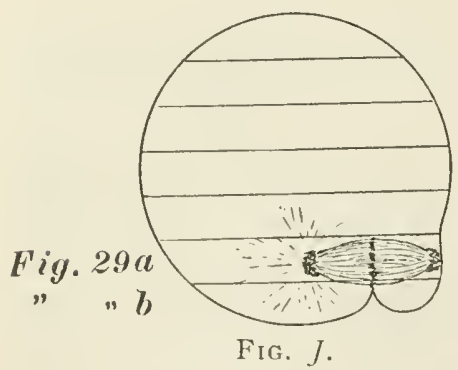
oblique; and in the stage of the telophase of the formation of the second polar cell (fig. 3o) the interzonal filaments are usually almost, if not quite, perpendicular.

\section{ABstriction of SeCOND POlar Cell.}

The process resulting in the formation of the second polar cell is precisely like that by which the first polar cell is produced. The beginning of the process is illustrated by an egg shown in part

in figs. $29 a$ and $29 b$ and in fig. $J$. The last is a diagrammatic, imaginary section of the egg, in a plane parallel with the axis of the spindle, but perpendicular to the actual sections shown in figs. $29 a$ and $29 b$. The daughter chromosomes have virtually reached the poles of the spindle and have lost their identity by being merged together; the " Zwischenkör- 
perchen " now occupy the midd'e of the interzonal filaments. The spindle is oblique to the surface of the egg, and one pole is so near the surface (fig. 29a) that the peripheral mass of chromatin lies close to the edge of the protrusion which is destined to be cut off to form the polar cell. The constriction has begun on the side nearest the "Zwischenkörperchen," the vitelline membrane being already in contact with the "Zwischenkörperchen" nearest the surface of the egg (fig. 29b). The rest of the process, involving the final separation of the polar cell, is as described on page 34 for the first polar cell.

\section{RIPE EGG.}

Stage Xi.-The Pronuclei.

A discussion of the further development of the ripe egg does not lie within the scope of the present work. It suffices to say that the chromatin mass resulting from the union of the chromosomes remaining after the formation of the second polar cell is quickly transformed into the egg nucleus. This usually occurs simultaneously with the development of the sperm nucleus. But in two cases the egg nucleus had reached a diameter of 6 micra, while the head of the spermatozoön had not been appreciably changed in form or size. In no case has the sperm nucleus been observed before the chromatin mass has begun to be transformed into the egg nucleus.

The observations on the polar cells here recorded do not extend to the cleavage stages of the egg. Therefore, no statement can be made concerning the further fate of the polar cells, or concerning the changes which take place in the second polar cell.

\section{FIRST POLAR CELL.}

The first polar cell, originating as described on page 34 , is usually an ellipsoidal or a flattened spheroidal body, the three diameters of which are nearly always unequal. The average dimensions of 28 polar cellseach of which had been recently formed (Stage VI), the first spindle being still in the telophase (plate 4 , fig. I 8 )-were $22.7 \times$ I9.2 $\times$ I3.5 micra. These figures indicate the average size at its largest stage. With age some polar cells diminish very rapidly in size (figs. I 8, 32-37, plate 6); others retain nearly their original dimensions. Disregarding for the present the very small forms (figs. $35^{-37}$ ), it is found that the first 50 polar cells (which could be measured most accurately) from roo of the youngest eggs which have the complete second spindle give as an average the following dimensions in micra: $20 \times 15.6 \times 1 \mathrm{I} .8$; and 22 polar cells (all that could be measured) from Ioo of the oldest eggs of the same stage give the following average dimensions: I $6 \times$ I $3 \times$ I0.5 micra. These averages show a considerable decrease in size; and, as a series of gradually diminishing sizes can be found down to that shown in fig. 37 , and as the smaller sizes are too numerous ( 55 out of 507 eggs) to be mere 
chance occurrences, it must necessarily follow that the first polar cell may, in many cases does, dwindle to almost nothing. Indeed, it may even disappear completely; for out of the 507 eggs with complete second spindle, I 89 have no polar cell. This is made clearer still when the 200 eggs, mentioned above, are examined further. The results are most conveniently presented in tabular form (table 5 ). This shows that of the older eggs, as compared with the younger ones, fewer have the large polar cells and more have no polar cell. The fewer cases with small polar cell among the older eggs show that most of the polar cells which degenerate do so early, being completely wanting in the later epochs. The same conclusions are borne out by the ${ }^{6} 6_{2}$ eggs of Stages IX to XI (table 2, p. I 4), which, as a whole, cover a longer period. Of these I 62 eggs, 77 have no polar cell, 22 have a small polar cell, and 63 the larger sizes of polar cell.

TABLE 5 .

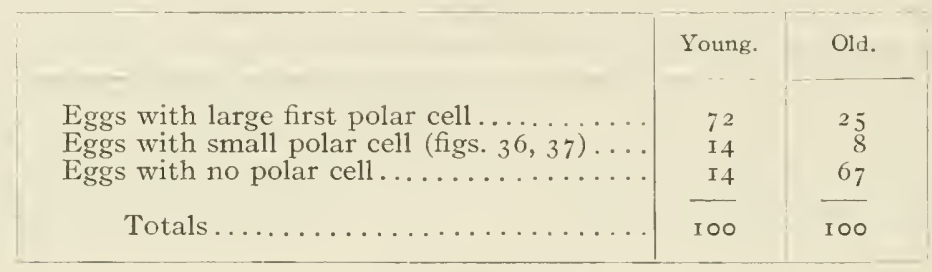

The first polar cell contains the peripheral group of chromosomes, which have become compacted into a single, usually flattened mass (plate 4, fig. I8). During the formation of the second spindle this mass divides into irregular parts (fig. I 9 ), which remain more or less in continuity with one another. It is only rarely that these parts separate from one another completely and assume the aspect of dumb-bell shaped bodies. Their number, however, has no significance, owing to their imperfect form and individuality. The chromatin may remain for a considerable period in one, or more than one, loosely formed mass. If it is more finely divided, the fragments may be distributed with tolerable uniformity throughout the cytoplasm (plate 5, figs. 30, 3 I a), or roughly aggregated into two groups, one at each end of the cell. Not infrequently the chromatin bodies exhibit thread-like forms, especially in connection with what appears otherwise to be a non-mitotic division of the polar cell (figs.32,33). In no case, however, has it been observed that the chromatin is drawn to the equator of a well-formed spindle and divided. Often the chromatin fragments, especially the enlarged ends of the thread-like forms, show vacuolation (figs. $30,32,33$ ). Besides the deeply staining chromosomal bodies, there are other less deeply staining bodies (figs. 29b, 32, 33, 34, 35), which apparently are modified chromatin; these occur either aloneespecially is this the case in small polar cells (figs. 34, 35)-or associated with vacuolating parts (figs. 32,33 ). These conditions all seem to point to a degeneration of the chromatin. A nucleus is never formed, unless 
perhaps it arises in divided first polar cells during the cleavage stages of the egg.

Although the cytoplasm of the polar cell has not been studied carefully by us, its general features are as follows. In the newly formed polar cell the more distal part of the cytoplasm appears very clear (figs. I 8, I9). Later, it is of uniform appearance throughout the cell, and in some cases is apparently like that of the egg; but more often it is either more granular or more homogeneous and clear than the egg cytoplasm. In the smaller polar cells it has the latter structure and it sometimes shows what appear to be ill-defined vacuoles (fig. 36). The interzonal filaments within the polar cell are, at first, very evident (figs. I 8, I 9). In time they lose their connection with the cell plate (figs. I 9 and 3 I $a$ ), which then quickly disappears. Occasionally there can be observed in the polar cell fibers which are parallel with one another; but it is uncertain whether they are the remains of interzonal filaments or fibers of an abortive spindle.

It may be inferred from the amitotic (or imperfect mitotic) division of the chromatin that the whole polar cell is capable of division. Such, indeed, is the case, for, previous to the formation of the second polar cell, the first polar cell may be observed in many instances to be dividing into two or more parts, as shown in figs. 32 and 33 , or to be simply constricted (fig. 3Ia). Less frequently the small polar cell is seen to be already divided into two parts. This dividing of the polar cell doubtless aids in its rapid degeneration by increasing the external surface exposed to the action of absorption.

The polar cell quickly loses its connection with the egg, because the interzonal filaments become severed from the cell plate. This separation is evident as early as the time of ovulation and may be aided by that process, as described on page 22 and shown in figs. $3 \mathrm{I} a$ and $3 \mathrm{I} b, 38$, 39 , and 40 (figs. $3 \mathrm{I} a$ and $3 \mathrm{I} b$ being enlarged views of sections of the egg and polar cell of which fig. 40 shows another section). In the egg illustrated in figs. $3 \mathrm{r} a$ and $3 \mathrm{r} b$ the polar cell is separated from the egg and probably from the cell plate, which is seen in fig. $3 \mathrm{I} b$. (In this case, however, the existence of the cell plate is a little doubtful.) The evidence leads to the belief that the first polar cell need not remain at the place where it was formed, but may, according to circumstances, change its position under the zona, even to such an extent as to come to lie diametrically opposite the point of its origin. The bearing of these observations on the question of the relative positions of the first polar cell and the second spindle will be considered later (p. 63). The first polar cell usually lies in a depression in the surface of the egg. 


\section{SECOND POLAR CELl.}

The shape of the second polar cell is similar to that of the first, though it is perhaps more often uniformly regular in shape. In order to compare the size of the second polar cell with that of the first, measurements were made of as many newly formed polar cells as possible (Stage X, fig. 30). Since the condition of the polar cells during cleavage stages of the egg has not been studied, changes in size are not here considered. For convenience the sizes of the first polar cells (exclusive of the small degenerate forms) are repeated in this connection (table 6).

TABLE 6.-Size of poiar cells.

Average dimensions of first polar cell.

Micra.

Newly formed polar cell (first spindle in telophase) ................... $22.7 \times 19.2 \times 13.5$

From eggs but a short time in the oviduct

(complete second spindle) ............20 $\times$ I5.6 III. 8

From eggs after 29 hours in the oviduct... r6 $\times$ r $3 \times 10.5$

Average dimensions of second polar cell.

Newly formed ................ $19.3 \times 16.7 \times 9.6$

When first produced the second polar cell, then, is smaller than the first polar cell of corresponding age, but is larger than the first polar cell which has been in existence for 29 hours or more.

At the beginning, the chromatin of the second polar cell is in a single mass, as in the case of the first polar cell, but it does not long remain so, for it is quickly transformed into a nucleus.

The cytoplasm in the recently cut off cell (fig. 30) has the clear appearance noted in the case of the first polar cell, but later it generally has the aspect of the protoplasm of the egg. The interzonal filaments persist for a time and can be observed joining the nucleus of the polar cell with that of the egg, the cell plate remaining as a conspicuous, deeply stained body outside both egg and polar cell.

The position of the second polar cell with regard to the first (when the latter is present) is variable, for the two polar cells may lie side by side or be far apart. The reason is probably to be found in the migration of the first polar cell, as discussed on page 63 . The second polar cell, like the first, occupies a slight depression in the surface of the egg. 


\section{CRITICISMS AND CONCLUSIONS.}

\section{A. MATERIAL.}

This work differs from that of previous investigators in that it has been done on mice of very mixed ancestry. It is therefore open to the possible criticism that the material is unlike that on which other papers have been based. It may be maintained, however, that there is no essential difference in material for the following reasons: first, the fact that the white mice of our stock, whether of colored ancestry or not, breed true, leads one to believe that, in the light of recent work on heredity of coat color, they are as pure as other white mice; secondly, there is no dissimilarity in the maturation processes of eggs from mice of different coat character; thirdly, there is no real difference in important points between Mr. Kirkham's preparations and our own.

Sobotta suggests in his paper published in 1907 that some of the differences between his results and those of Gerlach (I906) may be due, in part at least, to the fact that he used eggs set free at an ovulation 3 weeks after parturition, whereas Gerlach employed ova obtained during the first 3 days after parturition. Since Sobotta is the only one who has made use of eggs derived from an ovulation later than the first one after the birth of young, his explanation must apply to all other investigations, including the present one. There seems, however, to be no a priori reason for supposing a difference between the maturation processes of eggs maturing and ready for fertilization at different periods after parturition; moreover, the dissimilarities in the results of the several investigators can be accounted for to a large extent on other grounds, as will appear in the course of the remaining pages.

Considerable significance attaches to the amount of material studied by other investigators. Tafani, Gerlach, and Kirkham do not state the number of eggs which they observed, but the number was probably small. Lams et Doorme based their paper on only 90 ova. Sobotta in his large work (I895) used 1402 sound eggs; but of this number only 298 (compared with our 877 , table 2, Stages I-X), at the most, were of such age as to show stages in the formation or division of spindles, or the number of chromosomes, or the abstriction of polar cells. All the rest ( $\mathrm{IIO4}_{\text {) }}$ were either in stages showing the pronuclei or still older.

\section{B. METHODS.}

It is probable that the value of our results would have been enhanced had another set of eggs preserved by other methods been compared at each step with those which have served as the basis for the present paper. These have all been carefully studied and in part are described and figured here. However, it should be said that other fixing fluids were tried, and that, in cases where the preservation was good enough to give reliable pictures, the eggs showed conditions similar to those obtained with the special preserving fluid described at page 12. 
This modification of Zenker's fluid, however, is the only one tried which shows the finer structure of the chromosomes and does not shrink the nuclei. Most of the figures by other investigators of the mouse egg show imperfect preservation, and this has been, in our opinion, a potent factor in causing the differences in their results.

\section{TIME RELATIONS.}

The possibility of obtaining a complete series of stages of the processes of maturation depends on accuracy in determining the epochs of parturition and insemination. As we have seen (p. 22), there is probably some individual variation in the length of the periods between successive ovulations. If eggs from ovulations other than the one which immediately follows parturition had been used by us, it would have been extremely difficult, if not impossible, to secure a complete series, both because of this variability in ovulation, and also because (see p. I7) the stage of the second spindle may last for many more hours than the stages which reach from the transformation of the germinative vesicle to the formation of the first polar cell. It is probably a lack of precision in this matter which accounts for the failure of others to get those stages which pass quickly, such, for example, as the origin and metaphase of the first spindle.

$\Lambda$ s we have seen (pp. 16 and 19 ), the first maturation after parturition may occur during a period extending from about $\mathrm{I} 3$ hours to 29 hours p.p. Tafani (I 889, p. 20) makes the period extend from 24 hours to 48 hours, or even (I $889 b$, p. I I3) 2 or 3 days p.p., a time somewhat later than that indicated by our observations.

Sobotta (1907, p. 504) says that the prophases of the first spindle begin at least 24 hours before ovulation; but as he does not say when ovulation occurs with respect to parturition (which is the only event that can be determined directly), it is impossible to perceive how he arrives at this particular number of hours as the minimum time. Apparently Sobotta (p. 507) bases this conclusion on the parallelism which, he maintains, exists between the histological changes in the wall of the follicle (its ripening) and the ripening of the egg ; but admitting the parallelism, and granting that the prophase begins when the follicle is far from ripe, we are unable to see any very precise ground for the estimated time required for the ripening of the follicle.

Kirkham (I goza, p. 259) states that he killed mice at various times during pregnancy and at intervals from a few minutes after parturition up to 30 hours after that event. In his later paper (I907b, pp. 70, 7I) he adds:

The ovaries of every mouse examined during the height of the breeding season contained some eggs in which the first polar body had been already extruded and in which the spindle for the second polar mitosis was fully formed. A majority of the same ovaries revealed ovarian eggs at the end of the spireme or with the first polar spindle. 
Also (p. 75):

A large number of eggs in different ovaries have been examined, and in every instance where the size of the egg, its slightly denser protoplasm, and the large follicle gave evidence of ripeness, the egg was found to be accompanied by the first polar body. This agrees with the observations of Bellonci (1885), and with Sobotta's idea regarding ro per cent of the eggs, which he believed formed two polar bodies.

These two statements appear at first sight either to relate to different stages of maturation or else to be difficult to reconcile with cach other; but further consideration leads us to think that the same conditions are intended in both. According to the first quotation, a part of the more advanced eggs are only just beginning maturation (spireme or first spindle), while others are further along, showing the first polar cell and second spindle. In the second quotation only the older eggs, those with the first polar body, are mentioned; but it is perhaps fair to infer that here, too (as announced in the first statement quoted), others were just beginning the process of maturation, though it is explicitly stated that "in every instance" the first polar body was present. However that may be, it is clearly stated that in every mouse examined during the height of the breeding season the ovary contained some eggs which showed the first polar cell and the second spindle. Since the author certainly studied and figured (his figs. I2-I 7) eggs from the Fallopian tube, it is impossible to avoid the inference that in all females, even in those in which one set of eggs is in the oviduct, the ovaries contain eggs with the first polar cell and the second spindle already formed; that is to say, maturation may begin several weeks before parturition or ovulation. But such a state of affairs is incomprehensible to us, because, according to our studies, mice killed during pregnancy and at intervals of 7 and I 4 days after parturition furnished ovarian eggs (these have not been included in the 1,000 eggs recorded in table 2) some of which were in fairly large follicles. Those in the largest follicles (eggs which presumably were destined to leave the ovary at the next ovulation) possessed in all cases the germinative vesicle. Such was also the case in mice killed during a period extending from I to I 3 hours after parturition. Eggs with the germinative vesicle, which, as has already been explained (p. I6), do not acquire the first spindle before about i 3 hours post partum, manifestly could not originate by the transformation of eggs already possessing a polar cell and second spindle. Moreover, mice which showed a group of eggs in each oriduct never exhibited any of the large follicles in the ovary. Lastly, as has already been demonstrated (p. I 5), only two mice furnished eggs in stages as widely separated as those of the germinative vesicle and of the first polar cell and second spindle; and in these two cases the eggs exhibiting the early stage were in one ovary, while the eggs showing the later stage were in the oriduct of the other side of the body. At first the only explanation of the differences between Dr. Kirkham's results and our own which seemed to us possible was that his mice were of a different breed from ours. 
Through the kindness of Professor Coe, of Yale University (Dr. Kirkham being abroad), we had the privilege of examining a portion of Dr. Kirkham's preparations, some 25 slides, on which the position of eggs with first polar cell and second spindle and that of eggs with a single spindle had been marked by the author. An examination of these preparations revealed the fact that nearly all of the ovarian eggs so marked were in process of degeneration. They were of about normal size, but occurred in rather small follicles, approximately like the one shown in Kirkham's $(19 \circ 7 b)$ plate V, fig. II. The zona pellucida was gone, and the granulosa cells were only rarely in contact with the eggsure signs, in our opinion, of degeneration. Such eggs can be found in nearly all ovaries; but we have always rigidly excluded them, because they are so obviously different from the normal eggs contained in the large follicles. Sometimes in these small follicles there can be found clusters of cells resulting apparently from the abnormal cleavage of degenerating egg cells. These facts explain, we think, fig. 7 of Kirkham's second paper $(1907 \mathrm{~b})$, a figure which Sobotta (1908, p. 260) could not understand, and also fig. I I of the same paper, which is clearly that of a degenerating egg. Kirkham (1907b, p. 77) says, in explanation of the absence of the zona from this and all other eggs of the same series (presumably the same animal), that it is "probably due to the solvent action of the killing fluid." But it certainly would be remarkable if the same killing fluid operated so differently on different ovaries. The explanation which we have suggested-a degenerating condition of the ova - is rendered still more probable by the fact that "all the ovarian eggs in this series are likewise naked." Tafani (I889, p. 24) in his criticism of Bellonci expresses the opinion that the latter saw in degenerating follicles eggs which never would have been set free, but which formed polar cells. Such eggs are just what Bellonci, having little material, would probably have seen and misinterpreted, for the reason that they occur in all ovaries of mature mice at all times, whereas normal eggs containing the first spindle or the first polar cell and second spindle can be found only during a very limited period. However, it must be borne in mind that, while Tafani did not misinterpret degenerating eggs, he did confuse the first and second spindles. He saw the first spindle in the ovarian egg, but apparently not the formation of the first polar cell, and seeing a spindle (the second) in eggs in the oviduct without the first polar cell, he mistook it for the first spindle. That he missed the stage of the abstriction of the first polar cell is rendered the more probable by the fact that he placed the period of maturation rather late and studied so many eggs from the oviduct. Nevertheless, Tafani's criticism of Bellonci was probably sound.

There are apparently no statements in any of the works on the embryology of mammals which show precisely how much time is required for any part, or the whole, of the maturation process. Indeed, the 
length of time required in the mouse according to our observations, namely, from 4 to 5 hours, needs confirmation.

According to the calculations of Tafani (I $889 b$, p. I I 4) the interval between coitus and the penetration of the spermatozoön is 7 or 8 hours, of Sobotta (1895, p. 63) and Gerlach (1906, p. 8) 6 to io hours. Tafani and Sobotta think the formation of the pronucleus requires only about an hour from the time the spermatozoön penetrates the egg; whereas Gerlach does not believe the pronucleus is formed so quickly. We have already (p. 2I) shown that the interval between coitus and penetration may be much less, viz, 4 to 7 hours, and that the pronuclei probably require only a few minutes for their development.

\section{OVULATION.}

It is desirable to know whether the time of ovulation has any fixed relation to that of either coitus or parturition.

All investigators except Gerlach (I906, p. 22) agree that in the mouse ovulation is independent of coitus, although such is not the case in some other mammals, e.g., the rabbit and the guinea-pig. ${ }^{1}$ Regarding the relation of ovulation to parturition, Kirkham (1907b, p. 79) is the only one, so far as we know, who makes any statement. He says that ovulation takes place in from I to 2 hours after parturition; but as he cites no authority for the statement and furnishes no evidence of his own, one can not give his conclusion much weight. We have already given evidence that it occurs at some time during a period extending from $14 \frac{1}{2}$ to $28 \frac{1}{2}$ hours after parturition.

There is some difference of opinion concerning the relation of the time of ovulation to that of maturation, the chief cause of which seems to us to be the failure to find any critical basis for distinguishing between the first and the second maturation spindles. Tafani (1889, p. 22) says ovulation occurs during the stage of the first spindle. While this, in our opinion, is not true, the statement can be explained on the highly probable assumption that he confused the first and second spindles. Sobotta has changed his opinion since writing in 1895 , and now ( 1907 , pp. 5I5, 519, 546; I908, pp. 247, 250) believes that ovulation occurs only during the monaster stage of the second spindle. He never finds the first spindle in eggs encountered in the oviduct, but describes, as being found in the oviduct ( 1907, p. 524, fig. 8), what he thinks may be a transition stage between the first and the second spindles. Gerlach (I 906, p. I4) believes that the changes in the wall of the follicle that make ovulation possible are not directly connected with the maturation changes within the egg itself, and therefore that the rupture of the follicle may take place at various phases of maturation; but he says that at the earliest the egg leaves the ovary in the stage corresponding with the beginning of the first spindle, and at the latest in that of the second spindle; but this

${ }^{1}$ Cf. Kirkham, I907b, p. 79. 
statement is based on his assumption that oviducal eggs without polar cells contain the first spindle, a view which arises from his being unable to distinguish between the two spindles in the monaster stage. This statement of Gerlach's has been disproved by Sobotta.

Lams et Doorme (I907, p. 284) maintain that ovulation takes place only during the stage of the second spindle; but, as Sobotta (Igo 8 , p. 259) points out, they contradict themselves by describing as a first maturation spindle one found in an ovum occupying the oviduct. According to Kirkham, the first polar cell is always formed in the ovary; but, as we have seen, this statement is supported, in part at least, by false evidence. In spite of some diversity of opinion regarding the precise state of the egg at ovulation, all agree that ovulation occurs during the stage of the second spindle. We, too, find this to be generally but not invariably true. It is probably owing to the unusually large number of eggs in the earlier stages of maturation studied by us that we have found in the periovarial space eggs in the stage of the first spindle, and also in the oviduct others that have already formed the first polar cell but have not yet developed the second spindle. It might be maintained that these eggs had been abnormally retarded in their development, and it must be admitted that such cases are not numerous enough to allow one to say that it is a common condition. On the other hand, nothing else about these eggs pointed to their being in any way abnormal, and no signs of degeneration were discoverable. These cases seem, therefore, simply to prove that the general rule regarding the time of ovulation in relation to maturation is not so inflexible as one would infer from the observations hitherto published.

\section{E. SIZE OF EGG.}

Sobotta and Kirkham alone have published measurements of the egg, Sobotta on fixed material and Kirkham on living material. Sobotta (I9o8) states that ovarian eggs before the formation of the first polar cell measure from 65 to 70 micra in diameter, and oviducal eggs 60 micra; but he does not say what is the arerage in the former case, nor that the latter measurement is an average, though such is presumably the case. Gerlach thinks there is considerable individual variation, and Lams et Doorme hold that oviducal eggs are smaller than ovarian ones. Our conclusions (see table 2, p. I 4, also p. 24) substantially confirm the above, except that the averages we give are a little less than the dimensions published by Sobotta. Kirkham (rgo $7 b$, p. 72 ) arrives at a different conclusion, namely, 8o micra as the diameter of ovarian eggs and 73 to 78 micra of oviducal eggs; but there may be some doubt concerning the reliability of his measurements because his methods may have been somewhat faulty, as we shall explain directly. Tafani, who was the first to study living eggs, carefully states (I 889, p. 6) that he collected them from the oviduct and kept them at the proper temperature in the fluid 
from the ovarian capsule or oviduct; but, unfortunately, he does not give the dimensions, and his figures are too diagrammatic to serve as a means of determining size. Kirkham has apparently overlooked the above statement, for he says that Tafani makes no mention of the method used to obtain living eggs. Kirkham (I907b, p. 70) procures them by killing a female soon after ovulation is supposed to have occurred, removing the ovaries and Fallopian tubes to a slide, and gently teasing them with fine needles until the eggs are seen to drop out; he then transfers them to the stage of the microscope for study. Kirkham does not state in what fluid he studied the eggs. The medium, however, is important, since it might, if not like the natural fluid in osmotic action, either swell or shrink the egg. We have already shown that a prolonged stay of eggs in the oviduct in the several cases results in an increase in their size, the eggs used for comparison being also subjected to precisely the same treatment as those from the oviduct. Since Kirkham's determination of the time of ovulation is in error by ro hours or more, it is a little doubtful whether all his eggs were in a normal condition.

\section{F. MATURATION PROCESSES.}

\section{Germinative Vesicle.}

It is agreed by all investigators that the germinative vesicle is at first very near the center of the egg, and that it becomes more eccentric as the time of its transformation into the first spindle approaches. Tafani and Gerlach both state that its membrane becomes irregular and disappears soon after the chromosomes have begun to form.

\section{First SPINDle.}

Chromatin.

Tafani ( 1889, p. $2 \mathrm{I}$ ) believed that by the rupture of the germinative vesicle the nucleolus escaped as an angular chromatophilous mass and moved toward the surface of the egg, where it gave rise to the chromosomes, while the remnants of the vesicle degenerated in the cytoplasm. We have observed that the cluster of chromosome fundaments sometimes has the appearance of such an angular mass, and it is possible that Tafani mistook this for the nucleolus. He figures it as in the act of slipping out of the germinative vesicle. In Sobotta's opinion (I895, p. 44) the chromosomes in eggs which produce but one polar cell are formed from the chromatin of the whole nucleus, not merely from that of the nucleolus as was claimed by Holl (1893), whose conclusions are, in Sobotta's opinion, unreliable because of the poor preservation of his material. Sobotta's statement (1895, p. 44) that the chromosomes are very irregular in form before they become arranged in the equator of the spindle and his illustration of the condition (Taf. 4, fig. 9, 9a) must really relate to the second spindle, for they are both based on eggs from either the periovarial chamber or the beginning of the oviduct; but such eggs must have already passed beyond the stage of the first spindle, as 
Sobotta himself admits in a more recent paper (1907). Although he makes no mention of haring seen the beginning of the (large) first spindle, he states (1895, p. 52; 1907, p. 507), without qualification or conclusive evidence, that it originates about 24 hours before ovulation. According to Gerlach (I 906, p. 9) the nucleolus disappears completely, and from the chromatin spherules (which he believes owe their origin to the nucleolus) the chromosomes are differentiated before the disappearance of the nuclear membrane. Kirkham (I907b, p. 73), describing the prophase of the first maturation, says that in a few cases there were traces of the nuclear membrane, though more often it had entirely disappeared. His fig. I (plate I), though described as that of an ovarian egg before the formation of the first maturation spindle, looks more like the crosssection of a spindle in the monaster stage than an early stage in the metamorphosis of the germinative vesicle, and the two detached chromosomes may possibly owe their peculiar position to the displacement which sometimes is caused by the knife in sectioning.

It will be remembered (p. 25) that the wall of the nucleolus is thick and deeply stained, and that the chromatin bodies of the germinative resicle are especially numerous around the nucleolus, which lies at one side of the resicle. Since, in the next stage, the chromosome fundaments (see p. 26) are also at one side of the nucleus, it is probable that they replace both the resicular nucleolus and the chromatin bodies. This is rendered the more probable by the fact that these fundaments are arranged at one side of a slightly denser part of the nucleoplasm. Such conditions lead one to think it possible that the fundaments arise from both the wall of the nucleolus and the chromatin bodies, while the achromatic spindle comes from other parts of the nucleus, or possibly originates in the inner part of the nucleolus.

Precisely how the chromatin of the germinative vesicle is metamorphosed or differentiated into the fundaments of the chromosomes is unknown; but in three cases the arrangement of the curved fundaments (as in fig. $3 b$ ) suggests the possibility that they lie end to end and may therefore be regarded as parts of a potential thread or spireme. This possibility is perhaps strengthened by the fact that these fundaments usually show a longitudinal division first and the transverse division later. These observations suggest that the longitudinal division may correspond to the longitudinal split in the spireme of the synapsis stage observed in many invertebrates, and that each fundament consists of two univalent chromosomes united end to end. The univalent chromosomes would then be sometimes indicated by the cross-division, and would be separated at the first mitosis, as described on page 30.

An inspection of the figures of the chromosomes of the first spindle in the papers of Sobotta (1895, I899, I907), Gerlach (1906), Lams et Doorme (I907), and Kirkham (I907b) reveals the fact that there is no essential disagreement in regard to the general forms of the chromosomes, 
although Gerlach (I906, p. I3) believes that the typical forms appear in the prophase only and that, apparently as a result of shrinkage, the chromosomes of the equatorial plate are short, rounded rods, like those of the second spindle. This supposed change of form is explained when it is noted that in Gerlach's figures the chromosomes of the first spindle of ovarian eggs (Gerlach I 9o6, Taf. I, fig. 2,3) have the typical forms, while the oviducal egg (fig. 4) with supposed first spindle has the rodlike chromosomes; for, as pointed out before, what he calls first spindles in oviducal eggs are really second spindles. Therefore, Gerlach's material, after all, presents no reai exception.

Gerlach (1906, p. 25) regards the chromosomes of the first spindle as tetrads, those of the second as dyads. The conclusion that the chromosomes of the first spindle are tetrads is based entirely on indirect evidence and on reasoning from analogy with conditions demonstrated in many invertebrates. Since in the first polar cell he finds that the chromosomes sometimes seem to be present as dyads, he reasons that those of the first maturation spindle must have been tetrads.

None of these observers has recognized and figured the quadripartite structure of the chromosome of the first maturation spindle. Both Tafani and Gerlach (I906, pp. I $3^{-14}$ ), it is true, state that the chromosomes are composed of Pfitzner's granules embedded in a less deeply stainable substance; but that has no bearing on the question of quadripartite structure. That the first division is transverse is believed by all authors except Tafani (I889, p. 22), who thinks it longitudinal, though he has not directly observed it in the mouse. But, since he confused the two spindles with each other, this statement applies to the second spindle only. Sobotta (1899, I907) alone gives illustrations of migrating daughter chromosomes; but in none of his figures does he show their longitudinal division. There is no doubt, as both Sobotta (I907, p. 5 I I) and Kirkham ( $1907 b$, p. 73) state, that some chromosomes divide earlier than others.

When one examines carefully the accounts of the first maturation spindle given by Sobotta (I 895, I 907), it is evident that in his first paper he speaks of a relatively early stage (fig. $4 a$ ) of the spindle as showing the equatorial plate, a stage which he later designates correctly as the prophase. Subsequent writers-Gerlach, Kirkham-have figured similar stages, and Kirkham (I907b, p. 73, fig. 2) has applied the expression equatorial plate even to a stage in which the chromosomes are distributed over half the length of the spindle. Gerlach (I906, p. I 3), however, clearly states it as his opinion, and in this we believe he is right, that such spindles are still in process of formation; but, in our opinion, he fell into an error in ascribing to a later stage of the first spindle a condition which is to be found only in the second maturation spindle; for he says that when the equatorial plate is fully formed it presents in the side view of the spindle a fairly uniform appearance, its chromosomes having 
the form of short rounded rods such as Sobotta shows in his (I 895) fig. Ioa. But Sobotta, as we think, and as he would probably now admit, made a mistake in supposing that his figures ro and ro $a$ represented the first maturation spindle. The egg in question was taken from the oviduct, and therefore exhibits the second maturation spindle. It may be noted, in passing, that by some strange slip of the pen Sobotta (I895, p. 9I) describes his fig. IOC as representing the beginning of metakinesis instead of an advanced anaphase. In his more recent paper he (Sobotta, I907, pp. 508-5II, fig. 2, fig. 3) has figured two spindles which may more properly be said to exhibit an equatorial plate, though even here the chromosomes do not assume that rigid, plate-like arrangement which characterizes the equatorial plate in many other animals and also that of the second maturation spindle in the mouse. This equatorial-plate, or monaster, stage of the first spindle is distinguished (Sobotta, I895, pp. 508-5II) from the prophase by the possession of smoother and straighter spindle fibers and by the predominance of chromosomes having a large one-sided protuberance. There is no disagreement among authors concerning the orientation of the chromosomes on the spindle nor concerning the fact that they vary in size. But as to the number of chromosomes, there is a wide difference of opinion. Tafani and the present writers count 20. Sobotta-whose view has been accepted by all subsequent investigators, apparently under the influence of the large amount of his material-maintained in 1895 that there were 12 chromosomes; but recently, stimulated by Dr. J. A. Murray to a reexamination of his material, he has changed his opinion, and in two papers (I907, p. 512 ; I 908, pp. 248,259 ) has stated that the number is certainly I6. Holl (I 893, p. 284) argued that since at an earlier stage there were 24 chromatic balls, there should be as many loop-like chromosomes, and was able to count 20 ; but not much weight can be given to his conclusions. $\mathrm{He}$ admits that it was impossible to count the chromosomes accurately.

The short account by Melissinos ( 1907, p. 584) is remarkably uncritical. After stating that Tafani gave the number as 20 , Holl as i $8,{ }^{1}$ Sobotta as I 2 , and others as 24 , he remarks that Sobotta's counting seems to him the more accurate, and then proceeds to state that he can make out only 8. But his figures are too diagrammatic to inspire much confidence on the part of the reader.

As already shown (p. 45), the number of eggs in which Sobotta could possibly have counted chromosomes is really small. In 1895 (p. 46) he maintained on the strength of many successive countings of the same material that the slender (second) spindle in all probability possessed I 2 chromosomes, surely not over I 4 or I 5 . Moreover, in the case of the thicker first spindle (p. $5 \mathrm{I}$ ) there were three eggs in which he counted

${ }^{1}$ It is not clear how Melissinos comes to make Holl responsible for the view that the mouse egg shows 18 chromosomes, unless, perchance, his eye fell on the page ( 280 ) where Holl reports that Rückert found "about is chromatin rods" in Selachian eggs. 
"with absolute certainty" I 2 chromosomes, and in many other instances approximately r 2 . Now, however, apparently without any additional material, he (I907, p. 5I2; I908, p. 248) counts I6! Gerlach (I906, p. 23) expresses himself as emphatically agreeing with Sobotta in his early statement that the number is 12 , he (Gerlach) having repeatedly counted I 2 in both the first and the second spindle. Lams et Doorme count the same number, I2, in two polar cells; but we have shown (p. 42) that the number in the polar cell has no significance. Kirkham (I907b, pp. 74-78) likewise affirms that there are 12 chromosomes, and in those cases where there are obviously more than I 2 bodies he explains the higher number as being due to the precocious division of some of the chromosomes. Nevertheless, in Kirkham's own preparations, which were so generously loaned to us, out of four normal ovarian eggs in the stage of the first spindle there were three cases in which we could count 20 with certainty, and in the remaining one $I 7$.

\section{Achromatin.}

Gerlach (I906) and Sobotta (I908, p. 508) are the only writers on the maturation of the egg in mice who give any opinion as to the precise origin of the fibers of the first spindle. These they think arise from the linin network of the germinative vesicle. But this seems improbable in view of the fact that there is a stage before their appearance in which only shreds of the linin network are left, while most of the vesicle is filled with a clear fluid. It is possible that the linin plays some part in the origin of the spindle; but, as has already been suggested, other parts of the nucleus, including the nucleolus, are the more probable sources.

Tafani has pointed out that in its early stages the first spindle in ovarian eggs is short and fat, a condition we also have found. Sobotta (1 895, г 899, 1907) figures in a diagrammatic way the spindle with sharp poles, the fibers converging to a point. Lams et Doorme ( 1907, p. 274) say the fibers converge more or less to a point. Kirkham figures the shape of the first spindle as elliptical.

According to Sobotta ( 1907 ) the largest spindle is 30 to 32 micra long and 20 micra broad. The largest spindles we have found have the following dimensions: 29.5 micra in length by is in breadth, and 22.6 in length by 14 in breadth. From Sobotta's paper of 1899 it must be inferred that the size varies. The statement of Lams et Doorme (I907, p. 275) and our own observations accord with this inference. Gerlach's statement (p. Io) that the size depends in the main on the size of the germinative vesicle can not be accepted as demonstrated, for the spindle is not a result of the metamorphosis of a network confined in a rigid vesicle; besides, the membrane of the vesicle has nearly disappeared when the spindle is first differentiated.

Sobotta described the spindle fibers in 1895 (p. 5r) as fine, wary, and branched; in 1907 (p. 508) as wavy with slight thickenings. His latter description applies to the early stages of the first spindle, for later 
the fibers become thickened at the polar ends, as he and Lams et Doorme figure them. Gerlach does not agree with Sobotta that there is a central spindle. While we have no evidence of the existence of a central spindle like that discovered by Hermann, we agree with Sobotta that there are some fibers which run from pole to pole without being attached to chromosomes. These probably persist as a part of the interzonal filaments.

Centrosomes, Circumpolar Bodies, and Clear Region.

No one (with the possible exception of Gerlach, fig. 2) has figured the corpuscles near the poles of the spindles which we have called circumpolar bodies. Tafani (I889, p. 22), Sobotta (1907, p. 521 , for the second spindle only), and Gerlach (I906, p. 9), nevertheless, mention granules at the poles, which, according to the two latter authors, form a sort of mantle around the poles of the spindle and thus obscure its fibrous structure. Gerlach describes them as occurring with both spindles and adds that they sometimes have the form of tortuous threads, which suggests to him that they may be mitochondria.

The first impression one forms of these bodies is that they are artifacts due to improper fixation; but when one reflects that they occur in eggs fixed by different methods and that they are characteristic of certain stages (see p. 33), this interpretation seems unwarranted. These bodies were also seen in Kirkham's preparations, although he does not himself mention them.

A study of the occurrence of these bodies brings out the fact that they are characteristic of certain periods of morphological activity. For example, they can be found for a short time before and during metakinesis of the first spindle and during the early existence of the second spindle when division is likely to occur as a result of semination. Conversely, they are absent during periods of morphological quiescence, such as the telophase of both spindles, and when the second spindle persists in the absence of semination. It will be remembered that these periods of activity are very short (p. I6), while the quiescent periods are comparatively long; therefore these bodies exist during only brief periods. The question naturally arises, Are they the result or the cause of the morphological changes? Unless it can be shown that they are handed on from cell to cell, it seems reasonable to suppose them products rather than causes of spindle activity. On the other hand, the absence of typical centrosomes leads one to ask whether they may not in some way fulfill the function of centrosomes, especially since they are situated very close to the poles of the spindle. Such inquiries can not be answered at present; these bodies, the existence of which is beyond dispute, are worthy of more extensive study, and their possible relation to mitochondria should certainly be investigated further.

Tafani, Sobotta, and Gerlach deny the regular existence of centrosomes. Gerlach (1906, p. 26) saw in one case two centrioles at the pole of a spindle, and Sobotta (1907, p. 524, fig. 8) figures a disk-shaped 
body at one pole of a spindle, where a centrosome might be expected; but he declines to regard it as such, because it is an isolated casc. Lams et Doorme (1907, p. 274) and Kirkham (1907b, p. 74) alone assert the occasional presence of these structures, the formcr saying that there are usually none with the first spindle. Lams et Doorme illustrate two first spindles in side view, one in an egg from the ovary (fig. 2) and one from the oviduct (fig. 5), the latter being the case to which Sobotta calls attention as the exception to the rule that the first spindle is confined to ovarian eggs. In the first case (fig. 2) they show no centrosomes, but in the case of the egg from the oviduct (fig. 5) a curved rod occupies one pole of the spindle. The latter, however, is probably a second spindle, since the egg is in the oviduct and since all the second spindles figured by them have somewhat similar centrosomes; furthermore, the chromosomes of this spindle resemble the chromosomes of the second spindle rather than those of their fig. 2. As for the centrosomes drawn by Kirkham, their presence is probably referable to the condition of the eggs, many of which, as judged from an examination of his slides, were not normal. It will be noted that some of his spindles do not show centrosomes; they, we believe, are normal. There seems, then, to be no good ground for the assertion that centrosomes exist in connection with the first spindle.

Sobotta (I 895, p. 44) states that the clear region around the chromosomes of the spindle of eggs which produce only one polar cell has almost precisely the extent of the vanished germinative vesicle. Since this statement really relates to a spindle which does not originate from the germinative vesicle directly (as Sobotta himself now admits), it loses its significance. Lams et Doorme (1907, p. 274), who make a similar assertion in connection with the first spindle, apparently have not themselves seen the early stages (their fig. 3 being that of the second spindle), and consequently have no other ground than Sobotta for their assertion. According to our descriptions (pp. 26, 27,33) this clear region has no direct relation to the germinative vesicle. Since it exists, as the circumpolar bodies also exist, during the periods of morphological activity of the spindle, it also is probably a manifestation of such activity.

Position and Orientation.

Sobotta (1 895 , I 899, I907) places much emphasis on the position of the first spindle, which is situated deep in the egg. Our specimens substantially corroborate his statement. Regarding the angle which the axis of the spindle makes with the surface of the egg, there is some disagreement among authors, arising, as it seems to us, from the paucity of proper stages in the material which most of the investigators have studied. It has been shown (p. 33) that the spindle may be parallel or oblique to the surface, but that it is only rarely perpendicular at any stage. Tafani (I 889, p. 22) says that the spindle is from the first oblique, not perpendicular, and figures it in an oblique position during the abstric- 
tion of the polar cell. Although the statement may be based upon the sacond spindle, which Tafani mistook for the first, it nevertheless is true of the first spindle. Sobotta (I 895, p. 48) makes the unqualified statement that the slender spindle (which he now calls the second) turns from the paratangential position to the oblique and finally to the radial just before the polar cell is cut off. He saw three cases of metaphase spindles, all oblique, but all of those in the telophase were radial. Therefore, although he had not actually seen the process of abstriction, he thought the first spindle was radial at the time the polar cell was cut off. In a later paper (1899, p. I90) he describes the same process for the first spindle and gives a figure (fig. 4) of the spindle during the dyaster stage in what appears to be a radial position with one pole in the polar-cell protrusion. The figure has a somewhat rigid diagrammatic appearance and is not accompanied by any explanation to prove that the spindle is radial with respect to the center of the egg as well as the center of the section in which it lies. The relative shortness of the spindle suggests the possibility that its axis is oblique to the plane of the section and that consequently it may not be strictly radial in position. $\mathrm{He}$ mentions having three other spindles in the stage of his fig. 4, but does not state what their position is. In one of his recent papers Sobotta (I907, p. 517) figures a dyaster stage of the first spindle (fig. 4) and states that it is in an oblique position, having begun the rotation from the tangential to the radial position. In a foot-note, however, he admits that it really is never met with in a strictly radial position! He ( 1907 , p. 5 I 7 ) finds it difficult to decide whether the first spindle always rotates, yet he argues that it must remain tangential in most cases (one polar cell) because it is transformed in the monaster condition directly into the monaster of the second spindle, which is likewise tangential. $\mathrm{He}$ is not sure whether even in one-fifth of the cases (those in which it divides) it may not be oblique when the polar cell is formed, but thinks it may be assumed that as a rule it rotates, because the second spindle always rotates, and because it (the first) takes up a position so near the surface of the egg that no polar cell could be produced without its rotation. Sobotta does not give any proof, except that contained in his first paper (i 895), that the second spindle is radial at the moment the polar cell is abstricted. Moreover, he figures ( 1907 , fig. 9) a dyaster of the second spindle in a paratangential position and says (p. 525) that its not being radial is purely accidental! Thus, except for his 1899 paper, which he does not mention in this connection, there is no evidence that either polar cell is cut off while the spindle is in a strictly radial position. Gerlach (I go6, p. Io), while he does not take exception to the general conclusion of Sobotta that there is a rotation of the spindle from a tangential toward a radial direction, thinks that the strictly radial position is not necessary to the formation of the polar cell. Neither Gerlach, Lams et Doorme (p. 275), nor Kirkham (1907b, p. 75) mention having seen any 
stages of the metaphase, and the latter two, having seen spindles in oblique positions, apparently assume that Sobotta is right in his opinion that the spindle becomes radial and that the oblique position is simply an intermediate one.

Division of First Spindle and Abstriction of First Polar Cell.

Sobotta (1899) is the only observer who has figured stages in the migration of the daughter chromosomes towards the poles of the spindle. Because of the scarcity of such stages in his material he concludes that the first spindle divides in only one-fifth of the eggs. In the other fourfifths, therefore, the spindle does not divide and the first polar cell is not cut off. This may possibly be due to a failure of the spindle to rotate (Sobotta, I 907, p. 51 $\&$, footnote). This he thinks agrees with his observation that 80 per cent of the fertilized eggs have only one polar cell, this one being in his opinion the equivalent of the second polar cell of those eggs which form two such cells.

It has been shown (p. I6) that this stage is of very short duration. Hence we draw the conclusion that the infrequent occurrence of this stage is due, not to the failure of the spindle in some cases to divide, but to the fact that the chances of meeting with it are few.

Gerlach (1906, fig. 5) figures a recently formed polar cell in an ovarian egg, but he says nothing about the division of the supposed first spindle in oviducal eggs. As Sobotta points out, supposed first spindles in the oviduct have had as much time in which to divide as have the first spindles of adjacent eggs which have produced the first polar cells. These considerations go to show that Gerlach misinterpreted the spindles in oviducal eggs.

In the opinion of Sobotta the "Zwischenkörperchen," sometimes in two rows, are finally inclosed in the polar cell when it is cut off. He describes and illustrates this condition in his papers of 1895 and 1907 . Although his observations were really made on the second spindle, they hold also for the first. It is difficult to account for this conclusion except on the ground of variable conditions or poorly preserved material, for, as Lams et Doorme (for the second spindle) and Gerlach show, and as our material so clearly proves, the bodies in question do not lie inside the membrane of either egg or polar cell. Gerlach, however, thinks they are at first in two rows which then fuse.

In the process of abstriction, as described on pp. 34 and 40 , there appears to be an attraction between the "Zwischenkörperchen" and the vitelline membrane. Naturally any attraction between the membrane and these bodies would be exerted more readily with the spindle in an oblique or tangential position and its effect would be first manifested on the side of the spindle nearest the surface. It is perhaps possible, then, that the "Zwischenkörperchen" have some part to play in the abstriction of the polar cell. 


\section{SECOND SPINDLE.}

\section{Chromatin.}

It was Tafani (r889, p. 23) who first announced that in the greater number of cases in mice only a single polar cell is formed. It was therefore his opinion that the chromosomes which remained in the egg after the formation of the first polar cell gave rise either to the second spindle (few cases) or to the female pronucleus (greater number of cases). This opinion would be the natural consequence of his probable confusion of the second spindle with the first. Sobotta in his early paper (I 895, p. 44) also held that in those eggs which produced but one polar cell (in nine-tenths of the cases, in his opinion) the spindle was formed directly from the germinative vesicle, and ( 1895, p. 53) that in all other eggs (one-tenth of the total number) the second spindle was produced from the chromosomes which remained in the ovum after the first polar cell was abstricted. Since Sobotta considered the spindle in the former instance to be the equivalent of that in the latter, it follows that, according to his view, the second spindle was formed in some cases directly from the germinative vesicle. In a later paper (I907, p. 5I 4) he says that he has no observations to prove this view and that it is erroneous. As stated in this paper (1907, p. 519), he now believes that (in a larger proportion, about one-fifth of the cases) the second spindle originates as previously described for one-tenth; but in 4 out of every 5 eggs the monaster of the second spindle is derived directly from the monaster of the first, i.e., without the formation of a polar cell. That is, the first spindle in a large proportion of ova does not divide, but, in some way which involves a degeneration of half of the chromosomes within the cytoplasm of the egg (1907, p. 54I; I908, p. 250), is transformed into the corresponding condition of the second spindle. This belief he thinks accords with his observation that in preserved material the occurrence of the division of the first spindle is very infrequent.

This is Sobotta's explanation of the occurrence of only one polar cell in many oviducal eggs in the iate stages (the ones he worked with chiefly. See pp. I 4, 45). It is not based on any observation of degenerating chromosomes or of the supposed stages of transformation. In fact, Sobotta repeatedly says that he has seen no such stage, although he believes that in a single instance ( 1907 , fig. 8 , a spindle with more than I 6 chromosomes, which occurred in an oviducal egg) he may have had an example. It should be noted that, if this transformation occurs in four-fifths of all the eggs, the chances of meeting with it must be four times as many as the chances of encountering the division of the first spindle. In view of these considerations one may be warranted in questioning the existence of such a condition.

Gerlach (1906, fig. 6) illustrates an early stage in the origin of the second spindle, with which the description of the same stage in the present paper agrees. 
The chromosomes of the second spindle are not described by Tafani, except as the description which he gives of those of the supposed first spindle really applies to those of the second. Sobotta (I907, p. 52 I) holds that they are short rounded rods, similar in form to the daughter chromosomes of the first spindle, though generally somewhat smaller, or at least slimmer. Gerlach (I906, p. I 4) is unable to distinguish between the chromosomes of the first and second spindles, except that the latter are the smaller; he figures the same shapes as Sobotta, and also a spindle (fig. I6) having elongated granular chromosomes. We have found in many spindles in which the chromosomes are closely packed that the appearance-especially of those chromosomes which are seen in end view, without careful, critical study and comparison with more favorable examples--seems to be about like that figured by Sobotta and Gerlach. Lams et Doorme (I907, p. 283) think that the presence of the first polar cell is the only reliable criterion for identifying the second spindle. Kirkham (I9o7 $b$, p. 78), Sobotta (1895, p. 48), and Gerlach (I906, p. I9) state that the daughter chromosomes elongate, but they describe no other structure. We have shown this lengthening to be characteristic of old spindles.

So far we have made no definite statement concerning the homologies of the chromosomes of the second spindle with those of the first. Whether the mother chromosomes of the second spindle are identical with the daughter chromosomes of the first it is impossible to say with certainty, for the reason that there is no way of determining directly whether or not the chromosomes which become fused into a single mass in the egg after the first polar cell is cut off keep their individuality and reappear when the mass breaks up preparatory to the formation of the second spindle. The striking similarity between the daughter chromosomes of the first spindle and the mother chromosomes of the second in certain cases, and also analogy with those invertebrates in which the daughter chromosomes of the first spindle are known to pass directly to the second spindle without undergoing an intervening nuclear or resting stage, make it seem highly probable that in the mouse the daughter chromosomes of the first spindle are identical with the mother chromosomes of the second. If this is true, then the division between the parts of the chromosome of the second spindle is the same as the longitudinal division in the daughter chromosome of the first spindle and is therefore apparent in the fundaments. On this ground it is proper to call the chromosomes of the first spindle "tetrads," because they possess the two divisions which mark the planes of separation of the daughter chromosomes of two quickly ensuing mitoses, and to designate those of the second spindle "dyads." The division of the dyad, then, is a longitudinal splitting, and the reduction is a so-called prereduction.

Tafani (I889) makes the statement that the chromosomes of the first spindle divide longitudinally; but, as we have seen, this statement 
probably relates to those of the second spindle. Sobotta (I895, p. 46; 1907, p. 522) and Gerlach (1906, p. 14) state that the division is transverse, but for theoretical reasons they believe that the division of the chromosome of either the first or second spindle must be longitudinal. Sobotta (1908, fig. 7) alone figures a dividing second spindle. His "biscuit" shaped chromosomes remind one very much of some of the dyads we have described (p. 37) as constituted of 4 parts, inasmuch as the "biscuit" forms are in some instances in groups of 4 . What he calls a whole chromosome looks more like half of a dyad.

The same criticisms which have been made regarding the number of chromosomes of the first spindle apply also to those of the second. It was in polar views (the most favorable for counting) that Tafani found 20.

Achromatin.

In his paper of 1895 (p. 45) Sobotta stated that the spindle fibers of the single spindle (which occurred in nine-tenths of the eggs) were derived in part from the achromatic portion of the germinative vesicle. As already pointed out, he no longer holds this view.

The second spindle as drawn by Sobotta (I 895, I907) is barrel-shaped, the ends being somewhat truncate, the fibers only slightly curved, and the poles open. As illustrated by Gerlach, Kirkham, and the present writers, this spindle is elliptical, with fibers incurving at the poles.

The flattening of some of the second spindles described on page 38 is apparently a result of their lying close to the surface of the egg. There is a possibility that the flattening is caused by shrinkage due to fixing and dehydrating. Shrinkage to produce this result would have to be greater in a radial than in other directions, and could be explained only on the supposition that the substance in which the spindle lies, being probably more fluid than the surrounding cytoplasm, is extracted more rapidly on the side nearest to the surface of the egg. However, were the flattening due to shrinkage the chromosomes should be crowded in a radial direction; but that this crowding does not exist is clear from plate 4 , fig. 20, in which the spaces between the chromosomes are as uniform as in fig. 21 .

All investigators agree that the second spindle is smaller than the first. Sobotta $\left(\mathrm{I}_{907}, \mathrm{pp} .508,520\right)$ insists that the second is but half the size of the first, although he does not state whether he used averages for his conclusion. It seems unlikely that he did, since he says that his fig. 3 is the broadest first spindle. It must be admitted that a first spindle may be about twice the size of a second spindle, for we have found that the largest two first spindles measure $29.5 \times$ I I micra, and $22.6 \times$ I 4 micra, respectively, and the smallest second spindles $14 \times 6.5$ micra and $18 \times 5.5$ micra, respectively.

All who have published papers on the mouse, except Kirkham, figure the polar ends of the fibers as thickened. In regard to the fibers which are not attached to chromosomes, there is no conflict between the 
statement of Sobotta, that there are fibers stretching from pole to pole, and our own results. However, he gives the idea that such fibers form a bundle on the outside of which the chromosomes rest and on which they are drawn to the ends of the spindle, whereas the distribution of the chromosomes in the plane of the equator in our preparations forces us to conclude that such fibers, if present, must be interspersed among the chromosomes. Sobotta (1895, p. 47) places the number at I 2 (later as probably I6). As it has not been possible to count them in our preparations, we can not state what the number is.

\section{Centrosomes, Circumpolar Bodies, and Clear Region.}

The circumpolar bodies and the clear region have already been considered. The former dwindle away in old second spindles, leaving what might be mistaken for centrosomes (p. 39). Such remnants may well be what Sobotta (1907) and Gerlach (I 906) occasionaliy saw and what Lams et Doorme (I 907 , figs. 6 to 8) and Kirkham (1907) found more regularly. Lams et Doorme say that in the second spindle the "centrosomes" vary according to the method of fixing. But in our opinion these are not to be regarded as centrosomes.

\section{Position and Orientation.}

Gerlach (I906, pp. Is to 20) and Kirkham (I907b, p. 78) have observed that the second spindle or second polar cell may be at various distances from the first polar cell. Sobotta $(1907$, p. 532) finds only one such condition in I,000 eggs and thinks the difference between Gerlach's material and his may be due to the fact that he and Gerlach used eggs of different ovulations. We are at a loss to account for the difference in Sobotta's material; but the fact nevertheless remains that the polar cells may be found at various distances from each other. Gerlach ( 1906 , pp. I 8 to 20) accounts for this by supposing the spindle to migrate through the cytoplasm, and he figures a path which he thinks was made by such a moving spindle. The distance, he believes, is determined by the epoch of semination, because with that event the second spindle, wherever it may be, stops in its migration and forms the second polar cell (or at least divides). There is no final proof that this migration does not occur, but, from the evidence adduced (p. 43) in connection with the position of the first polar cell, it seems simpler and more reasonable to suppose that the polar cell shifts its position under the zona. This shifting might be aided by the power the polar cell has of changing its shape, as was observed by Tafani. Such an explanation makes it unnecessary to assume changes in the cytoplasm and a migration of the spindle that is so out of harmony with what is known in other animals, where the conditions are so favorable as to leave no doubt as to the events.

The orientation of the second spindle is like that of the first and needs no further discussion. 
Division of Second Spindle and Abstriction of Second Polar Cell.

The only illustrations showing the division of the second spindle in the maturation of the mouse egg are those of Sobotta (1895, 1907). The criticisms which we have made in connection with the division of the first spindle and the formation of the first polar cell (p. 59) are applicable to the corresponding processes in the second oöcyte.

\section{POLAR CELls.}

There is agreement among the investigators of the mouse egg that not all fertilized eggs have both polar cells. According to Tafani and Gerlach the first polar cell is always formed, but the second in a large proportion (respectively four-fifths and three-fourths) of the eggs is suppressed. Tafani does not state how the suppression is effected. Gerlach thinks that in the event of late semination the second spindle divides so quickly as to inhibit the formation of the polar cell and that the chromosomes which would have been contained in the second polar cell remain in the cytoplasm of the egg and degenerate. Although he avers that he has seen such degenerating chromatin, it should be borne in mind that it is possible he mistook for chromosomes cytoplasmic bodies which sometimes stain deeply like chromatin. Sobotta, on the other hand, believes that in most cases the first polar cell is never formed. In 1895 he stated that even the first spindle did not come into existence. Now (1907) he believes that the spindle is formed in all eggs, but that in 4 out of 5 eggs it is immediately metamorphosed into the second spindle, half of the chromatin disintegrating in the egg. As he has not seen either the metamorphosis or the degeneration of the chromatin he has no direct evidence for his belief. Kirkham states, but on evidence that in part at least is unsound, that all eggs produce the first polar cell. His explanation (1907b, p. 80) of the absence of one polar cell is apparently suggested by a single case in the bat, in which, according to van der Stricht, both polar cells lay outside of the zona pellucida. It is supported by one observation (Kirkham, I $907 \mathrm{~b}$, p. 8I), according to which the polar body of a living mouse egg (which he stained and dehydrated under the microscope) was forced through the zona pellucida by the contraction of the latter under the influence of changing osmotic conditions.

While the case in the bat is suggestive of a possible explanation for the loss of the first polar cell in the mouse, it can scarcely be admitted as evidence of the occurrence of such conditions in the mouse. As for his observation on the living egg, Kirkham does not say with what strength of solutions he stained and dehydrated the egg under the microscope. Although he may have seen the polar cell forced through the zona under direct action of reagents, the same thing need not necessarily occur under natural conditions, since eggs in the oviduct, and still more those in the ovary, are protected from the full vigor of osmotic action by the sur- 
rounding fluid in the oviduct or follicle and by the tissues of the oviduct or ovary. Kirkham, furthermore, states that this loss of the polar cells occurs during ovulation; but, since he has not seen any instances in which the eggs are passing from the follicles, this conclusion must be based on the presence of these bodies at one stage (viz, before ovulation) and their absence at another (viz, after ovulation). But, unfortunately for this explanation, they are not universally absent in the latter case.

None of the figures of mammalian eggs escaping from the folliclethe only ones known to us being those given by Barry ( 1839 ), Sobotta (I 895), van der Stricht (I 901), and the writers (figs. 38, 39, 40)-furnishes any evidence whatever that the polar cell is being pressed through the zona pellucida. Our preparations show, on the contrary, an increased space between the zona pellucida and the vitellus. The change in osmotic conditions in passing from the ovary to the periovarial space or to the oviduct in a living mouse can scarcely be great enough to cause the polar cell to be forced through the zona by shrinkage of the latter. Furthermore, if the loss of the first polar cell is caused by the action of reagents, why should not the second polar cell also be forced through the zona? In the case of the bat van der Stricht had the evidence of both polar cells lying outside the zona. There is not even this evidence in the case of the mouse, for, as Sobotta (1908, p. 253) has observed, no one has ever seen such a condition, though, if it occurs, the polar cells should be easily recognizable among the surrounding follicle cells.

There is, then, no good evidence of the suppression of either polar cell or of the loss of the first polar cell by extrusion through the zona pellucida. Lams et Doorme (1907, pp. 276, 287) were the first to offer the explanation that, while both polar cells are formed, the first undergoes degeneration within the zona and disappears. Their figures show this clearly, yet they suggest that what they call degenerating polar cells may possibly be bodies (follicular cells) which have slipped under the zona! Independently of Lams et Doorme, and before their paper was published, we, also, had come to the conclusion that the first polar cell degenerates, and can therefore support the view with unbiased observations. We have already described the decrease in size of the first polar cell and the evidence of the degeneration of its chromatin, using polar cells of eggs which contain the second spindle in order to avoid even the possibility of confusing the first polar cell with the second. Tafani (i 889 , p. 24) mentions that the first polar cells vary in size and also calls attention to cases where they are very small. Sobotta (1907, p. 544) alludes to these small forms by warning his readers not to mistake for polar cells what he says may be follicle cells under the zona, or bodies formed from the zona. He does not show why follicle cells should be under the zona, or in what manner they could get into such a position, or how the zona could give rise to bodies with nuclei. It must be remembered that, since Sobotta's material contained a large proportion of the 
late stages (pronuclei and cleavage stages), it presented few of the degenerate polar cells (see p. 41), those that persisted being of the larger size. Again, eggs fixed in osmic-acid mixtures (which he used chiefly) have the zona dark, which makes it difficult and often impossible to interpret or even to see such small objects. Upon consideration, it is not surprising that the first polar cell should degenerate, for usually both polar cells do so in time, forming no part of the embryo. It is quite possible that the substance of the polar cell is absorbed by the egg.

The decrease in size of the degenerating polar cell explains the disagreement of authors concerning the relative size of the first and second polar cells. Sobotta $(1907$, p. 536) maintains that sometimes one, sometimes the other, is larger. Gerlach (1906, p. I3) says the first is larger; Lams et Doorme (1907, p. 287) that the second is. It seems fairly certain that Lams et Doorme must have seen old first polar cells and young second ones, for they have few of the earlier stages, even though they show the first polar cell decreasing in size.

Gerlach (Igo6, p. 25) thought that in one first polar cell the chromosomes were dyads. Sobotta (1907, p. 537) says that both polar cells may have either scattered chromatin or a nucleus, which is formed later than the egg nucleus. In our opinion this statement must mean that he confused the polar cells, for, of the 507 eggs with the second spindle that we have studied, none have a first polar cell with a nucleus; whereas the second, in seminated eggs, always forms a nucleus without its chromosomes becoming scattered and distinct. Kirkham (I go $7 b$, fig. I 4), also, has probably mistaken the first polar cell for the second in the figure in which he shows the monads much separated.

The difference in chromatin contents of the two polar cells accords with the well-known fact that the first polar cell corresponds to the first oöcyte, while the second is a homologue of the second oöcyte; for, on the one hand, the chromatin of the first polar cell does not form a resting nucleus, but may divide (as it occasionally does), and, on the other hand, the chromosomes contained in the second polar cell immediately become metamorphosed into a nucleus corresponding to the egg nucleus. The first, being a cell which degenerates, divides not regularly and normally, but with what seems to be imperfect mitosis or even amitosis.

\section{REDUCTION.}

It is fair to assume from the preceding account that the longitudinal division in the tetrads corresponds to the longitudinal split in the spireme of a synapsis stage, and that the transverse division marks the place of union, end to end, of two somatic chromosomes. Since the tetrad gives rise to two dyads by parting along the transverse plane of division, and since the dyads form their daughter chromosomes by means of the longitudinal division, the maturation of the mouse egg belongs to the class of prereduction divisions. 


\section{SUMMARY OF THE PRINCIPAL RESULTS IN THE STUDY OF THE MATURATION OF THE EGG OF THE MOUSE.}

I. Parturition occurs at any time during the 24 hours of a day, but more frequently in the early morning.

2. The stages of the formation of the first spindle, the division of the first spindle, the formation of the second spindle, and the division of the second spindle are relatively, and probably absolutely, very short.

3. The whole maturation process requires not less than 4 nor more than 15 hours.

4. Maturation usually occurs at some time during the period extending from $13 \frac{3}{\frac{3}{4}}$ to $28 \frac{1}{2}$ hours after parturition.

5. Ovulation may occur at any time during a period beginning at I $4 \frac{1}{2}$ and ending at $28 \frac{1}{2}$ hours after parturition.

6. Ovulation may occasionally take place in the stage of the first spindle, sometimes during that of the telophase of the first spindle and the formation of the second polar cell, but usually not till the egg contains the second spindle.

7. Insemination is most successful when it occurs between the r 8th and 3 oth hours after parturition.

8. The spermatozoa reach the egg in from 4 to 7 hours, or more, after insemination.

9. The pronuclei are formed probably within a few minutes after the penetration of the spermatozoön.

Io. The diameter of the egg decreases from the stage of the germinative vesicle until it reaches the oviduct, when it increases slightly.

II. The chromosomes of the first spindle are formed from the chromatin of the germinative vesicle, and possibly also from the wall of the nucleolus.

I2. They are formed before the nuclear membrane disappears.

I3. They show indications of both transverse and longitudinal divisions, and are therefore "tetrads."

I4. In the first maturation division the tetrads divide transversely.

I5. All first spindles divide.

I6. The spindle fibers are probably derived in part from the nucleolus.

I7. The chromosomes of the second spindle are "dyads" and divide longitudinally, separating along a plane which is probably identical with the longitudinal division-plane of the tetrads.

I8. The chromosomes of each spindle number twenty.

19. Typical centrosomes are wanting in both spindle figures.

20. Bodies surrounding the poles of the spindles, here called circumpolar bodies, and the clear region surrounding the spindle are characteristic of morphologically active stages of the spindle. 
21. Each spindle is oblique to the surface of the egg at the beginning of the abstriction of its polar cell.

22. All eggs form two spindles and a first polar cell.

23. All seminated eggs form a second polar cell.

24. The first polar cell probably migrates in the perivitelline space inside the zona pellucida, and is aided in this movement by the process of ovulation.

25. The first polar cell may or may not degenerate.

26. Maturation division in the mouse egg belongs to the type known as prereduction division. 


\section{BIBLIOGRAPHY.}

Allen, G. M.

1904. The Heredity of Coat Color in Mice. Proc. Amer. Acad. Arts and Sci. BARRY, M. Vol. 40, No. 2, pp. 59-163.

1839. Researches in Embryology. Second Series. Phil. Trans. Roy. Soc., BELLONCI, G. London, I 839 , pp. 307-380, pl. 5-9.

I885. Del fuso direzionale e della formazione di un globulo polare nell' ovulo ovarico di alcuni mammiferi. Atti della R. Accad. dei Lincei, Roma,

BOVERI, T. Ser. 4, Rendiconti, Vol. I, pp. 285,286

I892. Befruchtung. Ergeb. Anat. u. Entwick., Bd. I, pp. 386-485.

Coe, W. R., and Kirkham, W. B.

1907. The Maturation of the Mouse Egg. Science, Vol. 25, p. 778, 779.

GERLACH, L.

I 890 . Beiträge zur Morphologie und Physiologie des Ovulationsvorganges der

Säugethiere. Sitzungsh. physik.-med. Societät in Erlangen, Heft 22, pp. $43^{-5}$ I.

1906. Über die Bildung der Richtungskörper bei Mus musculus. Festschr.

GRÉGOIRE, V f. J. Rosenthal. Wiesbaden, I906. vii + 3 I pp., 2 Taf.

I905. Les résultats acquis sur les Cinèses de maturation dans les deux Règnes.

HÄ CKER, V. (Première Mémoire.) La Cellule, Tom. 22 , pp. $22 \mathrm{I}-376$.

I 899. Die Reifungserscheinungen. Ergeb. Anat. u. Entwick., Bd. 8, pp.

HEAPE, W. $847-922$.

I 897. The artificial Insemination of Mammals and subsequent possible Fertilisation or Impregnation of their Ova. Proc. Roy. Soc., London, Vol. 6I, No. 370 , pp. 52-63.

HERTWIG, R.

1903. Kapitel: Eireife und Befruchtung. O. Hertwig's Handbuch der vergleichenden und experimentellen Entwickelungslehre der Wirbeltiere. Jena, I906. Bd. I, Lief. ro, I I [1903], pp. 477-568.

Holl, M.

I 893. Ueber die Reifung der Eizelle bei den Säugethieren. Sitzungsb. Akad.

IWANOFF, E. J. d. Wiss., math.-naturw. Cl., Wien, Bd. ro2, Abth. 3, pp. 249-309, 3 Taf.

I903. Ueber die künstliche Befruchtung von Säugetieren und ihre Bedeutung für die Erzeugung von Bastarden. Biol. Centralbl., Bd. 23, No. I9, pp. 640-646.

KIRKHAM, W. B.

I907a. The Maturation of the Mouse Egg. Biol. Bull., Vol. 12, No. 4, pp. $259-265$.

I907b. Maturation of the Egg of the White Mouse. Trans. Conn. Acad. Arts and Sci., Vol. I3, pp. $65^{-87}$, pl. $1-8$.

Korschelt, E., Und Heider, K.

I903. Lehrbuch der vergleichenden Entwicklungsgeschichte der wirbellosen Thiere. Allgem. Theil, Lief. 2, pp. 539-750. Jena, I903.

LAMS, H., eT DOORME, J.

1907. Nouvelles recherches sur la Maturation et la Fécondation de l'E Euf des

LANGE, J. Mammifères. Arch. de Biol., Tom. 23, pp. 259-365, pl. 9-I I.

I896. Die Bildung der Eier und Graaf'schen Follikel bei der Maus. Verh. d. phys.-med. Gesellsch. zu Würzburg, Bd. 30, Heft 2, pp. 55-76, I Taf.

LOUKIANOW, S. M.

I 898 . Contribution à l'étude de la spermatogénèse chez la souris blanche. Arch. Sci. Biolog., Inst. impér. Médecine expér. St. Pétersbourg, Tom.

MALLORY, F. B. 6 , No. 3, pp. $285-305,3$ pl.

1905. A Contribution to the Classification of Tumors. Jour. Med. Research, Melissinos, K. Vol. I3, pp. I I $3-\mathrm{I}_{3} 6$, pl. 5-8.

1907. Die Entwicklung des Eies der Mäuse von den ersten Furchungs-Phänomenen bis zur Festsetzung der Allantois an der Ectoplacentarplatte. Arch. f. mikr. Anat., Bd. 70, pp. 577-628, Taf. 32-34. 
RÜCKERT, J.

I894. Die Chromatinreduktion bei der Reifung der Sexualzellen. Ergeb. Anat. u. Entwick., Bd. 3, pp. $5 \mathrm{I}_{7}-583$.

Sовотта, J.

I 895. Die Befruchtung und Furchung des Eies der Maus. Arch. f. mikr. Anat., Bd. 45 , pp. $5_{5}-93$, Taf. $2-6$.

I 899. Ueber die Bedeutung der mitotischen Figuren in den Eierstockseiern der Säugetiere. Festschr. d. phys.-med. Gesellsch. zu Würzburg, pp. I85-r 92 , I Taf.

1907. Die Bildung der Richtungskörper bei der Maus. Anat. Hefte, Bd. 35, pp. $493-55^{2}$, Taf. 2 I, 22 .

1908. Über die Richtungsteilungen des Säugetiereies, speziell über die Frage der Zahl der Richtungskörper. Verhand1. d. phys.-med. Gesellsch. zu Würzburg, Bd. 39, pp. 24I-26r.

STRICHT, O. VAN DER.

I90I. La ponte ovarique et l'histogenèse du corps jaune. Bull. de l'Acad.

TAFANi, A. R. de Méd. de Belgique, sér. 4, Tom. I 5, pp. 2 16-236, I pl., I9or.

x889. I primi momenti dello sviluppo dei mammiferi. Studi di morfologia normale e patologica eseguiti sulle uova dei topi. Arch. Anat. norm. e patolog., Vol. 5, Fasc. I, pp. I-59. (Publ. del R. Ist. di Studi Sup. Prat. e di Perfez. in Firenze, Sez. di Med. e Chir.)

I 889 a. I primi momenti dello sviluppo dei mammiferi. Studi di morfologia normale e patologica eseguiti sulle uova dei topi. Atti R. Accad. Lincei, Roma, Ser. 4, Rendiconti, Vol. 5, semestre I, pp. Ir9-I 25.

I889 $b$. La fécondation et la segmentation étudiées dans les oufs des rats. Arch. Ital. de Biol., Tom. I I, pp. I r2-I I 7. 


\section{EXPLANATION OF PLATES.}

All drawings were made with the aid of a camera lucida. The figures as reproduced are four-fifths the diameter of the original drawings. The magnification appended to the description of each figure is that of the reduced reproduction, the magnification of the original drawing being in parenthesis.

The magnification of 2500 diameters (reduced $=2000$ ) was obtained with a Zeiss $2 \mathrm{~mm}$. homog. immersion apochromatic objective and No. I 2 compensating ocular; that of 1200 (reduced $=960$ ), with $2 \mathrm{~mm}$. objective and No. 6 compensating ocular; that of 880 (reduced $=704$ ), with $2 \mathrm{~mm}$. objective and No. 4 compensating ocular; and that of 170 (reduced $=136$ ), with Zeiss A objective and No. 4 Huyghenian eyepiece.

\section{PLATE 1.}

Origin of First Maturation Spindle.

Fig. I. Germinative vesicle shortly before the disappearance of its nucleolus and the transformation of its contents into the fundaments of the chromosomes and the spindle fibers. Ovarian egg. $\times(2500) 2000$.

Fig. 2. Early stage in the formation of the chromosome fundaments. Ovarian egg. $\times(2500) 2000$.

Figs. $2 a, 2 b$. Fundaments of chromosomes in sections adjacent to that of fig. 2.

Figs. $3 a, 3 b$. Two consecutive sections showing a somewhat later stage than the preceding. Ovarian egg. $\times(2500) 2000$.

Figs. 4, 4a. Chromosomes (20 in number) more completely differentiated. Spindle not yet formed. Nuclear membrane still intact. Ovarian egg. $\times(2500) 2000$.

Fig. 5. Section of a young spindle showing faint fibrillations. There are 20 chromosomes scattered over its surface. Nuclear membrane is dissolved at some points. Ovarian egg. $\times(2500) 2000$

Fig. 6. Composite drawing of a spindle cut into three parts. There are 20 chromosomes. Stage slightly more advanced than that illustrated in fig. 5 . Nuclear membrane completely vanished. Ovarian egg. $\times(2500)_{2000}$.

Figs. $7,7 a$. Two consecutive sections of a spindle, like that shown in fig. 6 , seen in end view. There are 20 chromosomes, 10 in each section. The cytoplasm shows faint radiations about the spindle. Ovarian egg. $\times(2500) 2000$.

\section{PLATE 2.}

First Maturation Spindle.

Fig. 8. Ovarian egg. The chromosomes have become arranged in the plane of the equator. $\times(880) 704$.

Figs. $8 a, 8 b$. Enlarged views of the two sections into which the spindle in fig. 8 is cut. There are 20 chromosomes. $\times(2500) 2000$.

Fig. 9. Section of a spindle like that in fig. $8 . \times(2500) 2000$

Figs. $1 \circ a, 1 \circ b$. The two sections of a spindle of which the fibers at one pole converge to a point. There are 20 chromosomes. Ovarian egg. $\times(2500) 2000$.

Fig. I I. Section of a spindle similar to the preceding. Ovarian egg. $\times(2500) 2000$.

Fig. I 2. Ovarian egg. The polar ends of the spindle fibers are becoming thickened, and the clear region about the spindle is visible. One of the 20 chromosomes (some of which are in adjacent sections) has been displaced

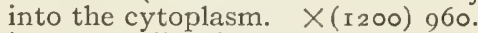

Fig. I3. Ovarian egg. The circumpolar bodies are formed at the poles of the spindle, and the clear region is evident. $\times\left(\mathrm{I}_{2} 200\right) 960$.

Fig. I3a. More highly magnified view of the spindle shown in fig. I $3 . \times(2500) 2000$. Fig. I $3 b$. View of that portion of the spindle seen in fig. I $3 a$ which falls in the following section. $\times(2500) 2000$.

\section{PLATE 3.}

Division of First Spindle and Abstriction of First Polar Cell (Figures I4 TO I8, INCLUSIVE).

Fig. I 4. Ovarian egg containing an oblique spindle. Several of the chromosomes have already divided. Circumpolar bodies numerous and conspicuous. $\times(\mathrm{I} 200)$ góo.

Fig. I $4 a$. One chromosome from the spindle in fig. I4.

Figs. I $5 a$, I $5 b$. An oblique spindle in two consecutive sections, showing the migration of the daughter chromosomes. Ovarian egg. $\times(2500) 2000$.

Figs. $16 a-16 d$. Four consecutive sections of a spindle similar in stage of division to that of fig. I7. See fig. $H($ p. 34). Ovarian egg. $\times(2500) 2000$. 


\section{PLATE 4.}

Second Maturation Spindle (Figures i $9 a-23 b$, Inclusive).

Figs. $17 a, 17 b$. The two sections show a spindle in a more advanced stage of division than that in figs. ${ }_{5} a, \mathbf{1}_{5} b$. The abstriction of the polar cell has begun in the vicinity of the "Zwischenkörperchen." Ovarian egg. $\times(2500) 2000$.

Fig. I 8. Polar cell recently abstricted. Ovarian egg. $\times(2500) 2000$.

Figs. I $a, I_{9} b$. Two sections of an oviducal egg showing polar cell and egg nearly severed from each other. Prophase of second spindle. $\times(2500)$ 2000.

Figs. 20, 2 I. Polar views of chromosomes of second spindle. Fig. 20 from an oviducal egg. Fig. 2 I from an egg in periovarial space. $\times(2500) 2000$.

Fig. 22. Side view of second spindle. Large first polar cell on nearly opposite side of egg. Oviducal egg. $\times($ I 200$) 960$.

Figs. $23 a, 23 b$. Spindle in paratangential position, cut obliquely into two sections. There are Ig chromosomes. Circumpolar bodies not stained deeply. First polar cell very small and near the spindle. Oviducal egg. $\times(2500) 2000$.

\section{PLATE 5.}

\section{Second Spindle and Formation of Second Polar Cell.}

Figs. $24 a, 24 b$. A spindle similar to that of fig. 23 , cut into two parts. There are 20 chromosomes. First polar cell absent. Oviducal egg. $\quad \times(2500)$ 2000.

Figs. 25-27. Old second-spindles from three eggs showing diminution of circumpolar bodies. All from oviducal eggs without first polar cell. $\times(2500)$ 2000.

Figs. $28 a, 28 b$. Polar views of the two daughter plates of a dividing second spindle in a stage corresponding to that in fig. 16 , plate 3 . The first polar cell is very small. Oviducal egg. $\times(2500) 2000$.

Figs. $29 a, 29 b$. Two sections of an oviducal egg. The oblique spindle is more advanced than the one in fig. 28. The stage of the abstriction of the polar cell (see also fig. $J$, p. 40) corresponds to that of figs. I6-I 7 . The first polar cell is seen lying at the left of the second in fig. $29 b$. The egg contains the heads of two spermatozoa. $\times(2500) 2000$.

Fig. 30. Oviducal egg showing second polar cell newly abstricted, the first polar cell, and the head of a spermatozoön. $\times\left(\mathbf{r}_{2} 200\right) 960$.

Figs. 3 I $a, 3$ I $b$.- Two sections of an egg (another section of which, less highly magnified, is shown in fig. 40) exhibiting in fig. 3 I $a$ the first polar cell lying in the enlarged perivitelline space. $\times(1200) 960$.

\section{PLATE 6.}

Figs. 32-37. First polar cells from oviducal eggs which contain the second spindle. They form a series of steps which illustrate the degeneration of the first polar cell. Figs. 32 and 33 are of polar cells which have divided into two or more parts. $\times(2500) 2000$.

Figs. 38-40. Three stages in the process of ovulation. In all three cases the egg contains the second spindle and is accompanied by the first polar cell. $\times($ I 70$)$ i 36 .

Note.-A minute body appearing in the clear space between zona pellucida and vitellus in fig. 38 is due to a defect in the plate.

\section{PLATE A.}

Fig. A. Mouse cage. For description see p. 6 .

Figs. $B, C$. Suspended mouse cages, with self-recording apparatus to indicate approximately the time of parturition of a gravid female. For description see pp. 7 -IO.

Fig. G. Chromosomes of first maturation spindle. See pp. 28-30.

$$
\text { (Plate A faces page 6.) }
$$



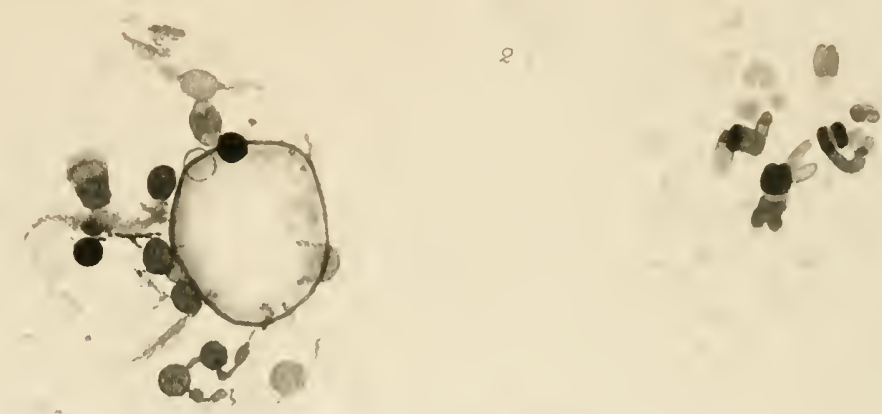

$\frac{605}{6}$
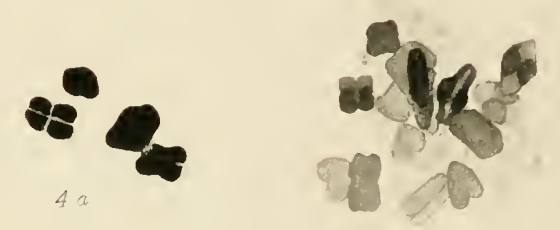

ang
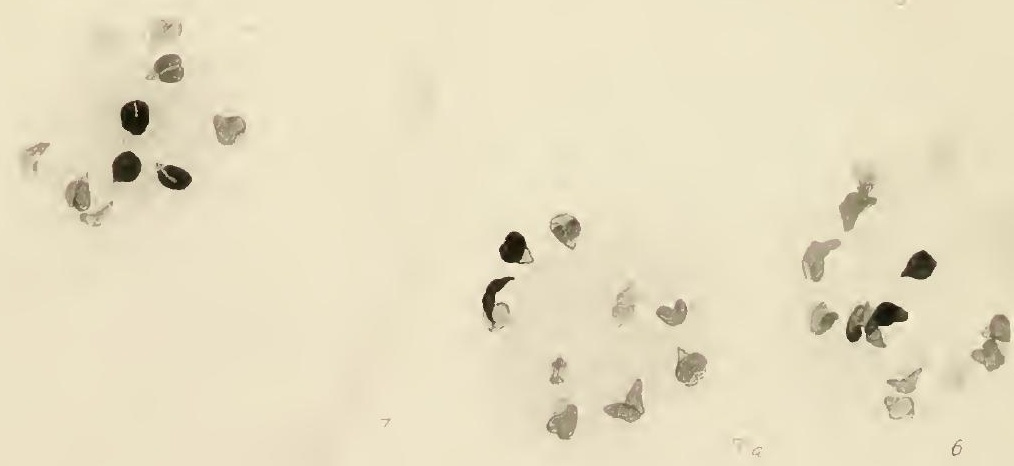

06

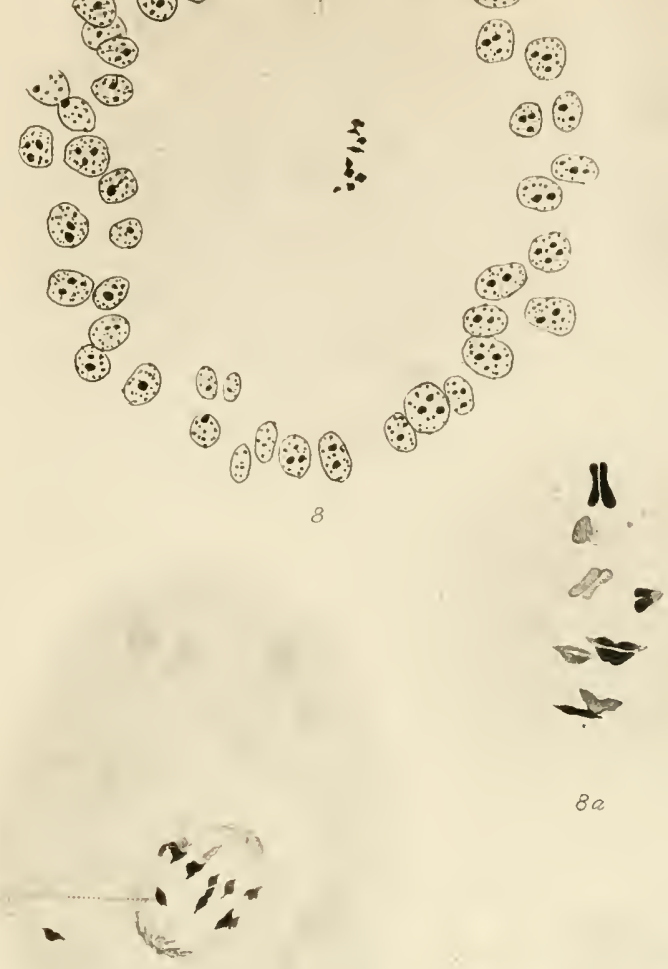

ad

$10 a$

ripe $\because 3$

8

$\infty$

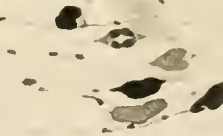

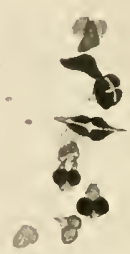

86

9
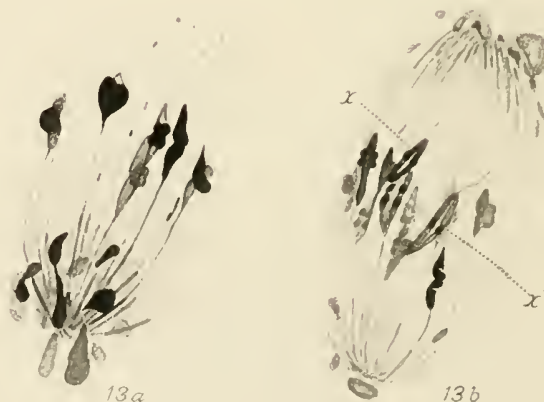



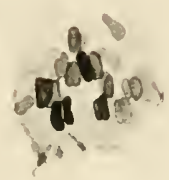

नी

(i)

162.5

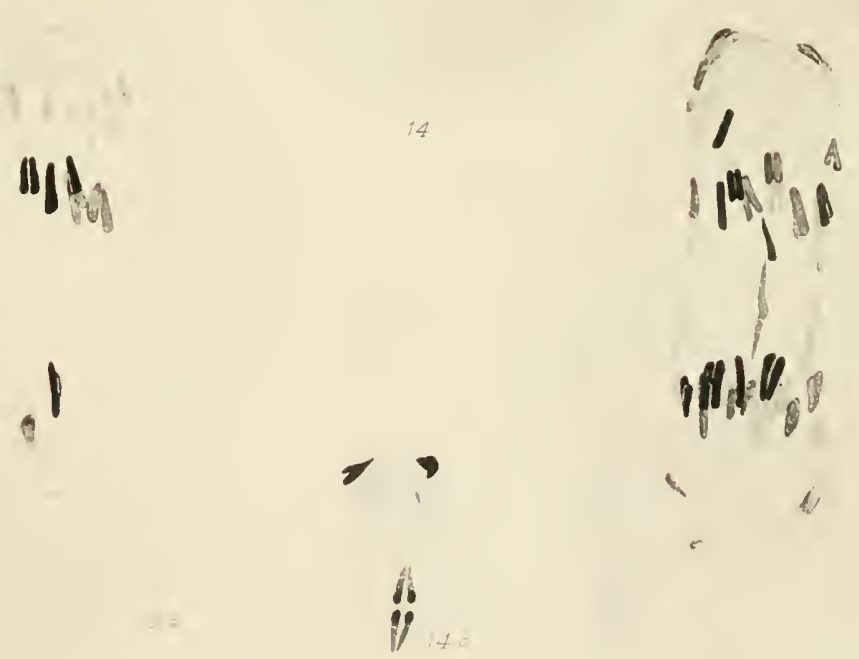





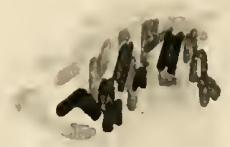

40.000000

$$
\text { i) }
$$

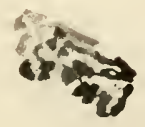

$\$$

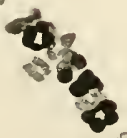

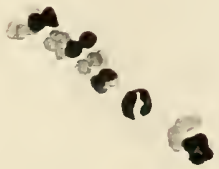

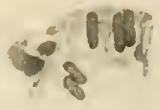
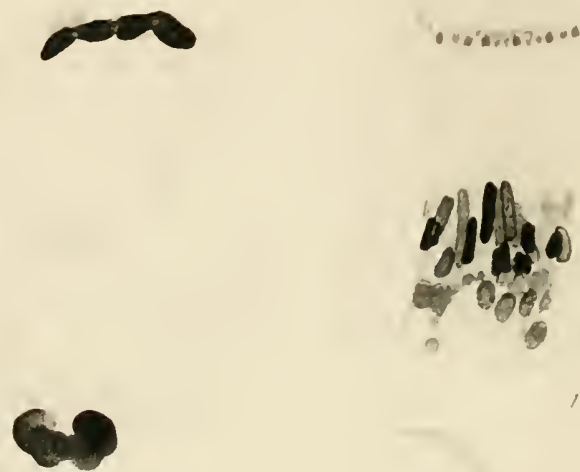

18

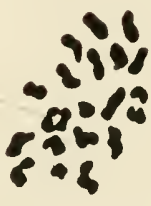

20

9

tie단

$0^{-0} 28$

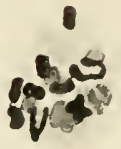

19

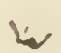




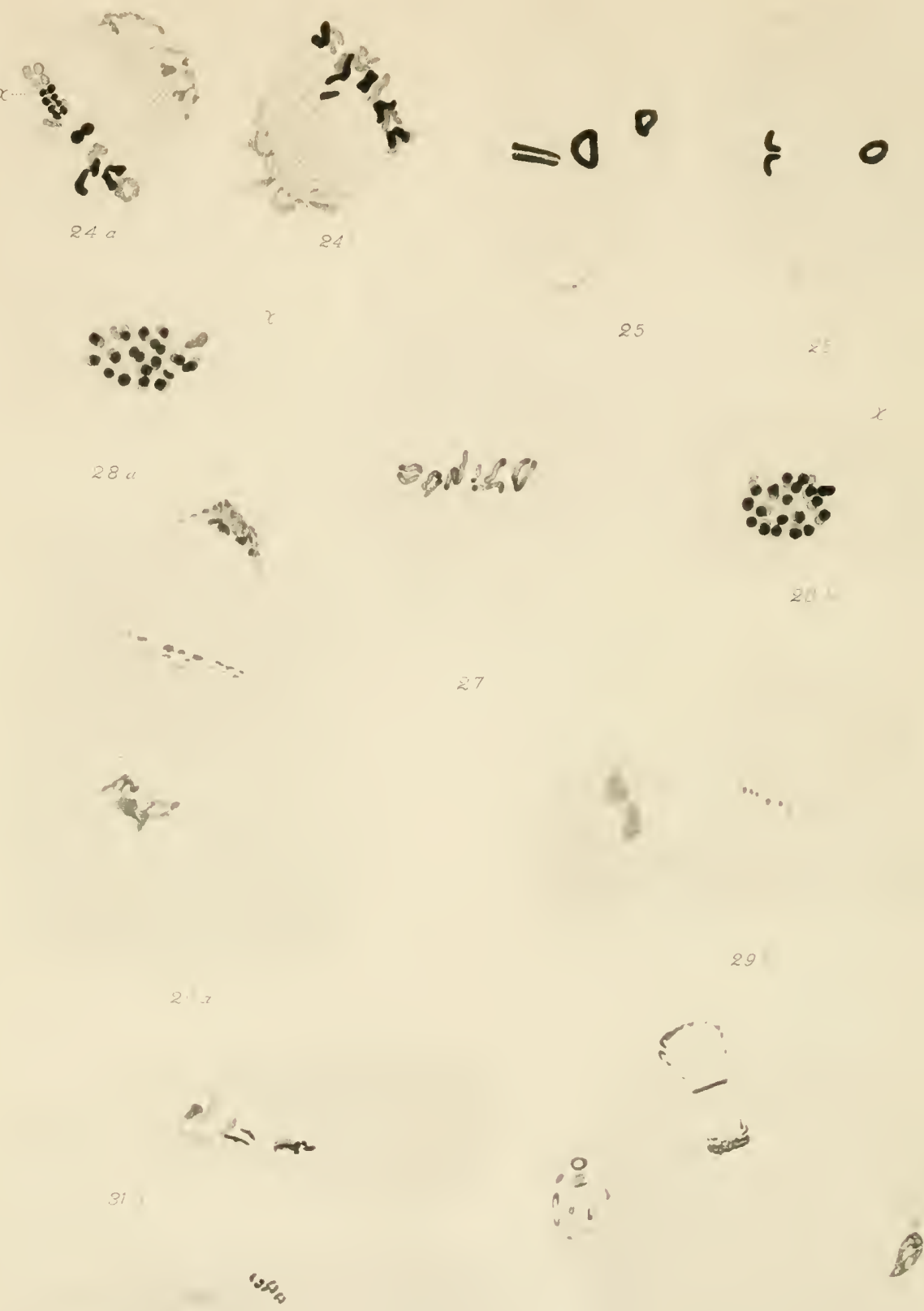


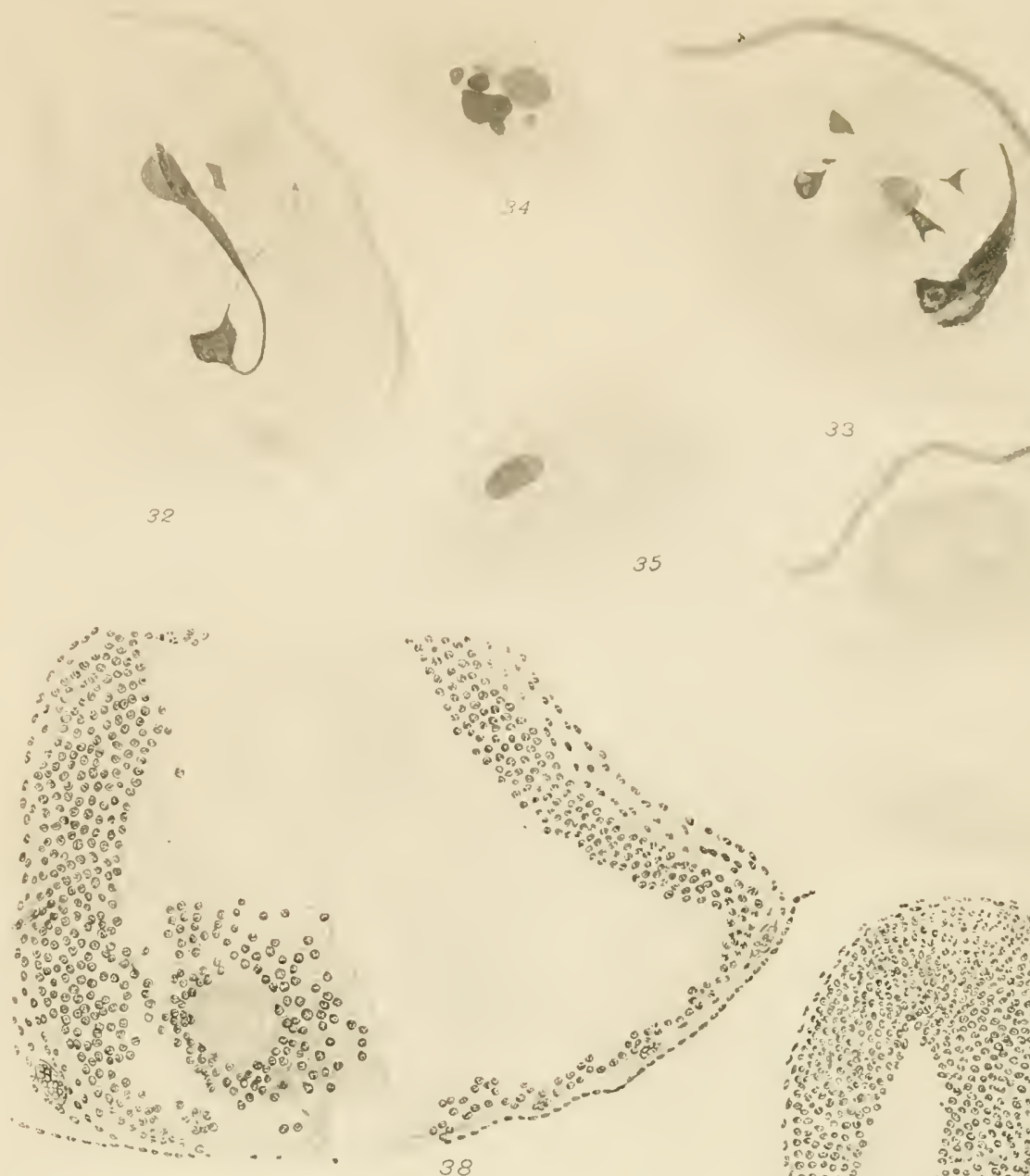

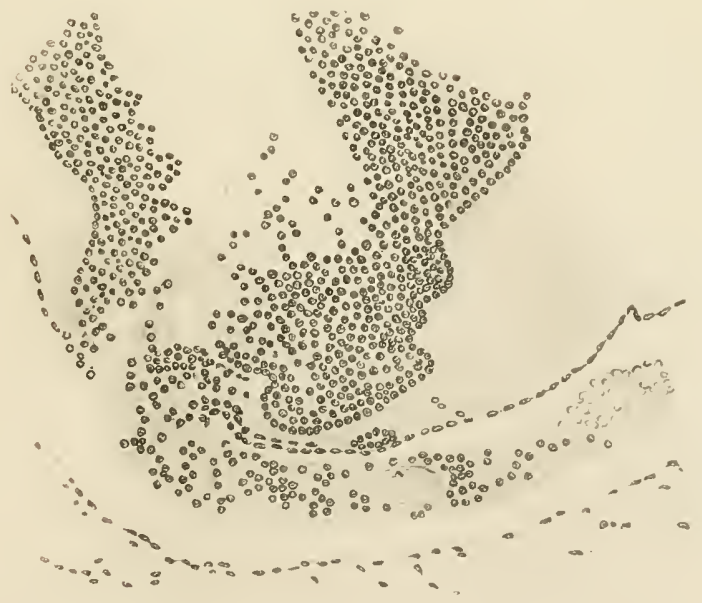

JA.L. del. 



QL Long, Joseph Abraham
965 The maturation of the
L7 egg of the mouse

BioMed.

\author{
PLEASE DO NOT REMOVE \\ CARDS OR SLIPS FROM THIS POCKET \\ UNIVERSITY OF TORONTO LIBRARY
}


